\title{
Tropical Cyclones within the Sedimentary Record: Analyzing Overwash Deposition from Event to Millennial Timescales
}

\author{
by \\ Jonathan D. Woodruff \\ B.S. Civil and Environmental Engineering, Tufts University, 1996 \\ B.S. Environmental Studies, Tufts University, 1996 \\ M.S. Applied Ocean Physics and Engineering, MIT/WHOI Joint Program, 1999 \\ Submitted in partial fulfillment of the requirements for the degree of \\ Doctor of Philosophy in Geology and Geophysics \\ at the \\ MASSACHUSETTS INSTITUTE OF TECHNOLOGY \\ and the \\ WOODS HOLE OCEANOGRAPHIC INSTITUTION
}

FEBRUARY 2009

(C)2009 Jonathan D. Woodruff. All rights reserved.

The author hereby grants MIT and WHOI permission to reproduce and to distribute publicly paper and electronic copies of this thesis document in whole or in part in any medium now or known hereafter created.

Signature of Author:

Joint Program in Oceanography/Applied Ocean Science and Engineering

Massachusetts Institute of Technology and Woods Hole Oceanographic Institution

December 16, 2008

Certified by:

Jeffrey P. Donnelly

Associate Scientist, Department of Geology and Geophysics

Woods Hole Oceanographic Institution

Thesis Supervisor

Accepted by:

Bradford H. Hager

Co-Chairman, Joint Committee for Geology and Geophysics

Massachusetts Institute of Technology

Woods Hole Oceanographic Institution 


\title{
Tropical Cyclones within the Sedimentary Record: Analyzing Overwash Deposition from Event to Millennial Timescales
}

by

\author{
Jonathan D. Woodruff
}

Submitted to the Massachusetts Institute of Technology-Woods Hole Oceanographic Institution Joint Program in Oceanography on December 16, 2008 in Partial Fulfillment of the Requirements for the Degree of Doctor of Philosophy in Geology and Geophysics

\begin{abstract}
Tropical cyclone activity over the last 5000 years is investigated using overwash sediments from coastal lagoons on the islands of Vieques, Puerto Rico and Koshikijima, Japan. A simple sediment transport model can reproduce the landward fining deposits observed at Vieques, and reveals that although the record exhibits centennial-tomillennial changes in hurricane overwash frequency, the magnitude of these flooding events has remained relatively constant. Stochastic simulations of hurricane overwash show that breaks in activity at Vieques are extremely long and unlikely to occur under the current hurricane climatology and the present barrier morphology. Periods of less frequent hurricane deposition at Vieques are contemporaneous with intervals of increased El Niño occurrences and reduced precipitation in West Africa, suggesting a dominant influence by these two climatic phenomena. Hiatuses in overwash activity between $3600-$ to-2500 and 1000-500 years ago are longer than what is generated by overwash simulations under a constant El Niño-like state, indicating that mechanisms in addition to variability in the El Niño/Southern Oscillation are required to completely produce the overwash variability at Vieques. Periods of low overwash activity at Vieques are concurrent with increased overwash activity at Kamikoshiki and may indicate a correspondence between tropical cyclone activity in the western Northern Atlantic and the western North Pacific.
\end{abstract}

Thesis Supervisor: Jeffrey P. Donnelly

Title: $\quad$ Associate Scientist, Department of Geology and Geophysics

Woods Hole Oceanographic Institution 


\section{Acknowledgements}

Above all, I would like to thank my advisor Jeff Donnelly. I have been extremely fortunate to have had Jeff as an advisor, and am indebted to him for his unwavering support over the course of my dissertation, both professionally and personally. I admire Jeff greatly for his scientific enthusiasm, insight, and generosity, and will always consider him a strong role model throughout my academic career. I am also grateful to Rocky Geyer, whose mentorship extends back over 14 years to when he first took me on as a Summer Student Fellow at WHOI. Rocky's help and guidance since I arrived in Woods Hole has been invaluable and I sincerely appreciate everything he has done for me. I would also like to thank David Mohrig who had been generous with both his ideas and expertise, especially with respect to the inverse modeling work described in Chapter 3 , which builds upon previously unpublished research of his. Most of Chapter 4 would not have been possible without the help of Kerry Emanuel who has been extremely gracious both with his time, knowledge, and resources. I also thank Delia Oppo whose door was always open to me, and Rob Evans for agreeing to act as the chair of my defense.

In addition to my committee, I would like to thank both the past and present members of the Coastal Systems Group at WHOI who I have enjoyed collaborating with immensely: Andrew Ashton, Katie Boldt, Ilya Buynevich, Zion Klos, Liviu Giosan, Maya Gomes, Phil Lane, Dana MacDonald, Paige Newby, Camilo Ponton, Rebecca Sobell, Michael Toomey, and Al Uchupi. This thesis has also benefitted through informative discussions with Konrad Hughen, Gail Kineke, Dan Lizarralde, Britt Raubenheimer, Ken Sims, Casey Saenger, and Andy Solow. Erin Bryant, Pat Donnelly, Elyse Scileppi and Jessica Tierney all provided assistance during the Caribbean field work. I am also grateful for the help from both the MIT/WHOI Education Office including Valerie Caron, John Farrington, Marsha Gomes, Judy McDowell, Jim Price, Julia Westwater, and Jim Yoder, and the Geology and Geophysics Department's administrative staff - Maryanne Ferreira, Pam Foster, Kelly Servant and Lynnette Stellrecht. I am particularly thankful to Masako Okusu, Akiko Okusu, Rick Woodruff and Jane Woodruff for their loving support, as well as their participation in the Koshikijima field work presented in Chapter 5 . This particular study was truly a family effort.

Finally, my deepest thanks to my wife Akiko Okusu. Her constant encouragement, patience, and faith in me has been inspiring, and allowed me to accomplish things I never thought possible for myself. This work is dedicated to her.

Funding for this research was provided by the Earth Systems History Program of the National Science Foundation, the Risk Prediction Initiative, the National Geographic Society, the Andrew W. Mellon Foundation Endowed Fund for Innovative Research, and graduate student fellowships from the Coastal Ocean Institute at Woods Hole Oceanographic Institution and the United States Geological Survey. 


\section{Table of Contents}

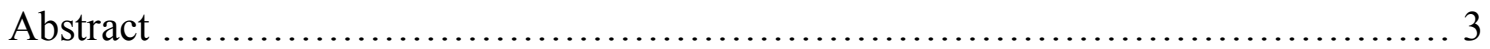

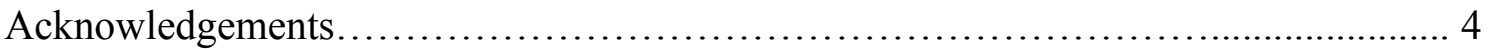

Chapter 1. Introduction .................................................... 6

Chapter 2. Intense hurricane activity over the past 5,000 years controlled by El Niño and the West African monsoon................................12

Chapter 3. Reconstructing relative flooding intensities responsible for hurricaneInduced deposits from Laguna Playa Grande, Vieques, Puerto Rico.....17

Chapter 4. Assessing sediment records of paleohurricane activity using modeled hurricane climatology .......................................22

Chapter 5. Exploring typhoon variability over the mid-to-late Holocene: evidence of extreme coastal flooding from Kamikoshiki, Japan.........35

\section{Appendices}

Appendix A1. Supplemental information for Chapter 2

Appendix A2. Supplemental information for Chapter 3

Appendix A3. Supplemental XRF Results from Vieques, Puerto Rico

.98

Appendix A4. Permission letters from co-authors 


\section{Introduction}

Tropical cyclones are among the most hazardous natural disasters on earth, responsible for substantial losses in both human life and economic resources (Pielke et al., 2008). Inter-annual to multi-decadal variability in tropical cyclone activity has been attributed to a number of climatic forcings (e.g. Bove et al., 1998; Elsner et al., 2000; Emanuel, 2005; Goldenberg et al., 2001; Gray, 1984; Landsea et al., 1999); however, the relatively short duration of the modern instrumental record precludes the direct analysis of processes controlling activity on centennial to millennial timescales.

Natural archives of tropical cyclones preserved within the geologic record extend well beyond instrumental observations and can identify how tropical cyclone activity has responded to past shifts in climate (Frappier et al., 2007; Nott, 2004). In particular, previous research has demonstrated that storm-induced sand deposits found within backbarrier environments serve as an effective recorder of tropical cyclone occurrences (e.g. Ball et al., 1967; Donnelly et al., 2001a; Donnelly et al., 2001b; Emery, 1969; Goman et al., 2005; High, 1969; Liu and Fearn, 1993, 2000; Scileppi and Donnelly, 2007; van de Plassche et al., 2004). To date there are relatively few sedimentary reconstructions of tropical cyclone activity which extend back more then a few centuries, and the longer-term records of overwash are still primarily restricted to the western North Atlantic. In addition, the transport processes which deposit overwash layers are still poorly understood, making it difficult for sedimentologists to effectively interpret paleodeposits, especially with respect to both quantifying the magnitude of prehistoric flood 
events, and evaluating potential changes in overwash sensitivity resulting from evolving coastal morphology. Finally, the stochastic nature of hurricane strikes to a few sites requires consideration when assessing the significance of trends observed within these paleo-storm reconstructions.

Given the importance of identifying the processes which govern tropical cyclone activity on the centennial and millennial time scales, and considering the significance that preserved overwash layers play in this effort, the primary questions I address in this thesis are:

(1) What are the mechanisms that determine the spatial distribution of overwash sediment in backbarrier environments during periods of coastal inundation?, (2) How can knowledge of these mechanisms be employed to reconstruct flow conditions during individual hurricane events, and evaluate changes in local flooding intensity at a site over time?, (3) Do geographic and temporal trends exist within tropical cyclone-induced overwash records over the later Holocene?, and (4) Are these trends statistically significant when considering the random variance in storm-strikes to a limited number of locations?

The results of this research are detailed in Chapters 2, 3, 4, and 5. In Chapter 2, a 5000 year reconstruction of overwash deposition is developed from a coastal lagoon on the island of Vieques, Puerto Rico. Flood deposits are determined to be hurricaneinduced, with modern event layers concurrent with historical hurricane strikes to the site (Donnelly and Woodruff, 2007). Periods of less frequent hurricane deposition are 
contemporaneous with intervals of increased El Niño occurrences and reduced precipitation in West Africa, suggesting that processes associated with these two climatic phenomena likely play an important role in governing hurricane activity on the centennial- to millennial time scales.

In Chapter 3, I apply a simple sediment transport model to explain grain-size sorting trends in the Vieques overwash record (Woodruff et al., 2008b). The method is effective in reconstructing flood conditions for the San Felipe Hurricane, a category 5 storm which struck the Vieques site in 1928 AD. Similar analyses are performed for each of the 29 overwash deposits within the record, and indicate that the flooding magnitude for these events has remained relatively constant through time, with no systematic shifts in intensity attributable to time-varying changes in barrier morphology. This study is the first to inversely model flooding conditions from resultant hurricane-induced deposits, and provides the groundwork for which future studies can expand upon to gain new insight into the overwash process.

In Chapter 4, I apply numerical modeling techniques to assess the statistical significance for trends observed within the paleo-hurricane overwash reconstruction from Vieques (Woodruff et al., 2008a). Results show that breaks in overwash activity occurring from 3600-to-2500 years ago and 1000-to-500 years ago are extremely long and unlikely to occur at the site under the current hurricane climatology and with the present barrier morphology. Similar temporal trends in overwash are observed from additional sites within the western North Atlantic suggest that these patterns resulted 
from a changes in overall hurricane activity rather than local changes in barrier morphology. Periods of quiescence are difficult to produce even when the hurricane model is forced to a constant El Niño state, suggesting that large-scale climatic changes in addition to variability in the El Niño/Southern Oscillation are required to produce the trends observed. This study is the first to provide quantitative evidence for the western North Atlantic exhibiting significant changes in hurricane climatology over the last 5000 years, and provides a framework for more rigorous statistical analyses of future overwash reconstructions.

Finally, in Chapter 5 I present sub-bottom seismic data and sedimentary records collected from two adjacent coastal ponds on the island of Kamikoshiki in southern Japan, in order to document the spatial and temporal distribution of marine deposits observed within both lakes (Woodruff et al., in review). The timing of the youngest deposit at the site correlates with the most recently documented breach to the barrier during a typhoon in $1951 \mathrm{AD}$, and in combination with the high occurrence rate of typhoon strikes to the site, strongly suggests that a majority of deposits at Kamikoshiki are induced by tropical cyclones. An inverse relationship is observed between the tropical cyclone reconstructions from Kamikoshiki and Vieques, which may indicate an oscillating pattern in tropical cyclone activity between the western Northern Atlantic and the western North Pacific. 


\section{References}

Ball, M.M., Shinn, E.A., and Stockman, K.W., 1967, The geologic effects of Hurricane Donna in south Florida: Journal of Geology, v. 75, p. 583-597.

Bove, M.C., Elsner, J.B., Landsea, C.W., Niu, X.F., and O'Brien, J.J., 1998, Effect of El Nino on US landfalling hurricanes, revisited: Bulletin of the American Meteorological Society, v. 79, p. 2477-2482.

Donnelly, J.P., Bryant, S.S., Butler, J., Dowling, J., Fan, L., Hausmann, N., Newby, P., Shuman, B., Stern, J., Westover, K., and Webb, T., 2001a, 700 yr sedimentary record of intense hurricane landfalls in southern New England: Geological Society of America Bulletin, v. 113, p. 714-727.

Donnelly, J.P., Roll, S., Wengren, M., Butler, J., Lederer, R., and Webb, T., 2001b, Sedimentary evidence of intense hurricane strikes from New Jersey: Geology, v. 29, p. 615-618.

Donnelly, J.P., and Woodruff, J.D., 2007, Intense hurricane activity over the past 5,000 years controlled by El Niño and the West African monsoon: Nature, v. 447, p. 465-468.

Elsner, J.B., Jagger, T., and Niu, X.F., 2000, Changes in the rates of North Atlantic major hurricane activity during the 20th century: Geophysical Research Letters, v. 27, p. 1743-1746.

Emanuel, K., 2005, Increasing destructiveness of tropical cyclones over the past 30 years: Nature, v. 436, p. 686-688.

Emery, K.O., 1969, A coastal pond studied by oceanographic methods: New York, American Elsevier Publishing, 80 p.

Frappier, A., Knutson, T., Liu, K.B., and Emanuel, K., 2007, Perspective: coordinating paleoclimate research on tropical cyclones with hurricane-climate theory and modelling: Tellus Series a-Dynamic Meteorology and Oceanography, v. 59, p. 529-537.

Goldenberg, S.B., Landsea, C.W., Mestas-Nunez, A.M., and Gray, W.M., 2001, The recent increase in Atlantic hurricane activity: Causes and implications: Science, v. 293, p. 474-479.

Goman, M., Joyce, A., and Mueller, R., 2005, Stratigraphic evidence for anthropogenically induced coastal environmental change from Oaxaca, Mexico: Quaternary Research, v. 63, p. 250-260. 
Gray, W.M., 1984, Atlantic Seasonal Hurricane Frequency. Part I: El Nino and $30 \mathrm{mb}$ Quasi-Biennial Oscillation Influences: Monthly Weather Review, v. 112, p. 16491668.

High, L.R., 1969, Storms and sedimentary processes along the northern British Honduras coast: Journal of Sedimentary Research, v. 39, p. 235-245.

Landsea, C.W., Pielke, R.A., Mestas-Nuñez, A.M., and Knaff, J.A., 1999, Atlantic Basin Hurricanes: Indices of Climatic Changes: Climatic Change, v. 42, p. 89-129.

Liu, K.B., and Fearn, M.L., 1993, Lake-Sediment Record of Late Holocene Hurricane Activities from Coastal Alabama: Geology, v. 21, p. 793-796.

—, 2000, Reconstruction of prehistoric landfall frequencies of catastrophic hurricanes in northwestern Florida from lake sediment records: Quaternary Research, v. 54, p. 238-245.

Nott, J., 2004, Palaeotempestology: the study of and implications Review article prehistoric tropical cyclones - a review for hazard assessment: Environment International, v. 30, p. 433-447.

Pielke, R.A., Gratz, J., Landsea, C.W., Collins, D., Saunders, M.A., and Musulin, R., 2008, Normalized Hurricane Damage in the United States: 1900-2005: Natural Hazards Review, v. 9, p. 29-42.

Scileppi, E., and Donnelly, J.P., 2007, Sedimentary evidence of hurricane strikes in western Long Island, New York: Geochemistry Geophysics Geosystems, v. 8.

van de Plassche, O., Wright, A.J., van der Borg, K., and de Jong, A.F.M., 2004, On the Erosive Trail of a 14th and 15th Century Hurricane in Connecticut (USA) Salt Marshes: Radiocarbon, v. 46, p. 775-784.

Woodruff, J.D., Donnelly, J.P., Emanuel, K., and Lane, P., 2008a, Assessing sedimentary records of paleohurricane activity using modeled hurricane climatology: Geochemistry Geophysics Geosystems, v. 9.

Woodruff, J.D., Donnelly, J.P., Mohrig, D., and Geyer, W.R., 2008b, Reconstructing relative flooding intensities responsible for hurricane-induced deposits from Laguna Playa Grande, Vieques, Puerto Rico: Geology, v. 36, p. 391-394.

Woodruff, J.D., Donnelly, J.P., and Okusu, A., in review, Exploring typhoon variability over the mid-to-late Holocene: evidence of extreme coastal flooding from Kamikoshiki, Japan: Quaternary Science Reviews. 


\title{
Chapter 2:
}

\section{Intense hurricane activity over the past 5,000 years controlled by El Niño and the West African monsoon}

\begin{abstract}
The processes that control the formation, intensity and track of hurricanes are poorly understood. It has been proposed that an increase in sea surface temperatures caused by anthropogenic climate change has led to an increase in the frequency of intense tropical cyclones, but this proposal has been challenged on the basis that the instrumental record is too short and unreliable to reveal trends in intense tropical cyclone activity. Storminduced deposits preserved in the sediments of coastal lagoons offer the opportunity to study the links between climatic conditions and hurricane activity on longer timescales, because they provide centennial- to millennial-scale records of past hurricane landfalls. Here we present a record of intense hurricane activity in the western North Atlantic Ocean over the past 5,000 years based on sediment cores from a Caribbean lagoon that contain coarse-grained deposits associated with intense hurricane landfalls. The record indicates that the frequency of intense hurricane landfalls has varied on centennial to millennial scales over this interval. Comparison of the sediment record with paleoclimate records indicates that this variability was probably modulated by atmospheric dynamics associated with variations in the El Niño/Southern Oscillation and the strength of the West African monsoon, and suggests that sea surface temperatures as high as at present are not necessary to support intervals of frequent intense hurricanes. To accurately predict changes in intense hurricane activity, it is therefore important to understand how the El Niño/Southern Oscillation and the West African monsoon will respond to future climate change.
\end{abstract}

*Published as: Donnelly, J.P., and Woodruff, J.D., 2007, Intense hurricane activity over the past 5,000 years controlled by El Niño and the West African monsoon: Nature, v. 447, p. 465-468. Both authors contributed equally (50-50) to this publication (see Appendix A4). 


\title{
Intense hurricane activity over the past 5,000 years controlled by El Niño and the West African monsoon
}

\author{
Jeffrey P. Donnelly ${ }^{1}$ \& Jonathan D. Woodruff ${ }^{1}$
}

The processes that control the formation, intensity and track of hurricanes are poorly understood ${ }^{1}$. It has been proposed that an increase in sea surface temperatures caused by anthropogenic climate change has led to an increase in the frequency of intense tropical cyclones ${ }^{2,3}$, but this proposal has been challenged on the basis that the instrumental record is too short and unreliable to reveal trends in intense tropical cyclone activity ${ }^{4}$. Storm-induced deposits preserved in the sediments of coastal lagoons offer the opportunity to study the links between climatic conditions and hurricane activity on longer timescales, because they provide centennial- to millennial-scale records of past hurricane landfalls $s^{5-8}$. Here we present a record of intense hurricane activity in the western North Atlantic Ocean over the past 5,000 years based on sediment cores from a Caribbean lagoon that contain coarse-grained deposits associated with intense hurricane landfalls. The record indicates that the frequency of intense hurricane landfalls has varied on centennial to millennial scales over this interval. Comparison of the sediment record with palaeo-climate records indicates that this variability was probably modulated by atmospheric dynamics associated with variations in the $\mathrm{El} \mathrm{Niño/Southern}$ Oscillation and the strength of the West African monsoon, and suggests that sea surface temperatures as high as at present are not necessary to support intervals of frequent intense hurricanes. To accurately predict changes in intense hurricane activity, it is therefore important to understand how the El Niño/Southern Oscillation and the West African monsoon will respond to future climate change.

At present there is significant debate about the cause of observed multi-decadal variability of hurricanes in the North Atlantic (for example, see refs 2,4$)$. To detect long-term patterns in tropical cyclone activity, reliable proxy reconstructions that extend back before the instrumental record are needed. To examine the centennial- and millennial-scale variability of Caribbean hurricane activity and to assess potential climate forcing we reconstruct the history of hurricane-induced overwash events from Laguna Playa Grande (LPG), Vieques, Puerto Rico.

The island of Vieques is located in the northeastern Caribbean Sea (Fig. 1) and is extremely vulnerable to hurricanes. LPG is a hypersaline, backbarrier lagoon separated from the Caribbean Sea by a wave-dominated, sandy barrier $80 \mathrm{~m}$ wide and $2-3 \mathrm{~m}$ high. The barrier is stabilized on either end by rocky headlands ${ }^{9}$ and anchored below by beach rock ${ }^{10}$. Tidal variability is modest (mean range $0.24 \mathrm{~m}$ ), which minimizes the influence of tidal currents and inlet dynamics. In addition, the relatively slow rates of sea-level rise over the past 6,000 years in the region ${ }^{11}$ and the steep topography and bathymetry contribute to barrier stability.

Cores collected from the site contain several metres of organic-rich silt interbedded with coarse-grained event layers comprised of a mixture of siliciclastic sand and calcium carbonate shells and shell fragments. These layers are the result of marine flooding events overtopping or breaching the barrier and transporting these barrier and nearshore sediments into the lagoon. Patterns of coarse-grained event deposits are consistent among all cores (Fig. 2, Supplementary Fig. 1). To determine which historical events left coarse-grained layers at LPG, we developed a detailed age model for the upper $20 \mathrm{~cm}$ of LPG12 (Fig. 2). Three coarse-grained deposits are evident in the sediments deposited within the past 100 years. These layers are consistent with three of the most intense hurricanes to strike Vieques over this interval. Seven hurricanes passed within $50 \mathrm{~km}$ of the site between 1900 and 2006. Of these, the dates for the two most extreme storms (hurricanes San Felipe in 1928 (category 5) and Hugo in 1989 (category 4)) are consistent with the age of two of the three layers

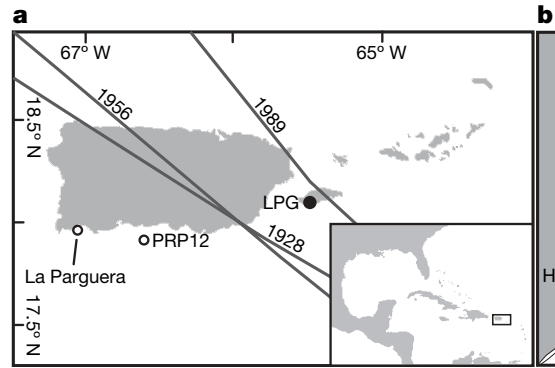

Figure 1 Site map and core locations. a, Map of Puerto Rico with inset map of the tropical Western Atlantic. The location of LPG on the southeastern coast of Vieques is noted with a solid circle. Tracks of the hurricanes mentioned in the text are noted. The location of Puerto Rico (box) is indicated in the inset. Locations of SST reconstructions from La Parguera ${ }^{17}$ b

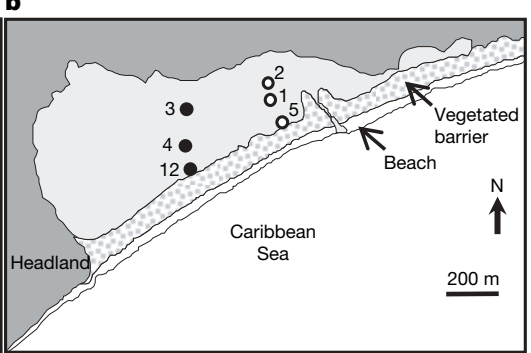

and PRP $12^{16}$ are noted. b, Map of LPG showing core locations (circles). The locations of the cores (LPG12, LPG4 and LPG3) presented in Fig. 2 are noted with solid circles. Cores LPG5, LPG1 and LPG2 included in Supplementary Fig. 1 are also noted. 
observed in LPG12 (Fig. 2). Of the less intense storms (categories 1 and 2) only hurricane Betsy (1956) correlates well with the third deposit. However, an analysis of wind damage in eastern Puerto Rico for this particular storm indicates wind speeds more consistent with category 3 intensity ${ }^{12}$. In contrast to the three layers in LPG12, only two layers are preserved in the upper $15 \mathrm{~cm}$ of LPG4. The same pattern is evident in cores collected along the easternmost transect (Fig. 1 and Supplementary Fig. 1). The more distal coarse-grained layers in LPG4 were probably deposited by the two most intense hurricanes in the past 100 years (hurricanes San Felipe in 1928 and Hugo in 1989).

Areas of the lagoon adjacent to the barrier (for example, LPG5 (Fig. 2) and LPG12 (Supplementary Fig. 1)) are more likely to experience localized breaching associated with less intense events and are also more susceptible to erosion and truncation of the sediment record during overwash. Conversely, coarse-grained sediments do not always reach the most distal locations (for example, LPG3 (Fig. 2) and LPG2 (Supplementary Fig. 1)) during extreme events, and as a result these areas provide an incomplete record (Fig. 2). The coarsegrained deposits in central locations of the lagoon (for example, LPG4 (Fig. 2) and LPG1 (Supplementary Fig. 1)) provide a relatively complete record of the most intense hurricane (category 4 and greater) strikes, because only these extreme events are capable of producing storm surges high enough to overtop the entire length of the barrier and carry and deposit coarse-grained layers to these locations. Storminduced deposits within LPG4 reveal large fluctuations in the frequency of intense hurricanes (Fig. 3a). On the basis of our age model (Supplementary Fig. 2) an interval of relatively frequent intense hurricane strikes at Vieques is evident between 5,400 and 3,600 calendar years before present ( $\mathrm{yr} \mathrm{BP}$, where present is defined as $1950 \mathrm{AD}$ by convention), with the exception of a short-lived quiescent interval between approximately 4,900 and 5,050 yr BP. Following this relatively active period is an interval of relatively few extreme coastal flooding events persisting from 3,600 until roughly $2,500 \mathrm{yr}$ BP. Evidence of another relatively active interval of intense hurricane strikes is evident between 2,500 and approximately 1,000 $\mathrm{yr} \mathrm{BP}$. The interval from 1,000 to $250 \mathrm{yr}$ BP was relatively quiescent with evidence of only one prominent event occurring around $500 \mathrm{yr} \mathrm{BP}$. A relatively active regime has resumed since about $250 \mathrm{yr} \mathrm{BP}(1700 \mathrm{AD})$.

Evidence of hurricane landfalls in New York indicates periods of activity similar to those of Vieques over the past 2,500 years ${ }^{13}$. In addition, sediment-derived records of intense hurricanes from the Gulf coast also indicate a relatively quiescent interval beginning about 1,000 years ago ${ }^{5}$. The synchronous transition from frequent to infrequent hurricane landfalls in these three regions indicates that a North-Atlantic-wide decrease in hurricane activity occurred about 1,000 years ago and was not simply a change in prevailing hurricane tracks away from the Gulf coast, as has previously been suggested ${ }^{5,14}$.

Warm sea surface temperatures (SSTs) in the tropical North Atlantic are thought to be a key ingredient for fuelling intense hurricanes $^{1,15}$ and are at the centre of the debate over the impact of global warming on tropical cyclone activity. Unfortunately, few reconstructions of SST spanning the past 5,000 years from the main development region (MDR) for hurricane formation (Supplementary Fig. 3) are available. However, SST reconstructions from off Puerto Rico (PRP12 $2^{16}$ and La Parguera ${ }^{17}$; Fig. 1a) are probably good proxies for the MDR (Supplementary Fig. 3). The PRP12 reconstruction indicates that summer SSTs in the tropical North Atlantic have generally been cooler than at present, varying by as much as $2{ }^{\circ} \mathrm{C}$ (roughly $26-$ $28^{\circ} \mathrm{C}$ ) over the past 2,000 years (Fig. $\left.3 \mathrm{~b}\right)^{16}$. In addition, coral-based SST reconstructions from La Parguera, Puerto Rico (Fig. 1a), indicate that mean annual Little Ice Age (250-135 yr BP or $1700-1815 \mathrm{AD})$ SSTs were $2-3{ }^{\circ} \mathrm{C}$ cooler than they are now (Fig. 3b) ${ }^{17}$. Despite cooler Little Ice Age SSTs in the region, the sediment record from LPG and New York ${ }^{13}$ indicates an increase in intense hurricane landfalls since about $1700 \mathrm{AD}$ (250 yr BP) (Fig. 3b).

Historical records from Puerto Rico also suggest an increase in severe hurricane damage in the 18th and 19th centuries. Only three storms are documented as resulting in severe damage ( $\geq \mathrm{F} 2$ on the Fujita scale) in Puerto Rico between 1550 and 1700 AD, while at least sixteen severe hurricanes affected Puerto Rico between 1700 and $1850 \mathrm{AD}^{12}$. Although the historic archives may be less complete during the early part of these records and so some hurricanes may have gone unrecorded, sediment-based reconstructions are unaffected by this type of biasing. Therefore, the good agreement between the sedimentbased reconstructions and the historic archives strongly suggests that the frequency of intense hurricanes increased at around $1700 \mathrm{AD}$. In addition, an analysis of Caribbean hurricanes documented in Spanish archives indicates that $1766-1780$ was one of the most active intervals in the period between 1500 and $1800 \mathrm{AD}$ (ref. 18), when tree-ring-based reconstructions indicate a negative (cooler) phase of the Atlantic Multidecadal Oscillation ${ }^{19}$. Furthermore, the sediment record from LPG indicates that an interval of relatively frequent intense hurricane strikes persisted for over a millennium (2,500 to 1,000 years ago) despite cooler-than-modern SSTs. Thus the information available suggests that tropical Atlantic SSTs were probably not the principal
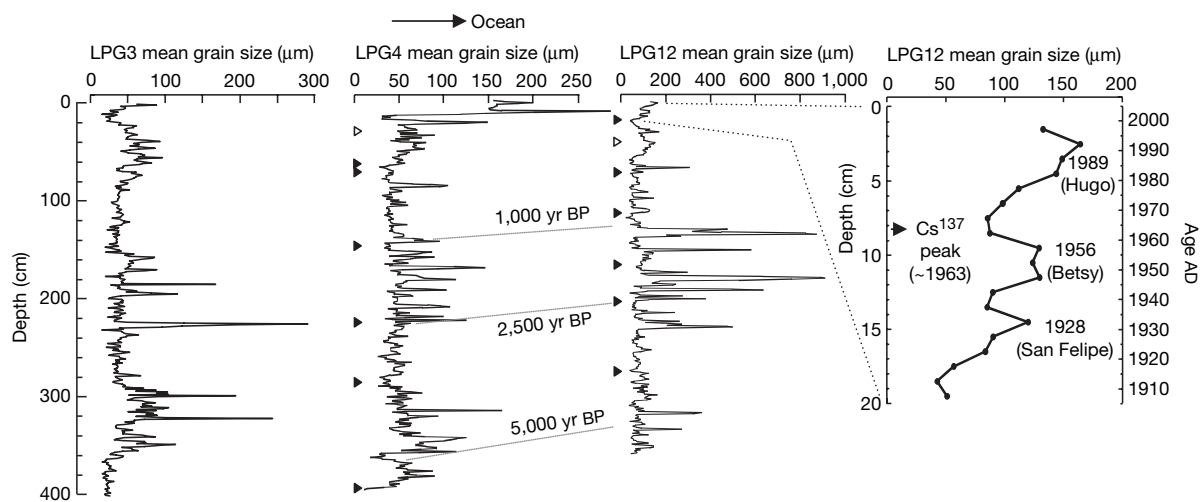

LPG4 and LPG12, based on the age models presented in Supplementary Fig. 2. The enlarged upper $20 \mathrm{~cm}$ mean grain-size plot of LPG12 (far right) with an age model based on an accumulation rate of $2 \mathrm{~mm} \mathrm{yr}^{-1}$ is derived from $\mathrm{Cs}^{137}$ data and evidence of land clearance $(\sim 1840 \mathrm{AD})$. Deposits attributable to documented hurricanes are noted. The arrow above plots indicates the direction of the ocean relative to core sites.

Figure 2 | Bulk grain-size data revealing storm-induced deposits. The mean grain-size scale is set at 250 and $300 \mu \mathrm{m}$ for LPG4 and LPG3, respectively, because the coarse-grained layers are generally finer in these more distal locations. Solid arrows represent the depth of radiocarbon-dated samples from LPG4 and LPG12. The depth of abrupt increase in Ti and Fe associated with land clearance at approximately $1840 \mathrm{AD}(110 \mathrm{yr} \mathrm{BP})$ is noted with an open triangle. Dashed grey lines indicate depths of equal age between 
driver of intense hurricane activity over the past several millennia; however, more high-resolution records of SSTs, including depth of the mixed layer, are required to address the role of SSTs on intense hurricane activity over this period adequately.

Studies relying on recent climatology indicate that North Atlantic hurricane activity is greater during La Niña years and suppressed during El Niño years ${ }^{20,21}$, due primarily to increased vertical wind shear in strong El Niño years hindering hurricane development. A comparison between LPG4 and a proxy record of El Niño events from Laguna Pallcacocha, Ecuador ${ }^{22}$, suggests that the evolution of El Niño/Southern Oscillation (ENSO) variability has also played a key part in governing Atlantic intense tropical cyclone activity for much of the past 5,000 years (Fig. 3). For example, intervals of frequent intense hurricane strikes at LPG (for example, $\sim 2,500$ to $1,000 \mathrm{yr} \mathrm{BP}$, 3,600 to $4,400 \mathrm{yr} \mathrm{BP}$, and $250 \mathrm{yr} \mathrm{BP}$ to present) correspond primarily to periods with relatively few El Niño events. Conversely, periods with more frequent, strong El Niño events generally correspond to periods with fewer intense hurricane strikes on Vieques (for example, $\sim 3,600$ to $2,500 \mathrm{yr} \mathrm{BP}$ and 1,000 to $250 \mathrm{yr} \mathrm{BP}$ ) (Fig. 3c). A possible exception to this correlation is the interval between 4,600 and 5,000 yr BP; however, a small ( $\sim 100-200$ years) shift within the uncertainty range of the age model in either record would also result in the lull in El Niño events corresponding to the active hurricane interval here.

In addition to the El Niño record there is also a strong correspondence between a precipitation record from Lake Ossa, West Cameroon
(Fig. 3d $)^{23}$, and the record of intense hurricane activity from Vieques. Intervals of increased precipitation (thought to result from more frequent convective storms) in tropical Africa correspond to times of increased frequency of intense hurricanes recorded at LPG. Conversely, less convective storminess in tropical Africa appears to be associated with relatively few intense hurricanes in the Western Atlantic. The amount of precipitation in tropical Africa is probably related to the strength of the West African monsoon. This correlation between tropical African precipitation and North Atlantic hurricanes is consistent with recent findings ${ }^{24}$ linking periods of increased hurricane activity in the middle of the 20th century with increased monsoonal strength in Africa and a well-developed African easterly jet. Increased cyclonic vorticity in the MDR results from a welldeveloped African easterly jet. During intervals of increased monsoonal strength (with a well-developed African easterly jet) and cool ENSO phase, African easterly disturbances (waves) pass through a region of enhanced cyclonic vorticity, warm SSTs, and low vertical shear, enhancing the development of hurricanes in the central and western portions of the MDR.

Increases in precipitation in tropical Africa are a likely positive feedback mechanism contributing to the formation and enhancement of the African easterly jet by increasing the soil moisture gradient ${ }^{25}$. The negative correlation between precipitation proxies in West Cameroon and Ecuador may also point to ENSO modulation of the West African monsoon. In fact, El Niño events combined with

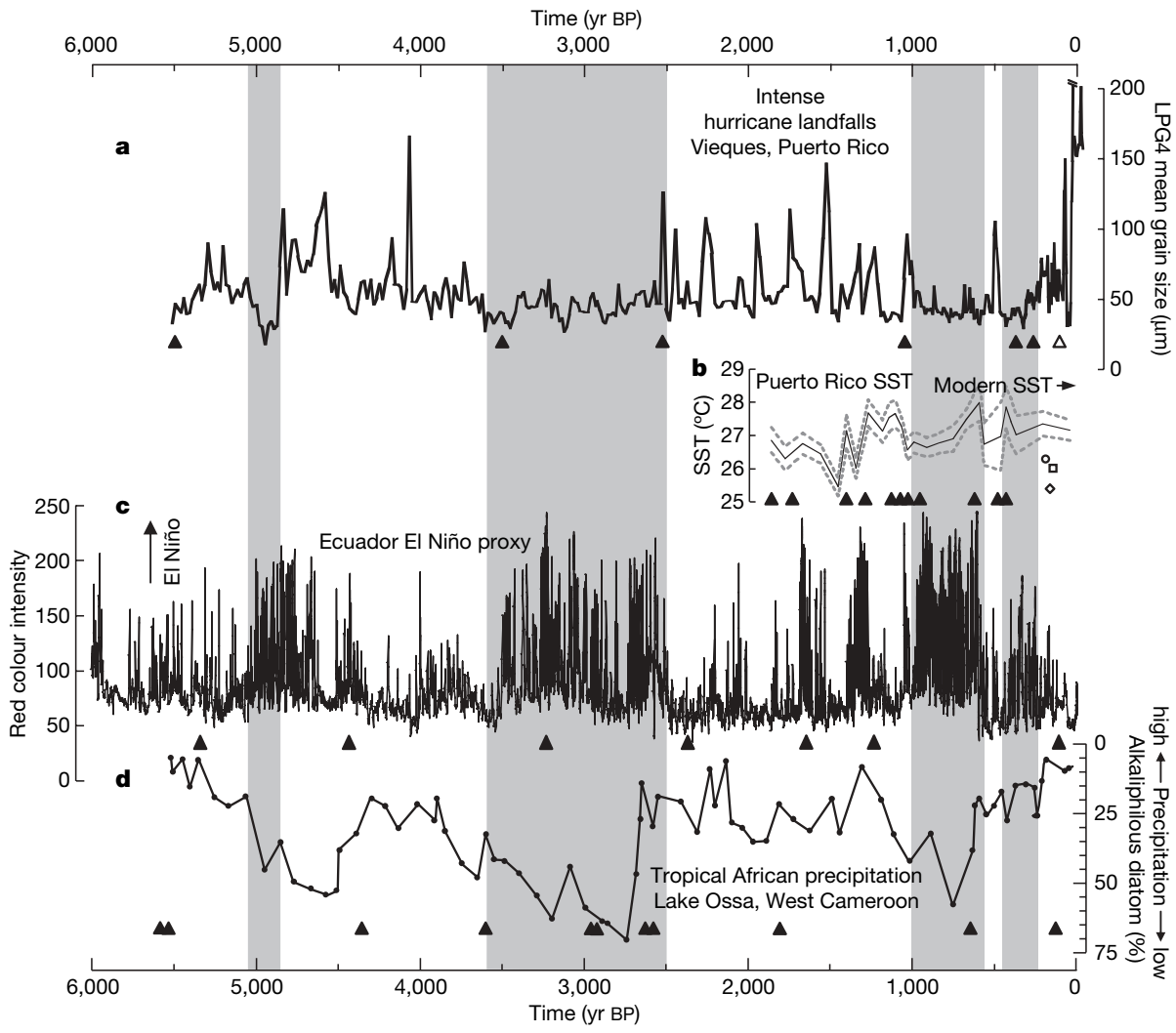

Figure 3 | Comparison of the intense hurricane record from LPG with other climate records. a, Mean bulk grain-size record from LPG4. Intervals of relatively few intense-hurricane-induced layers in all cores are noted with shading. $\mathbf{b}$, The thin line with the $2 \sigma$ uncertainty envelope (dashed lines) is a reconstruction of summer SSTs off Puerto Rico ${ }^{16}$ (core PRP12) and coralbased reconstruction of mean annual SSTs from La Parguera, Puerto Rico ${ }^{17}$, are noted: $26.2^{\circ} \mathrm{C}$ for $1700-1705 \mathrm{AD}$ (circle), $25.3{ }^{\circ} \mathrm{C}$ for $1780-1785 \mathrm{AD}$ (diamond), and $26.0^{\circ} \mathrm{C}$ for $1800-1805 \mathrm{AD}$ (square). The modern mean annual SST is noted with an arrow. c, El Niño proxy reconstruction from Laguna Pallcacocha, Ecuador ${ }^{22}$. Peaks in red colour intensity are documented as allochthonous material washed into the lake primarily during strong El Niño events. d, Changes in precipitation in West Cameroon inferred from alkaliphilous diatoms (thriving in alkaline conditions) from Lake Ossa ${ }^{23}$. Radiocarbon age control points are noted with black arrows below all panels. 
negative SST anomaly in the eastern equatorial Atlantic have been linked to drought in western Africa ${ }^{26}$. However, controls on eastern equatorial Atlantic SST fluctuations independent of ENSO may also have played an important part in modulating the intensity of the West African monsoon over the Holocene epoch ${ }^{27}$.

A coherent pattern of climate change over the past 5,000 years appears to have modulated intense hurricane activity in the northeastern Caribbean. The evolution of ENSO variability over the past several millennia probably played an important part in controlling the frequency of intense hurricanes in the Caribbean and perhaps the entire North Atlantic Basin, with intervals of fewer strong El Niño events resulting in less vertical wind shear over the tropical North Atlantic and more favourable conditions for intense hurricane development. In addition, variations in the West African monsoon and African easterly jet probably also play a critical role in modulating the frequency of North Atlantic intense hurricanes, with increases in convective storms over tropical Africa leading to stronger easterly waves moving into the tropical North Atlantic. Given the increase of intense hurricane landfalls during the later half of the Little Ice Age, tropical SSTs as warm as at present are apparently not a requisite condition for increased intense hurricane activity. In addition, the Caribbean experienced a relatively active interval of intense hurricanes for more than a millennium when local SSTs were on average cooler than modern. These results suggest that in addition to fluctuations in tropical Atlantic SST, changes in atmospheric dynamics tied to ENSO and the West African monsoon also act to modulate intense hurricane activity on centennial and millennial timescales. A better understanding of how these climate patterns will vary in the future is therefore required if we are to predict changes in intense hurricane activity accurately.

\section{METHODS}

Cores were collected using a Vohnout/Colinvaux piston corer in 5-cm-diameter polycarbonate barrels. Short $10-\mathrm{cm}$-diameter push cores were taken at select core locations to capture the sediment/water interface better and to provide adequate material for radio-isotopic analyses. These push cores were extruded in the field and sampled every $0.5 \mathrm{~cm}$. Measurements of the activity of $\mathrm{Cs}^{137}$ (a product of atmospheric nuclear weapons testing) were conducted using a highresolution gamma detector. The locations for all coring sites were determined using a handheld GPS unit which provided a horizontal accuracy of 3 to $6 \mathrm{~m}$. Sediment cores were split in the laboratory and selected core halves were run through a non-destructive Itrax core scanner to obtain millimetre- to submillimetre-resolution X-ray fluorescence measurements of the sediment's elemental composition, on the basis of methods described in ref. 28. Bulk grain-size analysis was conducted on contiguous $1-\mathrm{cm}$ samples using a Beckman-Coulter LS13320 laser diffraction particle-size analyser. As the bulk mean grain-size data represent siliciclastic, organic and calcareous material of varying densities, the relative magnitude of events cannot be directly inferred by comparing values for individual coarse layers. Samples of wood, seeds and shells were radiocarbon-dated at the National Ocean Sciences AMS Facility at Woods Hole Oceanographic Institution. The resulting radiocarbon ages were calibrated to calendar years using the IntCal $04^{29}$ and Marine $04^{30}$ calibration data sets (Supplementary Table 1).

\section{Received 21 November 2006; accepted 10 April 2007.}

1. Goldenberg, S. B., Landsea, C. W., Mestas-Nunez, A. M. \& Gray, W. M. The recent increase in Atlantic hurricane activity: Causes and implications. Science 293, 474-479 (2001).

2. Emanuel, K. Increasing destructiveness of tropical cyclones over the past 30 years. Nature 436, 686-688 (2005)

3. Webster, P. J., Holland, G. J., Curry, J. A. \& Chang, H.-R. Changes in tropical cyclone number, duration, and intensity in a warming environment. Science 309, 1844-1846 (2005)

4. Landsea, C. W., Harper, B. A., Hoarau, K. \& Knaff, J. A. Can we detect trends in extreme tropical cyclones. Science 313, 452-454 (2006).

5. Liu, K. B. \& Fearn, M. L. Reconstruction of prehistoric landfall frequencies of catastrophic hurricanes in northwestern Florida from lake sediment records. Quat. Res. 54, 238-245 (2000)

6. Donnelly, J. P. et al. $700 \mathrm{yr}$ sedimentary record of intense hurricane landfalls in southern New England. Geol. Soc. Am. Bull. 113, 714-727 (2001).
7. Donnelly, J. P., Butler, J., Roll, S., Wengren, M. \& Webb, T. A backbarrier overwash record of intense storms from Brigantine, New Jersey. Mar. Geol. 210, 107-121 (2004).

8. Donnelly, J. P. Evidence of past intense tropical cyclones from backbarrier salt pond sediments: A case study from Isla de Culebrita, Puerto Rico, USA. J. Coast. Res. SI42, 201-210 (2005)

9. Roy, P. S., Cowell, P. J., Ferland, M. A. \& Thom, B. G. in Coastal Evolution: Late Quaternary Shoreline Morphodynamics (eds Carter, R. W. G. \& Woodroffe, C. D.) 121-186 (Cambridge Univ. Press, Cambridge, UK, 1994).

10. Cooper, J. A. G. Beachrock formation in low latitudes-implications for coastal evolutionary models. Mar. Geol. 98, 145-154 (1991).

11. Lighty, R. G., Macintyre, I. G. \& Struckenrath, R. Acropora Palmata reef framework: a reliable indicator of sea level in the western Atlantic for the past 10,000 years. Coral Reefs 1, 125-130 (1982).

12. Boose, E. R., Serrano, M. I. \& Foster, D. R. Landscape and regional impacts of hurricanes in Puerto Rico. Ecol. Monogr. 74, 335-352 (2004).

13. Scileppi, E. \& Donnelly, J. P. Sedimentary evidence of hurricane strikes in western Long Island, New York. Geochem. Geophys. Geosyst. (in the press).

14. Elsner, J. B., Liu, K. B. \& Kocher, B. Spatial variations in major US hurricane activity: Statistics and a physical mechanism. J. Clim. 13, 2293-2305 (2000).

15. Emanuel, K. The dependence of hurricane intensity on climate. Nature 326, 483-485 (1987)

16. Nyberg, J., Malmgren, B. A., Kuijpers, A. \& Winter, A. A centennial-scale variability of tropical North Atlantic surface hydrography during the late Holocene. Palaeogeogr. Palaeoclimatol. Palaeoecol. 183, 25-41 (2002)

17. Winter, A., Ishioroshi, H., Watanabe, T., Oba, T. \& Christy, J. Caribbean sea surface temperatures: two to three degrees cooler than present during the Little Ice Age. Geophys. Res. Lett. 27, 3365-3368 (2000).

18. Garcia-Herrera, R., Gimeno, L., Ribera, P. \& Hernandez, E. New records of Atlantic hurricanes from Spanish documentary sources. J. Geophys. Res. 110, 1-7 (2005).

19. Gray, S. T., Graumlich, L. J., Betancourt, J. L. \& Pederson, G. T. A tree-ring-based reconstruction of the Atlantic Multidecadal Oscillation since 1567 A.D. Geophys. Res. Lett. 31, 1-4 (2004).

20. Gray, W. M. Atlantic seasonal hurricane frequency. Part I: El Nino and $30 \mathrm{mb}$ quasi-biennial oscillation influences. Mon. Weath. Rev. 112, 1649-1668 (1984).

21. Bove, M. C., Elsner, J. B., Landsea, C. W., Niu, X. F. \& O'Brien, J. J. Effect of El Nino on US landfalling hurricanes, revisited. Bull. Am. Meteorol. Soc. 79, 2477-2482 (1998)

22. Moy, C. M., Seltzer, G. O., Rodbell, D. T. \& Anderson, D. M. Variability of El Nino/ Southern Oscillation activity at millennial timescales during the Holocene epoch. Nature 420, 162-165 (2002).

23. Nguetsop, V. F., Servant-Vildary, S. \& Servant, M. Late Holocene climatic changes in west Africa, a high resolution diatom record from equatorial Cameroon. Quat. Sci. Rev. 23, 591-609 (2004).

24. Bell, G. D. \& Chelliah, M. Leading tropical modes associated with interannual and multidecadal fluctuations in North Atlantic hurricane activity. J. Clim. 19, 590-612 (2006).

25. Cook, K. H. Generation of the African easterly jet and its role in determining West African precipitation. J. Clim. 12, 1165-1184 (1999).

26. Janicot, S., Harzallah, A., Fontaine, B. \& Moron, V. West African monsoon dynamics and eastern equatorial Atlantic and Pacific SST anomalies (1970-88) J. Clim. 11, 1874-1882 (1998).

27. Weldeab, S., Schneider, R. R., Kolling, M. \& Wefer, G. Holocene African droughts relate to eastern equatorial Atlantic cooling. Geology 33, 981-984 (2005).

28. Croudace, I. W., Rindby, A. \& Rothwell, R. G. ITRAX: description and evaluation of a new X-ray core scanner. In New Techniques in Sediment Core Analysis (ed. Rothwell, R. G.) Geol. Soc. Lond. Spec. Publ. 267, 51-63 (2006).

29. Reimer, P. J. et al. IntCal04 terrestrial radiocarbon age calibration, $0-26$ cal kyr BP. Radiocarbon 46, 1029-1058 (2004).

30. Hughen, K. A. et al. Marine04 marine radiocarbon age calibration, 0-26 cal kyr BP. Radiocarbon 46, 1059-1086 (2004).

Supplementary Information is linked to the online version of the paper at www.nature.com/nature.

Acknowledgements Funding for this research was provided by the National Science Foundation, the Risk Prediction Initiative, the National Geographic Society, the Coastal Ocean Institute at Woods Hole Oceanographic Institution, and the Andrew W. Mellon Foundation Endowed Fund for Innovative Research. We are grateful to E. Bryant, E. Scileppi, J. Tierney, and A. Jovanovic who assisted with the field and laboratory work. E. Uchupi and P. Lane provided advice and D. Oppo, J. Russell, T. Webb III, K. Emanuel and L. Giosan made suggestions for improving this manuscript. This is a contribution of IGCP 495-'Holocene land-ocean interactions: driving mechanisms and coastal responses'.

Author Information Reprints and permissions information is available at www.nature.com/reprints. The authors declare no competing financial interests. Correspondence and requests for materials should be addressed to J.P.D. (jdonnelly@whoi.edu). 


\title{
Chapter 3:
}

\section{Reconstructing relative flooding intensities responsible for hurricane- induced deposits from Laguna Playa Grande, Vieques, Puerto Rico*}

\begin{abstract}
Extreme coastal flooding, primarily during hurricane strikes, has deposited sand-rich layers in Laguna Playa Grande, a backbarrier lagoon located on the island of Vieques, Puerto Rico. Siliciclastic grain-size distributions within these overwash deposits fine landward (away from the barrier and toward the mainland). A simple advective-settling model can explain this pattern of lateral sorting and is used to constrain the relative magnitude of past flooding events. A deposit associated with the A.D. 1928 San Felipe hurricane is used as a modern analogue to test the technique, which produces reasonable estimates for wave heights that exceed the barrier during the event. A $5000 \mathrm{yr}$ reconstruction of local flooding intensity is developed that provides a measure of the competence for each overwash event to transport coarser-grained sediment a fixed distance into the lagoon. This reconstruction indicates that although the Laguna Playa Grande record exhibits large-scale changes in hurricane frequency on centennial to millennial time scales, the magnitude of these events has stayed relatively constant. Over the last $5000 \mathrm{yr}$, no evidence exists for an anomalously large hurricane or tsunami event with a competence for sediment transport greater than historical hurricane events.
\end{abstract}

*Published as: Woodruff, J.D., Donnelly, J.P., Mohrig, D., and Geyer, W.R., 2008b, Reconstructing relative flooding intensities responsible for hurricane-induced deposits from Laguna Playa Grande, Vieques, Puerto Rico: Geology, v. 36, p. 391-394. 


\title{
Reconstructing relative flooding intensities responsible for hurricane- induced deposits from Laguna Playa Grande, Vieques, Puerto Rico
}

\author{
Jonathan D. Woodruff Massachusetts Institute of Technology-Woods Hole Oceanographic Institution Joint Program in \\ Oceanography, Woods Hole, Massachusetts 02543, USA \\ Jeffrey P. Donnelly Woods Hole Oceanographic Institution, Woods Hole, Massachusetts 02543, USA \\ David Mohrig Jackson School of Geosciences, University of Texas at Austin, Austin, Texas 78712, USA \\ Wayne R. Geyer Woods Hole Oceanographic Institution, Woods Hole, Massachusetts 02543, USA
}

\begin{abstract}
Extreme coastal flooding, primarily during hurricane strikes, has deposited sand-rich layers in Laguna Playa Grande, a backbarrier lagoon located on the island of Vieques, Puerto Rico. Siliciclastic grain-size distributions within these overwash deposits fine landward (away from the barrier and toward the mainland). A simple advective-settling model can explain this pattern of lateral sorting and is used to constrain the relative magnitude of past flooding events. A deposit associated with the A.D. 1928 San Felipe hurricane is used as a modern analogue to test the technique, which produces reasonable estimates for wave heights that exceed the barrier during the event. A $\mathbf{5 0 0 0} \mathbf{y r}$ reconstruction of local flooding intensity is developed that provides a measure of the competence for each overwash event to transport coarser-grained sediment a fixed distance into the lagoon. This reconstruction indicates that although the Laguna Playa Grande record exhibits large-scale changes in hurricane frequency on centennial to millennial time scales, the magnitude of these events has stayed relatively constant. Over the last $5000 \mathrm{yr}$, no evidence exists for an anomalously large hurricane or tsunami event with a competence for sediment transport greater than historical hurricane events.
\end{abstract}

Keywords: Caribbean, tropical cyclones, tsunamis, paleotempestology, sediment transport, grain-size distribution.

\section{INTRODUCTION}

Records of storm-induced overwash deposits serve as valuable resources for assessment of tropical cyclone frequency and intensity (Donnelly et al., 2001; Liu and Fearn, 1993; Nott, 2004). This previous work has focused on reconstructing the frequency of extreme flooding events without quantifying event magnitudes. Methods based on the physics of sediment transport can be applied to estimate the local flow conditions associated with past hurricanes. Recently, techniques for quantifying the magnitude of past inundation events have been tested for modern tsunami-induced overwash layers, sorted both vertically (Jaffe and Gelfenbaum, 2007) and laterally (Moore et al., 2007). These studies have focused on validating techniques with modern tsunami deposits of known intensity; however, an inverse modeling approach has yet to be applied to hurricane deposits. Here, we first validate an inverse hurricane modeling technique using the A.D. 1928 San Felipe hurricane deposit. The model is then used to reconstruct flooding conditions for 28 additional overwash layers deposited over the past 5000 yr at Laguna Playa Grande, a Caribbean lagoon located on the island of Vieques, Puerto Rico (Fig. 1).

Donnelly and Woodruff (2007) reconstructed a 5000 yr record of hurricane strikes using coarse-grained overwash deposits from Laguna Playa Grande. The location of the Laguna Playa Grande barrier appears to have remained relatively stable through this time, and lagoonal sedimentation rates are similar to the rates of sea-level rise measured for the region. The tidal range at the site is small $(\sim 0.2 \mathrm{~m})$, and bathymetry in the lagoon is relatively flat and free of aquatic vegetation. Cores collected from Laguna Playa Grande contain several meters of organic-rich, cohesive clays and silts, interbedded with coarser-grained deposits. These coarser-grained layers are composed of material similar to that observed along the barrier beach, a mixture of rounded siliciclastic sand and calcium carbonate shells and shell fragments. Measured ages for the topmost coarser-grained layers correlate well with the timing of documented intense hurricane strikes. The Donnelly and Woodruff (2007) reconstruction for intense hurricanes was based on bulk grain-size measurements from a deposit of mixed and varying composition. As a result, the relative event magnitudes for individual deposits could not be assessed.

To quantify flooding intensities, we applied a simple advectivesettling model to the isolated siliciclastic fraction of overwash deposits from cores along three shore-normal transects at the site (Fig. 1). To calibrate the model, we examined the spatial distribution of the 1928 San Felipe hurricane deposit, as well as a deposit that has particularly large bulk grain sizes dating to ca. A.D. 600 or $1350 \mathrm{yr}$ B.P. Finally, a reconstruction of local flooding intensity was developed for the entire $5000 \mathrm{yr}$ Laguna Playa Grande record by applying the inverse model to lagoon sediments collected at a suitable distance inland from the barrier.

\section{METHODS FOR IDENTIFYING A.D. 1928 AND 1350 YR B.P. DEPOSITS}

Based on the work of Donnelly and Woodruff (2007), the category 5 San Felipe hurricane of 1928 appears to have been one of the most intense hurricanes to leave a deposit at Laguna Playa Grande over the past $100 \mathrm{yr}$. This deposit is located $\sim 15 \mathrm{~cm}$ below the lagoon-sediment interface. This burial depth is based on the mean sedimentation rate of $2 \mathrm{~mm} / \mathrm{yr}$ obtained using both the A.D. 1963 peak in Cs-137, as well as evidence for abrupt clearing of vegetation from the island in A.D. 1840 (Fig. 2). The signal of land clearance is indicated by an increase in bulk sedimentary Ti at the burial depth of $\sim 34 \mathrm{~cm}$ (Fig. 2; Appendix DR2 in the GSA Data Repository $\left.^{1}\right)$. Ti has been found to be insensitive to redox processes and a relatively good sedimentary proxy for changes in terrestrial run-off (Haug et al., 2001). The abrupt ca. 1840 increase in Ti occurs at $\sim 34 \mathrm{~cm}$ across the entire lagoon and suggests a similar sedimentation rate of $\sim 2 \mathrm{~mm} / \mathrm{yr}$ throughout the basin over approximately the past $160 \mathrm{yr}$.

In addition to the 1928 A.D. event layer, we also sampled a substantially larger deposit (both in thickness and bulk grain size) that was deposited ca. A.D. 600 or $1350 \mathrm{yr}$ B.P. (Fig. 2). The deposit can be correlated throughout the cores based on a second abrupt basinwide increase in Ti that occurs just above the burial depth of this event deposit (Fig. 2; Appendix DR2). The sudden Ti increase at this layer is also accompanied by a distinct color change, a lightening from dark brown to light brown up-core, which provides an additional stratigraphic marker for identifying the $1350 \mathrm{yr}$ B.P. deposit. A similar step-function increase in terrestrial-sourced material at roughly the same time was observed in a sediment core collected off the southern coast of Puerto Rico and has been interpreted to represent a rapid regional increase in precipitation (Nyberg et al., 2001).

'GSA Data Repository item 2008095, Appendices DR1-DR6 (methods, archival data, wave runup estimates, flow approximations, suspended sediment flux estimates, and a discussion of deposit genesis), is available online at www. geosociety.org/pubs/ft2008.htm, or on request from editing @ geosociety.org or Documents Secretary, GSA, P.O. Box 9140, Boulder, CO 80301, USA. 


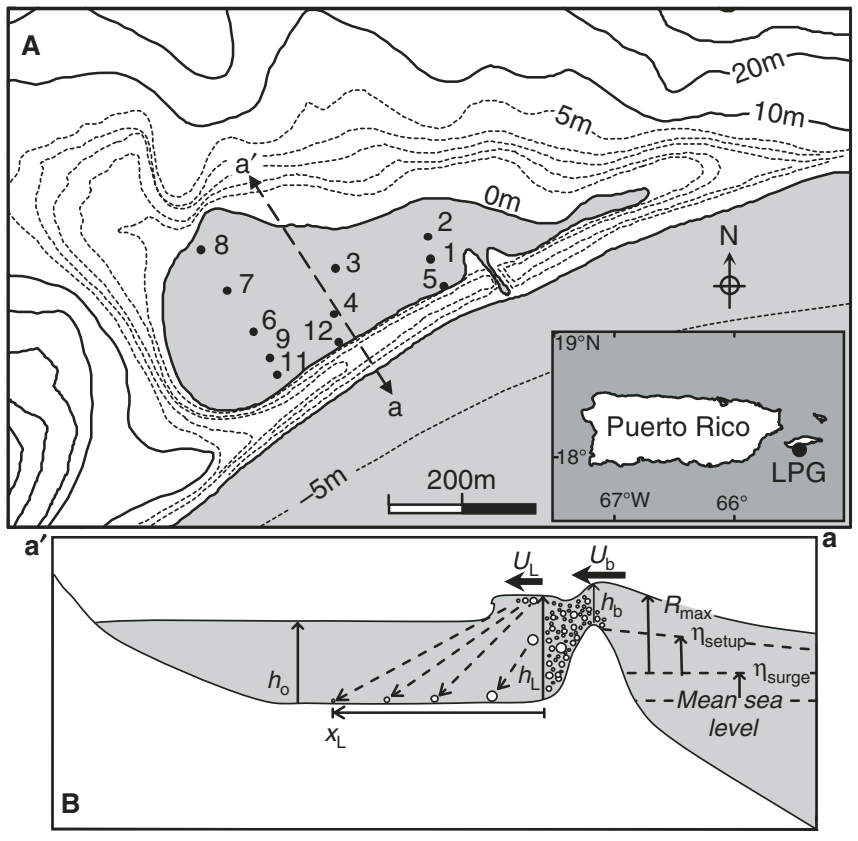

Figure 1. A: Site map of Laguna Playa Grande (LPG), Vieques, Puerto Rico $\left(18.09^{\circ} \mathrm{N}, 65.52^{\circ} \mathrm{W}\right)$. Numbered dots indicate core positions, inset map shows regional location, and a-a' dashed line identifies location of cross section shown in B. B: Shore-normal cross section illustrating overwash process described by advective-settling model, where $\eta_{\text {setup }}$ and $h_{\circ}$ represent time-averaged wave setup and lagoon's partially flooded water depth, respectively. All other variables are defined in text.

\section{DEPOSIT COMPARISON AND SORTING PATTERNS}

Siliciclastic particles were consistently smaller in the 1928 deposit compared to the $1350 \mathrm{yr}$ B.P. deposit (Fig. 3), indicating that the 1350 yr B.P. event was capable of transporting coarser sediment farther into the lagoon. However, in the case of the 1350 yr B.P. deposit, siliciclastic particles were often significantly smaller than bulk sediments (Fig. 3B), primarily due to larger marine shells and shell fragments within the bulk material (carbonates composed $25 \% \pm 6 \%$ of the samples by mass). In many cases, grain sizes for the bulk samples were observed to increase landward, probably due in part to the significantly smaller settling velocities associated with the porous and therefore less dense shell material (Appendix DR2). The grain-size discrepancies between bulk and siliciclastic measurements within the 1350 yr B.P. deposit demonstrate that the flooding intensity for the event was likely not as large as might be inferred using only the bulk sample. In contrast to the landward coarsening for bulk sediments, once shell and organic material were removed, the size of the remaining siliciclastic particles in the $1350 \mathrm{yr}$ B.P. deposit systematically decreased away from the barrier and toward the mainland (Fig. 3). This same landward-fining trend was evident for the siliciclastic fraction of the 1928 deposit, and it provides additional evidence that both layers were deposited while being advected landward during marine flooding events. No clear vertical sorting trends could be discerned from the analyzed Laguna Playa Grande deposits (Appendix DR2).

\section{ADVECTIVE-SETTLING MODEL}

The landward-fining trends seen in the Laguna Playa Grande deposits indicate that all available particle sizes were not uniformly mixed throughout the basin during overwash activity but instead were spatially sorted during transport across the lagoon. The observed grainsize trends from deposits in each of the three shore-normal transects

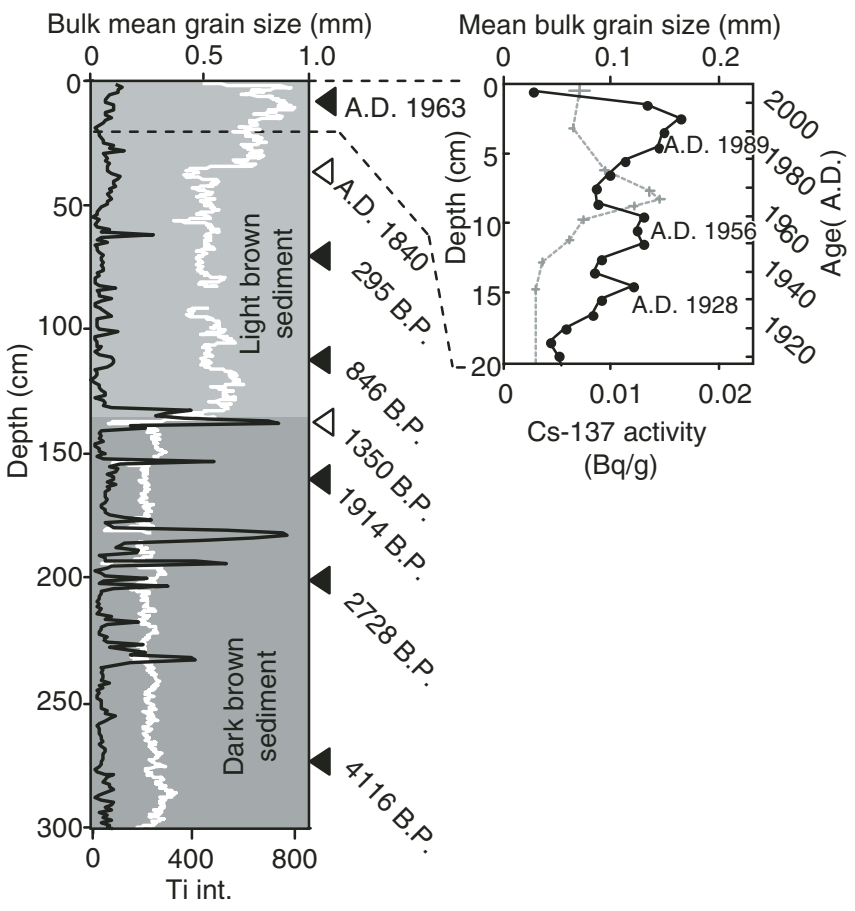

Figure 2. Ti peak area integral (white) and mean bulk grain sizes (black) for core 12 (left plot). Solid arrows represent approximate ages of radiocarbon-dated samples and A.D. 1963 Cs-137 peak obtained by Donnelly and Woodruff (2007). Depths of abrupt increases in $\mathrm{Ti}$ associated with land clearance ca. 1840 (110 yr B.P.) and ca. 1350 yr B.P. (A.D. 600) are noted with open triangles (ages based on a linear interpolation between Cs-137 and C-14 age controls). Change in shading indicates depth for observed change in sediment color and abrupt increase in Ti just above $1350 \mathrm{yr}$ B.P. deposit. Right plot shows enlarged upper $20 \mathrm{~cm}$ of mean bulk grain size for core 12 (solid black line) and Cs-137 activities (dashed gray line). Age model is based on an accumulation rate of $2 \mathrm{~mm} / \mathrm{yr}$ derived from A.D. $1963 \mathrm{Cs}-137$ peak at $8.5 \mathrm{~cm}$ and evidence of land clearance (ca. 1840) at $34 \mathrm{~cm}$. Deposits attributable to documented hurricanes are noted. Methods for obtaining grain size, Cs-137, Ti, and radiocarbon measurements are provided in Appendix DR1 (see text footnote 1).

are also consistent with each other (Fig. 3), suggesting that sediment was carried into the lagoon by waves large enough to overtop the entire length of the barrier during large-scale inundation events. Field and experimental observations suggest that flow along the sloping backside of the barrier during these overwash conditions transitions to supercritical (Donnelly et al., 2006; Holland et al., 1991), where the top of the barrier acts as a hydraulic control (Baldock et al., 2005). Limited observations also suggest that sediment transport under extreme inundation is dominated by suspended load (Donnelly et al., 2006; Visser, 1998), and the temporal structure of velocities and concentrations under dissipative conditions occur on infragravity time scales, $\mathrm{T}=20-250 \mathrm{~s}$ (Ruessink et al., 1998; Stockdon et al., 2006).

The observed patterns in lateral sorting can be reproduced using a relatively simple advective-settling model similar to that used by Moore et al. (2007). The model is relevant for sediment traveling primarily in suspension and assumes that the time it takes a particle to settle from the top of the flow to the bed is equal to the time associated with inundating currents transporting the suspended particle a horizontal distance into the lagoon, $x_{\mathrm{L}}$, at an average flow velocity, $U_{\mathrm{L}}$ :

$$
t=\frac{x_{\mathrm{L}}}{U_{\mathrm{L}}}=\frac{h_{\mathrm{L}}}{w_{\mathrm{s}}},
$$



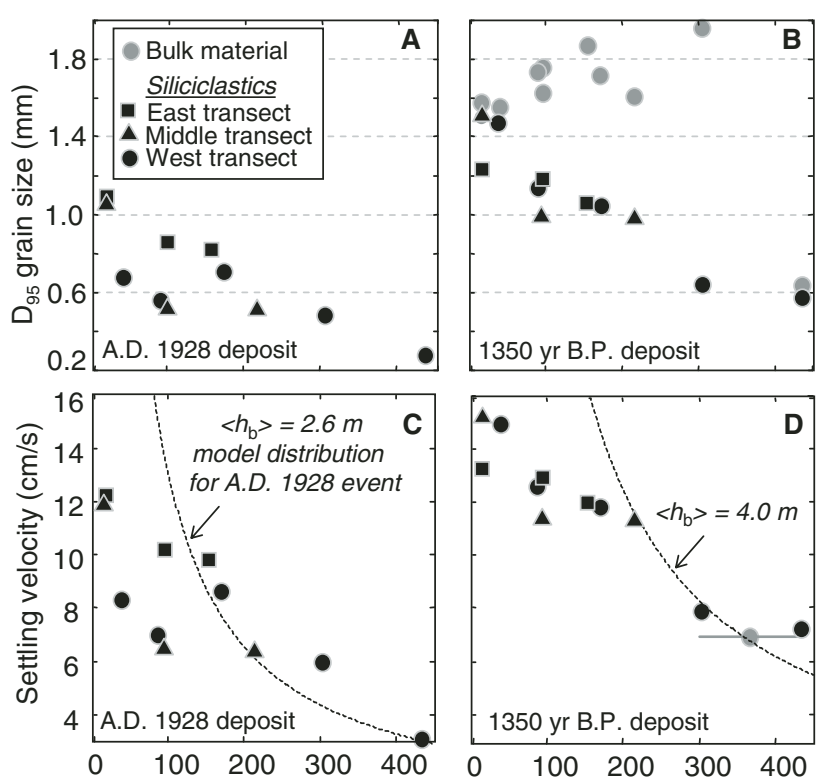

Distance from back of barrier $(\mathrm{m})$

Figure 3. A-B: Shore-normal grain-size distributions measured for coarse fraction $(>63 \mu \mathrm{m})$ of A.D. 1928 and $1350 \mathrm{yr}$ B.P. deposits. C-D: Particle settling velocities estimated for grain sizes shown in $A$ and B. Black dashed line indicates distribution predicted by advectivesettling model using $2.6 \mathrm{~m}$ and $4 \mathrm{~m}$ flooding depths estimated for the 1928 and the $1350 \mathrm{yr}$ B.P. events. Gray line in D indicates the average settling velocity and maximum range that shell material was transported into lagoon.

where $h_{\mathrm{L}}$ is the flow depth in the lagoon during flooding, and $w_{\mathrm{s}}$ is the particle settling velocity (Figure 1B). The product of flow depth and flow velocity can be obtained by Equation 1 but still requires an additional constraint to attain a unique solution. We build on this advective-settling approach by assuming that the inflow occurs as a bore propagating across the barrier and into the lagoon, where hydraulically critical flow occurs at the crest of the barrier, i.e., the Froude number, $\mathrm{Fr}=U_{\mathrm{b}} /\left(g h_{\mathrm{b}}\right)^{1 / 2}=1$. Here, $g$ is gravity, $U_{\mathrm{b}}$ is the flow speed over the barrier, and $h_{\mathrm{b}}$ is the flow depth over the barrier (Fig. 1B). In addition, based on mass continuity, we assume that the flow rate per unit width in the lagoon is equal to the flow rate of the bore. Because $h_{\mathrm{L}}$ exceeds $h_{\mathrm{b}}$ (Fig. 1B), the velocity in the lagoon is significantly less than the velocity at the barrier (Appendix DR4). We assume that the high velocities and wave-induced turbulence over the barrier cause intense resuspension, leading to a high concentration and relatively well-mixed vertical distribution of sediment at the barrier crest. As the sediment is advected into the lagoon, settling is assumed to be much more important than turbulent resuspension due to the large reduction of turbulent intensity between the barrier and the lagoon. Because the distance a particle is carried landward is inversely related to its settling velocity, smaller siliciclastic particles are advected further into the lagoon, which results in a landward-fining deposit similar to that observed within the event layers at Laguna Playa Grande.

Assuming the volumetric flow rate per unit width, $q$, at the barrier crest is critical and equal to the flow across the lagoon, the following relationship is obtained,

$$
q=U_{\mathrm{L}} h_{\mathrm{L}}=U_{\mathrm{b}} h_{\mathrm{b}}=\sqrt{g h_{\mathrm{b}}{ }^{3}} .
$$

Equation 2 provides the additional constraint required by Equation 1 in order to obtain a unique solution for a quantity that scales with the flow depth over the barrier:

$$
<h_{\mathrm{b}}>=\left(\frac{x_{\mathrm{L}}{ }^{2} w_{\mathrm{s}}{ }^{2}}{g}\right)^{1 / 3} .
$$

For this analysis, we used the settling velocity for the siliciclastic $\mathrm{D}_{95}$ size class (defined as the grain size for which $95 \%$ of sample has smaller grain sizes [by volume]) to represent the maximum grain size at each site (scatter in the data increased significantly for size fractions greater than $\mathrm{D}_{95}$ as a result of the limited number of grains in these larger size classes). Based on empirical results, $w_{\mathrm{s}}$ is related to the grain-size diameter for siliciclastic particles using the relationship developed by Ferguson and Church (2004). Predictions using this relationship produced similar settling velocities to those observed by settling-tube analyses of sieved samples from Laguna Playa Grande deposits (Appendix DR2).

\section{MODEL ASSESSMENT AND RESULTS}

To test the accuracy of the advective-settling model, we compared the $<h_{\mathrm{b}}>$ predictions using grain-size distributions from the 1928 deposit to storm-surge $\left(\eta_{\text {surge }}\right)$ and maximum wave runup $\left(R_{\max }\right)$ estimates at Laguna Playa Grande during this hurricane event (Fig. 1B). We assume that $<h_{\mathrm{b}}>$ is most likely related to the maximum instantaneous water level above the barrier during breaching, which is equal to the cumulative effects of storm surge and maximum wave runup $\left(\eta_{\text {surge }}+R_{\text {max }}\right)$ minus the elevation of the barrier. Given that Vieques is a small island with steep offshore bathymetry, storm surge during hurricane activity is relatively small, and $\eta_{\text {surge }}$ is estimated at $0.9 \mathrm{~m}$ (Mercado, 1994). Based on the meteorological conditions for the 1928 hurricane, we estimated a value of $\sim 3.7 \mathrm{~m}$ for $R_{\max }$ (Appendix DR3). If this approximation for $R_{\max }$ is added to the estimate for $\eta_{\text {surge }}$ by Mercado (1994), maximum water levels reached $4.6 \mathrm{~m}$ above mean sea level during the 1928 hurricane and exceeded the $2 \mathrm{~m}$ barrier by roughly $2.6 \mathrm{~m}$.

Estimates for $<h_{\mathrm{b}}>$ using observations from the 1928 deposit are consistent with the $2.6 \mathrm{~m}$ flooding depths estimated for the event, but only at a suitable distance away from the barrier (>200 m, Fig. 3C). The observed settling velocities closer to the barrier are smaller than the values Equation 3 predict. This is most likely because the larger grain sizes required to predict wave heights close to the barrier do not mix to the top of the water column at sufficient concentrations. As an example, at $50 \mathrm{~m}$ from the barrier, Equation 3 predicts a particle settling velocity of $26 \mathrm{~cm} / \mathrm{s}$ or a grain size of $3.9 \mathrm{~mm}$ for the 1928 event. These grain sizes are much larger than anything observed along the barrier $\left(\mathrm{D}_{95} \approx 1.7 \mathrm{~mm}\right.$ for Laguna Playa Grande beach samples).

Estimates of $<h_{\mathrm{b}}>$ from the $1350 \mathrm{yr}$ B.P. deposit are $\sim 4 \mathrm{~m}$, consistently greater than those predicted for the 1928 hurricane (Fig. 3D). These estimates are also consistent with approximations based on the distribution of shell material from the same deposit, the largest particles of which $\left(\mathrm{D}_{95}=1-2 \mathrm{~mm}, w_{\mathrm{s}} \approx 7 \mathrm{~cm} / \mathrm{s}\right.$; Appendix DR2) appear to have settled out between core sites 7 and $8(x=300-430 \mathrm{~m}$; Fig. 3B), producing an estimate for $<h_{\mathrm{b}}>$ of $\sim 4 \mathrm{~m}$.

Results from the A.D. 1928 and 1350 yr B.P. event layers suggest that $<h_{\mathrm{b}}>$ can be estimated for individual deposits within the Laguna Playa Grande record if the advective-settling model is applied to sediments collected at a sufficient distance $(>200 \mathrm{~m})$ from the barrier. As a result, we chose overwash deposits from core 3 ( $214 \mathrm{~m}$ from barrier; Fig. 1) to develop a reconstruction of $\left\langle h_{\mathrm{b}}\right\rangle$. The resulting calculated values of $\left\langle h_{\mathrm{b}}\right\rangle$ are similar throughout the record, ranging between $2 \mathrm{~m}$ and $4 \mathrm{~m}$ (Fig. 4).

Theoretical calculations suggest that model assumptions are valid for the range of wave heights estimated from core 3 (Appendixes DR4 and DR5). For instance, suspended sediment fluxes over the barrier are $\sim 100-1000$ times greater than the equilibrium fluxes that can be supported strictly by resuspension in the lagoon. This strongly suggests that for the conditions presented in Figure 4, settling dominates resuspension in the lagoon, a primary assumption made by the model. The preservation of historical hurricane deposits at Laguna Playa Grande, as well as markers 
Figure 4. Mean bulk grain size data for core 3 along with estimates of $\left\langle h_{b}\right\rangle$ for isolated event layers. Equivalent $\mathrm{D}_{95}$ siliciclastic grain sizes used to calculate incremental values of $\left\langle h_{b}\right\rangle$ are noted. Depths of abrupt increases in $\mathrm{Ti}$ associated with land clearance ca. 1840 (110 yr B.P.) and ca. 1350 yr B.P. are noted with open triangles. Depths for approximate ages of 2500 and $5000 \mathrm{yr}$ B.P. are based on the chronological constraints presented in Appendix DR2 (see text footnote 1). Years of the four most intense hurricanes passing within $75 \mathrm{~km}$ of the site since 1850 are noted, along with the less documented 1825 Santa Ana hurricane.

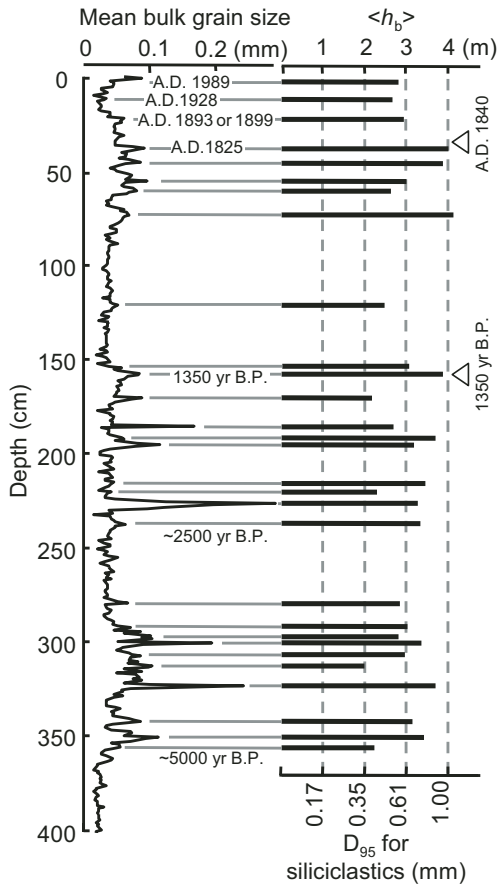

for other modern strata (A.D. 1840 land clearance and 1963 Cs-137 peak), also supports this conclusion by showing that erosion during inundation events has not been significant enough to disrupt past event layers. Finally, the suspended sediment flux from the barrier is 10-100 times greater than approximations for the bed-load flux in the basin based on calculations presented by Meyer-Peter and Müller (1948), which suggest that suspended loads from the barrier likely govern the distribution of overwash sediment in the lagoon.

Results from the reconstruction in Figure 4 show that the magnitude of $\left\langle h_{\mathrm{b}}\right\rangle$ does not appear to have systematically varied over the past $5000 \mathrm{yr}$, and they indicate similar intensities of coast flooding for all 29 events analyzed. The reconstruction provides no evidence for anomalously large-scale tsunami or hurricane events when compared to historical deposits. For example, estimates of $\left\langle h_{\mathrm{b}}\right\rangle$ for the $1350 \mathrm{yr}$ B.P. event are relatively large when compared to the 1928 event but are similar to estimates for a deposit at $38 \mathrm{~cm}$, which likely dates to the 1825 Santa Ana hurricane (Fig. 4). The Santa Ana hurricane was one of the most intense hurricanes to hit eastern Puerto Rico in the nineteenth century (Sola, 1995). Although direct observations of the event are limited, an analysis of damage caused by the event indicates that winds reached F3 intensity on the Fujita scale, exceeding 96 knots (Boose et al., 2004). Our analysis suggests that the sediment transport competence for this event was similar to that of the $1350 \mathrm{yr}$ B.P. event.

\section{CONCLUSIONS}

Using inverse modeling techniques, a $5000 \mathrm{yr}$ reconstruction of local flooding intensity from the northeast Caribbean is provided. Model results match observations for the 1928 San Felipe deposit and validate the technique for reconstructing hurricane-induced flooding at the site. Results show that although the Vieques overwash record indicates periods in which hurricane strikes have occurred more frequently, no event appears to have carried coarse-grained sediment any farther than storms occurring during the historic period. Thus, none of the 29 overwash deposits analyzed in this study appears to have been associated with an anomalously large hurricane or tsunami event, with a sediment transport competence significantly greater than intense historical hurricanes.

\section{ACKNOWLEDGMENTS}

Funding for this research was provided by the Earth Systems History Program of the National Science Foundation, Risk Prediction Initiative, National Geographic Society, Coastal Ocean Institute at Woods Hole Oceanographic Institution (WHOI), and the Andrew W. Mellon Foundation Endowed Fund for Innovative Research. Major Research Instrumentation Program grant from the National Science Foundation provided funds for the acquisition of the X-ray fluorescence (XRF) core scanner. We are grateful to E. Bryant, M. Gomes, E. Scileppi, and J. Tierney, who assisted with the field and laboratory work. We also thank B. Raubenheimer and S. Elgar for informative discussions. Jody Bourgeois, Chris Paola, and anonymous referees provided helpful reviews of this paper.

\section{REFERENCES CITED}

Baldock, T.E., Hughes, M.G., Day, K., and Louys, J., 2005, Swash overtopping and sediment overwash on a truncated beach: Coastal Engineering, v. 52, p. 633-645, doi: 10.1016/j.coastaleng.2005.04.002.

Boose, E.R., Serrano, M.I., and Foster, D.R., 2004, Landscape and regional impacts of hurricanes in Puerto Rico: Ecological Monographs, v. 74, p. 335-352, doi: 10.1890/02-4057.

Donnelly, C., Kraus, N., and Larson, M., 2006, State of knowledge on measurement and modeling of coastal overwash: Journal of Coastal Research, v. 22, p. 965-991, doi: 10.2112/04-0431.1.

Donnelly, J.P., and Woodruff, J.D., 2007, Intense hurricane activity over the past 5,000 years controlled by El Niño and the West African monsoon: Nature, v. 447, p. 465-468, doi: 10.1038/nature05834.

Donnelly, J.P., Roll, S., Wengren, M., Butler, J., Lederer, R., and Webb, T., 2001, Sedimentary evidence of intense hurricane strikes from New Jersey: Geology, v. 29, p. 615-618, doi: 10.1130/0091-7613(2001)029<0615:SEOIHS >2.0.CO;2.

Ferguson, R.I., and Church, M., 2004, A simple universal equation for grain settling velocity: Journal of Sedimentary Research, v. 74, p. 933-937, doi: 10.1306/051204740933.

Haug, G.H., Hughen, K.A., Sigman, D.M., Peterson, L.C., and Rohl, U., 2001, Southward migration of the intertropical convergence zone through the Holocene: Science, v. 293, p. 1304-1308, doi: 10.1126/science.1059725.

Holland, T.K. Holman, R.A., and Sallenger, A.H., Jr., 1991, Estimation of overwash bore velocities using video techniques, in Kraus, N.C., Gingerich, K.J., and Kriebel, D.L., eds., Coastal Sediments '91: Seattle, Washington, American Society of Civil Engineers, p. 489-497.

Jaffe, B.E., and Gelfenbaum, G., 2007, A simple model for calculating tsunami flow speed from tsunami deposits: Sedimentary Geology, v. 200, p. 347-361, doi: 10.1016/j.sedgeo.2007.01.013.

Liu, K.B., and Fearn, M.L., 1993, Lake-sediment record of late Holocene hurricane activities from coastal Alabama: Geology, v. 21, p. 793-796, doi: 10.1130/0091-7613(1993)021<0793:LSROLH>2.3.CO;2.

Mercado, A., 1994, On the use of NOAA's storm surge model, SLOSH, in managing coastal hazards-The experience in Puerto Rico: Natural Hazards, v. 10, p. 235-246, doi: 10.1007/BF00596144.

Meyer-Peter, E., and Müller, R., 1948, Formulas for bed-load transport, in Proceedings of the 2nd Meeting of the International Association for Hydraulic Structures Research: Delft, Netherlands, International Association for Hydraulic Research, p. 39-64.

Moore, A.L., McAdoo, B.G., and Ruffman, A., 2007, Landward fining from multiple sources in a sand sheet deposited by the 1929 Grand Banks tsunami, Newfoundland: Sedimentary Geology, v. 200, p. 336-346, doi: 10.1016/ j.sedgeo.2007.01.012.

Nott, J., 2004, Palaeotempestology: The study of and implications of prehistoric tropical cyclones-A review for hazard assessment: Environment International, v. 30, p. 433-447, doi: 10.1016/j.envint.2003.09.010.

Nyberg, J., Kuijpers, A., Malmgren, B.A., and Kunzendorf, H., 2001, Late Holocene changes in precipitation and hydrography recorded in marine sediments from the northeastern Caribbean Sea: Quaternary Research, v. 56, p. $87-102$, doi: 10.1006/qres.2001.2249.

Ruessink, B.G., Kleinhans, M.G., and van den Beukel, P.G.L., 1998, Observations of swash under highly dissipative conditions: Journal of Geophysical Research, v. 103, p. 3111-3118, doi: 10.1029/97JC02791.

Sola, E.M., 1995, Historia de los Huracanes en Puerto Rico: Puerto Rico, First Book Publishing, $76 \mathrm{p}$

Stockdon, H.F., Holman, R.A., Howd, P.A., and Sallenger, A.H., Jr., 2006, Empirical parameterization of setup, swash, and runup: Coastal Engineering, v. 53, p. 573-588, doi: 10.1016/j.coastaleng.2005.12.005.

Visser, P.J., 1998, Breach Growth in Sand Dikes: Delft, Netherlands, Delft University of Technology, $172 \mathrm{p}$.

Manuscript received 31 August 2007

Revised manuscript received 22 January 2008

Manuscript accepted 24 January 2008

Printed in USA 


\title{
Chapter 4:
}

\section{Assessing sedimentary records of paleo-hurricane activity using modeled hurricane climatology"}

\begin{abstract}
Patterns of overwash deposition observed within back-barrier sediment archives can indicate past changes in tropical cyclone activity; however, it is necessary to evaluate the significance of observed trends in the context of the full range of variability under modern climate conditions. Here we present a method for assessing the statistical significance of patterns observed within a sedimentary hurricane-overwash reconstruction. To alleviate restrictions associated with the limited number of historical hurricanes affecting a specific site, we apply a recently published technique for generating a large number of synthetic storms using a coupled ocean-atmosphere hurricane model set to simulate modern climatology. Thousands of overwash records are generated for a site using a random draw of these synthetic hurricanes, a prescribed threshold for overwash, and a specified temporal resolution based on sedimentation rates observed at a particular site. As a test case we apply this Monte Carlo technique to a hurricane-induced overwash reconstruction developed from Laguna Playa Grande (LPG), a coastal lagoon located on the island of Vieques, Puerto Rico in the northeastern Caribbean. Apparent overwash rates in the LPG overwash record are observed to be four times lower between 2500 and 1000 years B.P. when compared to apparent overwash rates during the last 300 years. However, probability distributions based on Monte Carlo simulations indicate that as much as $65 \%$ of this drop can be explained by a reduction in the temporal resolution for older sediments due to a decrease in sedimentation rates. Periods of no apparent overwash activity at LPG between 2500 and 3600 years B.P. and 500-1000 years B.P. are exceptionally long and are unlikely to occur (above $99 \%$ confidence) under the current climate conditions. In addition, breaks in activity are difficult to produce even when the hurricane model is forced to a constant El Niño state. Results from this study continue to support the interpretation that the western North Atlantic has exhibited significant changes in hurricane climatology over the last 5500 years.

*Published as: Woodruff, J.D., Donnelly, J.P., Emanuel, K., and Lane, P., 2008, Assessing sedimentary records of paleohurricane activity using modeled hurricane climatology: Geochemistry Geophysics Geosystems, v. 9.
\end{abstract}




\title{
Assessing sedimentary records of paleohurricane activity using modeled hurricane climatology
}

\author{
Jonathan D. Woodruff \\ Massachusetts Institute of Technology/Woods Hole Oceanographic Institution Joint Program in Oceanography, Woods \\ Hole, Massachusetts 02543, USA (jwoodruff@whoi.edu)
}

\section{Jeffrey P. Donnelly}

Department of Geology and Geophysics, Woods Hole Oceanographic Institution, Woods Hole, Massachusetts O2543, USA

\author{
Kerry Emanuel \\ Program in Atmospheres, Oceans, and Climate, Massachusetts Institute of Technology, Cambridge, Massachusetts 02139, \\ USA
}

\section{Philip Lane \\ Massachusetts Institute of Technology/Woods Hole Oceanographic Institution Joint Program in Oceanography, Woods Hole, Massachusetts 02543, USA}

[1] Patterns of overwash deposition observed within back-barrier sediment archives can indicate past changes in tropical cyclone activity; however, it is necessary to evaluate the significance of observed trends in the context of the full range of variability under modern climate conditions. Here we present a method for assessing the statistical significance of patterns observed within a sedimentary hurricane-overwash reconstruction. To alleviate restrictions associated with the limited number of historical hurricanes affecting a specific site, we apply a recently published technique for generating a large number of synthetic storms using a coupled ocean-atmosphere hurricane model set to simulate modern climatology. Thousands of overwash records are generated for a site using a random draw of these synthetic hurricanes, a prescribed threshold for overwash, and a specified temporal resolution based on sedimentation rates observed at a particular site. As a test case we apply this Monte Carlo technique to a hurricane-induced overwash reconstruction developed from Laguna Playa Grande (LPG), a coastal lagoon located on the island of Vieques, Puerto Rico in the northeastern Caribbean. Apparent overwash rates in the LPG overwash record are observed to be four times lower between 2500 and 1000 years B.P. when compared to apparent overwash rates during the last 300 years. However, probability distributions based on Monte Carlo simulations indicate that as much as $65 \%$ of this drop can be explained by a reduction in the temporal resolution for older sediments due to a decrease in sedimentation rates. Periods of no apparent overwash activity at LPG between 2500 and 3600 years B.P. and 500-1000 years B.P. are exceptionally long and are unlikely to occur (above 99\% confidence) under the current climate conditions. In addition, breaks in activity are difficult to produce even when the hurricane model is forced to a constant El Niño state. Results from this study continue to support the interpretation that the western North Atlantic has exhibited significant changes in hurricane climatology over the last 5500 years.

Components: 8066 words, 8 figures.

Keywords: tropical cyclones; paleotempestology; paleoclimate; Holocene; climate change; sedimentology. 
Index Terms: 3344 Atmospheric Processes: Paleoclimatology (0473, 4900); 3374 Atmospheric Processes: Tropical meteorology; 4564 Oceanography: Physical: Tsunamis and storm surges.

Received 1 April 2008; Revised 13 June 2008; Accepted 29 July 2008; Published 18 September 2008.

Woodruff, J. D., J. P. Donnelly, K. Emanuel, and P. Lane (2008), Assessing sedimentary records of paleohurricane activity using modeled hurricane climatology, Geochem. Geophys. Geosyst., 9, Q09V10, doi:10.1029/2008GC002043.

Theme: Interactions Between Climate and Tropical Cyclones on All Timescales

Guest Editors: K. Emmanuel, Jay Gulledge, M. Hufer, M Mann, and P. J. Webster

\section{Introduction}

[2] Tropical cyclones are among the most hazardous of natural disasters, both in terms of human lives and economic loss. Although more rare, intense tropical cyclones (category 3 and greater, maximum sustained winds $\geq 96$ knots or $49 \mathrm{~m} / \mathrm{s}$ ), are responsible for the vast majority of hurricane damage. For example, only 70 intense landfalling hurricane have occurred along the U.S. mainland since 1900 A.D., yet these extreme events are responsible for more than $85 \%$ of all normalized U.S. mainland hurricane damage between 1900 A.D. and 2005 A.D. [Pielke et al., 2008]. The limited number of intense tropical cyclones within relatively short historical data sets limits our ability to confidently assess how climate variability may control intense hurricane activity, thus longer records are needed.

[3] Recent work shows that certain natural systems contain prehistoric archives of tropical cyclone activity [Frappier et al., 2007a; Nott, 2004]. Proxies for tropical cyclones include, but are not limited to, negative $\delta^{18} \mathrm{O}$ anomalies in speleothems and tree rings [Frappier et al., 2007b; Malmquist, 1997; Miller et al., 2006; Nott et al., 2007], and storm-induced beach ridge, dune and coral rubble deposits along the coast [Nott and Hayne, 2001]. In addition, overwash deposits preserved within backbarrier lagoons, lakes and salt marshes have also provide a record of past tropical cyclone activity [Donnelly et al., 2001a, 2001b, 2004a; Donnelly, 2005; Donnelly and Woodruff, 2007; Liu and Fearn, 1993, 2000]. Previously these overwash records have been used to estimate the reoccurrence frequencies for intense hurricane events to a location [Donnelly et al., 2001b; Liu and Fearn, 1993] and for identifying shifts in hurricane climatology over the later Holocene [Donnelly and Woodruff, 2007; Liu and Fearn, 2000].
[4] Donnelly et al. [2001b] estimate probabilities for extreme storm inundation along the New Jersey coast based on salt marsh overwash layers associated with the Ash Wednesday Storm in 1962, the 1821 hurricane, and a paleoevent occurring between A.D. 1278 and 1438. In a similar study, Liu and Fearn [1993] use sand layers deposited in coastal Lake Shelby, Alabama over the last 3500 years to estimate the reoccurrence interval for hurricaneinduce flooding to the lake. Given that no historical sand layers were observed in the center of the lake, it was inferred that prehistoric overwash deposits must represent events with intensities significantly greater than those observed for historical hurricanes strikes to the site (greater than category 3 ). Recently, Elsner et al. [2008] combined the average reoccurrence interval observed for paleostorm deposits at Lake Shelby with results from a statistical return-period model based on the "best track" hurricane data set in order to estimate the wind speed threshold required for overwash at the site. The analyses of Liu and Fearn [1993] and Elsner et al. [2008] both assume that hurricane climatology has remained constant over the last 3500 years.

[5] When developing centennial-scale to millennial-scale records of past hurricane occurrences at a site, it is necessary to assess whether observed variability is related to a changing climate or simply attributable to the random clustering of events under a steady climate. For example, if climate were to remain constant in time, what types of variability should be expected solely due to the random nature of hurricane strikes to a single site? In addition, with respect to overwash records, a storm deposit can only be clearly attributed to a single event if enough fine-grain lagoon or marsh sediment is deposited between overwash events. Sedimentary records are therefore prone to undercounting the exact number of overwash events at a site, especially during periods when sedimentation 


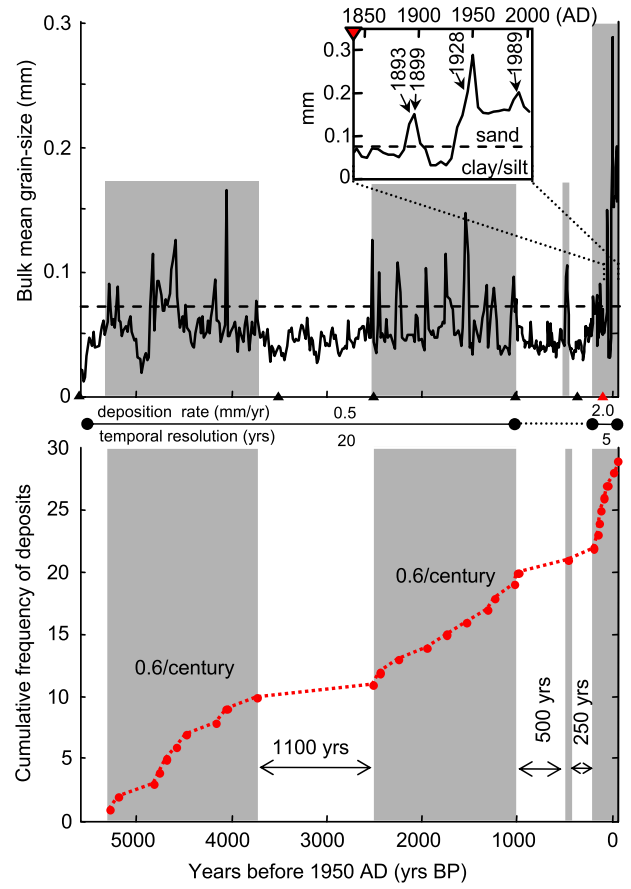

Figure 1. (top) Bulk mean grain size for core LPG4 plotted against sediment age. Depth to age conversion based on radiocarbon dates (black triangles) and 1840 A.D. land clearance horizon (red triangle) obtained by Donnelly and Woodruff [2007]. Dashed line represents grain size criteria used to identify coarse-grained deposits $(>70 \mu \mathrm{m})$ and is at roughly the silt-to-sand transition. Inset shows historical sediments with noted hurricane deposits. (bottom) Cumulative frequency plot for overwash layers identified in Figure 1(top). Sedimentation rates and resulting temporal sampling resolutions are presented between top and bottom figures.

rates are low. Methods for assessing this potential for undercounting are required when sedimentary records with low or time-varying deposition rates are employed to assess the reoccurrence frequency of extreme events for a region.

[6] Here we develop a Monte Carlo technique for assessing the statistical significance for trends observed within sedimentary records of paleohurricane activity with time-varying sedimentation rates. A large number of separate time series $\left(10^{3}\right)$ for maximum annual onshore wind speed are developed for a specific site using a random draw from an archive of simulated tropical cyclones, with statistical properties that conform to present-day climatology. Sedimentary records are generated for these time series using a prescribed threshold for overwash and a temporal resolution set by observed sedimentation rates at the site. As a test case, the technique is applied to a 5500 year paleohurricane reconstruction from Laguna Playa Grande (LPG), a coastal lagoon located on the small island of Vieques, Puerto Rico [Donnelly and Woodruff, 2007; Woodruff et al., 2008], in order to assess the statistical significance for overwash trends observed at the site.

\section{Description of Laguna Playa Grande Overwash Record}

[7] Donnelly and Woodruff [2007] and Woodruff et al. [2008] provide a detailed description for the methods and analyses used to develop the 5500 year overwash reconstruction from LPG. Here we provide a summary. Sediment cores collected from the lagoon contain fine-grained organic mud episodically punctuated with coarse-grained event deposits. These coarser units are composed of material similar to that observed along the barrier beach (a mixture of siliciclastic rounded sand and shell material), and exhibit lateral sorting trends which are indicative of transport and deposition during extreme coastal inundation [Woodruff et al., 2008]. Sediments collected throughout the lagoon exhibit similar temporal patterns in coarse grain deposition with recent event layers correlating well to the timing of intense hurricane strikes [Donnelly and Woodruff, 2007].

[8] For this study we choose to examine trends observed within the sedimentary record from core LPG4 (Figure 1), one of the primary cores used to develop the hurricane reconstruction for the site [Donnelly and Woodruff, 2007]. LPG4 was collected from the middle of the lagoon and likely provides the most complete record for overwash (sediments adjacent to the barrier were determined to be more susceptible to erosion and truncation during overwash, while sediments from more distal parts of the lagoon did not always receive enough coarse grained material to form identifiable event deposits). In total 29 deposits are evident in the LPG4 record (Figure 1). A comprehensive grain-size analysis of deposits for a core collected roughly $100 \mathrm{~m}$ to the north of LPG4, but with fewer chronological constraints, also reveals the same number of deposits as observed at LPG4 [Woodruff et al., 2008]. Intervals of increased overwash activity observed at LPG4 are consistent with trends observed for additional cores collected from the site [Donnelly and Woodruff, 2007], with periods of more frequent overwash deposition occurring between approximately 5000 3600 years B.P., $2500-1000$ years B.P., and 250 years B.P. to present (Figure 1). 

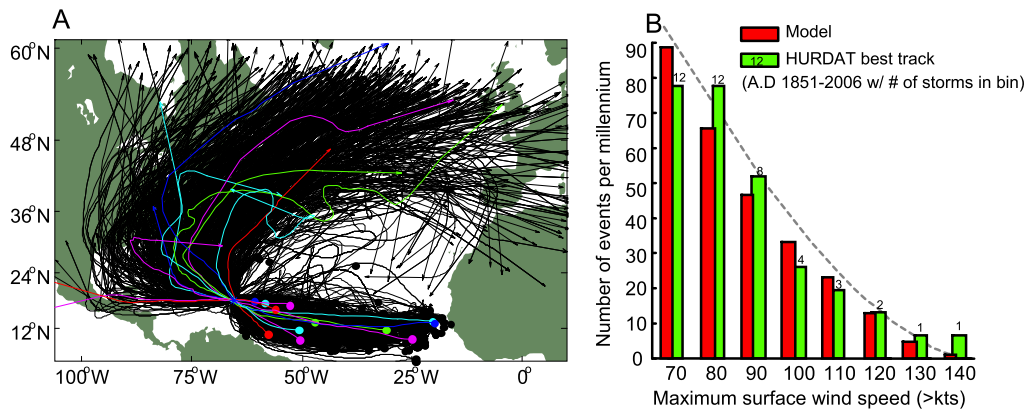

Figure 2. Path and intensity comparisons between modeled and historical hurricanes. (a) Historical (colored) and modeled hurricane tracks (black) passing within $75 \mathrm{~km}$ of Vieques. (b) Cumulative frequency distribution for maximum sustained wind speed for historical (green bars) and synthetic storms (red bars) shown in Figure 2a while passing within $75 \mathrm{~km}$ of Vieques. Grey dashed line represents the cumulative frequency distribution obtained using the peaks-over-threshold (POT) statistical model presented by Elsner et al. [2008].

[9] The reoccurrence frequency of identifiable event deposits at LPG4 is almost 4 times as large within historical sediments deposited since 1851 A.D. ( 2.0 deposits/century) as those observed for the two earlier active intervals between 5000 and 3600 years B.P. and $2500-1000$ years B.P. $(\sim 0.6$ deposits/century). Although the high frequency of overwash occurrences within historical sediments may appear to be a period of unprecedented hurricane activity, it is also possible that it is an artifact produced solely by more storms being undercounted earlier in the record when sedimentation rates were significantly lower (Figure 1). For example, sedimentation rates since 1851 A.D. $\left(\sim 2.0 \mathrm{~mm} \mathrm{a}^{-1}\right)$ are 4 times greater than rates observed within sediments older than 1000 years B.P. $\left(\sim 0.5 \mathrm{~mm} \mathrm{a}^{-1}\right)$. These deposition rates correspond to temporal resolutions of 5 and 20 years per centimeter, respectively (sediment were sampled in $1 \mathrm{~cm}$ increments). The increased rate in accumulation for sediments deposited at LPG4 during the 19th century and 20th centuries is also common in other back-barrier marshes and lagoons along the western North Atlantic [Donnelly and Bertness, 2001; Donnelly et al., 2004b; Gehrels et al., 2005; González and Törnqvist, 2006] and has been interpreted to reflect increased rates of relative sea level rise during the last 100-200 years.

\section{Methods}

\subsection{Generation of Synthetic Storm Archive for Laguna Playa Grande}

[10] Over the last 150 years only three or four hurricanes have been intense enough to produce an identifiable overwash deposits in the central portion of LPG (Figure 1). To overcome restrictions associated with this limited number of historical overwash events, we use the stochastic and deterministic model developed by Emanuel et al. [2006] to generate a large number of synthetic tropical cyclones passing within $75 \mathrm{~km}$ of LPG (Synthetic Tropical Cyclone Climatology). The model was used to generate a statistical database of over 10,000 "years" of storm impacts (from tropical depressions to category 5 storms; assuming modern climatic conditions).

[11] Synthetic storms are initiated using a random draw of observed genesis locations from the tropical cyclone best track data set since 1970 A.D. and based on the space-time probability distribution developed for these storms. Once generated, storm tracks are determined using a beta and advection model (BAM); the second track generation technique described by Emanuel et al. [2006]. The BAM technique propagates storms through randomly generated wind fields which conform to the monthly means, variances, and covariances derived from the National Centers for Environmental Prediction (NCEP)-National Center for Atmospheric Research (NCAR) reanalysis data set (developed by assimilating global atmospheric data for the years of 1957 A.D. to 1996 A.D. [Kalnay et al., 1996]). The time varying intensity for each storm is modeled numerically using the Coupled Hurricane Intensity and Prediction System (CHIPS), as described by Emanuel et al. [2004]. Wind fields for each storm in the CHIPS model are framed in angular momentum coordinates, permitting a very high resolution of each storm's inner core.

[12] Three thousand synthetic storms passing within $75 \mathrm{~km}$ of LPG were generated, with a total model run time of 10,563 years, and yielding an average reoccurrence rate of 0.284 storms a $^{-1}$ for the site. The tracks of these simulated storms 
typically fit within the bounds for the 12 observed hurricanes passing within $75 \mathrm{~km}$ of LPG since 1851 A.D. (Figure 2a). Both modeled and historic hurricanes primarily develop to the east of the site within in the Main Development Region of the Atlantic $\left(10^{\circ}-20^{\circ} \mathrm{N}\right.$ [Goldenberg et al., 2001]) and typically track either up the eastern seaboard of the United States or back out into the North Atlantic once passing the site. In addition to storm tracks, the distribution of intensities for the 3000 simulated storm events is also reasonable when compared to the distribution of intensities for historical hurricanes affecting the site (Figure 2), especially considering the scarcity of major hurricanes within the documented data set. The distribution of modeled storm intensities are also similar to the distributions obtained using the alternative peaks-over-threshold (POT) statistical method put forth by Elsner et al. [2008] (Figure 2b). This comparison provides additional validation for the Emanuel et al. [2006] model because the two approaches are fundamentally different, with obtained statistical parameters for the POT method derived solely using the best track data set, while the Emanuel et al. [2006] model uses the best track data set only to determine genesis locations, with storm tracks and intensities derived independently using the 40 year NCAR/NCEP reanalysis data set.

\subsection{Criteria for Overwash at Laguna Playa Grande}

[13] Hurricane-induced flooding at LPG is primarily due to the combination of storm surge and wave runup [Woodruff et al., 2008], where storm surge is the rise in water elevations due to wind and pressure [Simpson and Riehl, 1981] and wave runup is the time varying rise in water elevations at the shoreline due to breaking waves [Stockdon et al., 2006]. At landfall, storm surge is typically highest in the front right quadrant of a hurricane (when located in the Northern Hemisphere), where rotational winds and the storm's translational speed constructively act to elevate water levels [Simpson and Riehl, 1981]. Storm surges can also be amplified by shallow sloping bathymetry and concave coastlines [Jelesnianski et al., 1992]. In the case of LPG, however, the relatively straight coastline and steep offshore bathymetry reduces the influence of storm surge [Mercado, 1994; Woodruff et al., 2008]. In addition, the timing of a storm strike in relation to the lunar tidal cycle is less important at LPG because the tidal range is small $(\sim 0.2 \mathrm{~m})$.
[14] In areas where storm surges are moderate, such as at LPG, elevated water levels along the coast due to breaking waves can be more important for determining the magnitude of barrier inundation. Waves are typically the largest in the front right quadrant of a hurricane [Wright et al., 2001]. Therefore, similar to storm surge, wave runup is also likely most pronounced at LPG when the front right quadrant of a storm strikes the site from the south. Storm winds and the resultant flooding potential generally diminish away from the storm's radius of maximum wind. Consequently, wind speeds and flooding at a site can be equal for category 3 and category 5 hurricanes of equal size if the weaker of the two storms passes significantly closer to the site. For this analysis we therefore assume that the magnitude of overwash at LPG is directly related to the maximum onshore wind speed occurring at the site during each modeled storm event, rather than the overall intensity of the event.

[15] On the basis of the best track data set, historical overwash deposits at LPG4 are all attributed to hurricanes whose maximum sustained wind speeds were at or in excess of 100 knots $(51 \mathrm{~m} / \mathrm{s})$ while passing nearby the site (1989 A.D., 1928 A.D., 1899 A.D., and 1893 A.D.). The threshold wind speed required for overwash deposition at LPG4 therefore appears to be less than 100 knots. Further, no evidence for overwash deposition was observed for two slightly less intense hurricanes passing just to the south of the site with maximum sustained wind speeds of 90 knots or $46 \mathrm{~m} / \mathrm{s}$ (1876 A.D. and 1998 A.D.). Since 1983 A.D. the National Hurricane Center has used satellite data to provide additional information with respect to a storm's windfield distribution [Demuth et al., 2006]. This "extended best track" data set indicates that the 1998 A.D. Georges Hurricane had a radius of maximum wind of $45 \mathrm{~km}$ and likely passed within approximately $10 \mathrm{~km}$ of the site. Hurricane Georges therefore likely struck the site near its maximum sustained wind speeds of 90 knots, but did not leave a deposit at LPG4. Accurate windfield data for the 1876 A.D. hurricane is not available; however, the best track data set indicates that the storm also passed within $\sim 10 \mathrm{~km}$ of the site with maximum sustained winds of 90 knots. Therefore, onshore winds at the site during the 1876 A.D. hurricane likely approached 90 knots, but similar to Hurricane Georges, did not leave a layer at LPG4. On the basis of the data available it appears that an approximate constraint of at least 90 knots but no more than 100 knots roughly bound the threshold wind speed required for depo- 


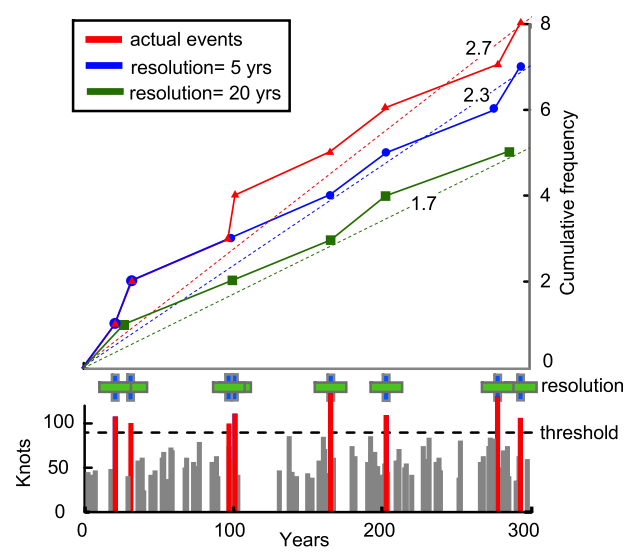

Figure 3. Example of synthetic overwash record. (bottom) A 300 year synthetic overwash record created for Vieques. Gray bars indicate maximum onshore winds recorded at the site using a random draw of synthetic storms. Red bars indicate storms which exceed the threshold (horizontal black dashed line) required for overwash to occur at the site. The blue and green bars above the wind reconstruction indicate discernable periods of overwash for temporal resolutions of 5 years and 20 years, respectively. (top) Actual (red) and discernable cumulative frequencies for a temporal resolution of 5 years (blue) and 20 years (green) for the synthetic overwash record in bottom plot. Numbers indicate the rate of resolvable overwash events per century based on the indicated temporal resolutions.

sition at LPG4 in its modern geomorphic configuration, although these bounds are presented acknowledging that maximum wind speeds in the best track are estimates with a relatively high level of uncertainty.

\subsection{Monte Carlo Simulations for Hurricane Deposition}

[16] To obtain probability distributions for overwash rates at LPG for a specified period of time under modern hurricane climatology we first use a random draw from the synthetic storm archive to generate $10^{3}$ separate records of storm occurrences at the site, all with the same set duration (see Figure 3 for example). Storms are selected for a given year only if a randomly generated number from 0 to 1 exceeds the probability determined for a storm occurrence. The arrival of a storm to the site is treated as a Poisson process [Bove et al., 1998; Elsner and Bossak, 2001], such that the probability, $P$, for $k$ number of storms to occur during any given year is obtained by:

$$
P=\frac{e^{-\lambda} \lambda^{k}}{k !}
$$

Here $\lambda$ is the average annual storm occurrence frequency determined by the Emanuel et al. [2006] hurricane model (i.e., 0.284 storms $^{-1}$ ).

[17] Overwash deposition is identified within each time series when a storm's maximum onshore wind speed at the site exceeds the site's flooding threshold. Each of these identified overwash events are then assigned a time interval based on a specified temporal resolution. For example, a storm layer occurring at year 250 with a temporal resolution of 20 years would be given a time period beginning at year 240 and ending at year 260. If the intervals between two or more individual storms overlap then only one deposit is created since these separate storm layers would not likely be distinguishable within the sedimentary record (Figure 3).

\section{Results}

\subsection{Model-Observation Comparison for Historical Sediments}

[18] To assess how well simulated overwash records reproduce hurricane deposition at the site, we first compare simulated and observed overwash rates for sediments deposited at LPG4 over the historical record from 1851 A.D. to 2006 A.D (Figure 4a). One thousand synthetic overwash records, all 156 years in length, are constructed at the temporal resolution obtained for modern sediments $\left(5 \mathrm{a} \mathrm{cm}^{-1}\right)$. Runs are then assessed using threshold onshore wind speeds from 70 to 120 knots at 10 knot increments (or $36 \mathrm{~m} \mathrm{~s}^{-1}$ to $62 \mathrm{~m} \mathrm{~s}^{-1}$ at $5.2 \mathrm{~m} \mathrm{~s}^{-1}$ increments).

[19] Since 1851 A.D. four hurricanes with onshore winds in excess of 90 knots have struck Vieques, resulting in three recognizable deposits at LPG4 (Figure 1). Our best estimates for the actual and resolvable rates of overwash activity over the last 156 years in core LPG4 are therefore 2.6 events per century and 1.9 deposits per century, respectively. Simulated reoccurrence rates are consistent with these observations using threshold onshore winds of 90 and 100 knots (Figure 4a). However, a 90 knots exceedance threshold appears to produce overwash results more consistent with historical rates obtained from LPG4. For instance, 2.6 events per century and 1.9 deposits per century are well within one standard deviation $(1 \sigma)$ for the model's simulated distributions using an exceedance threshold of 90 knots but above $1 \sigma$ for 100 knots (Figure $4 a$ ).

[20] Overwash simulations for historical sediments suggest that on average, $11 \%$ of overwash events 

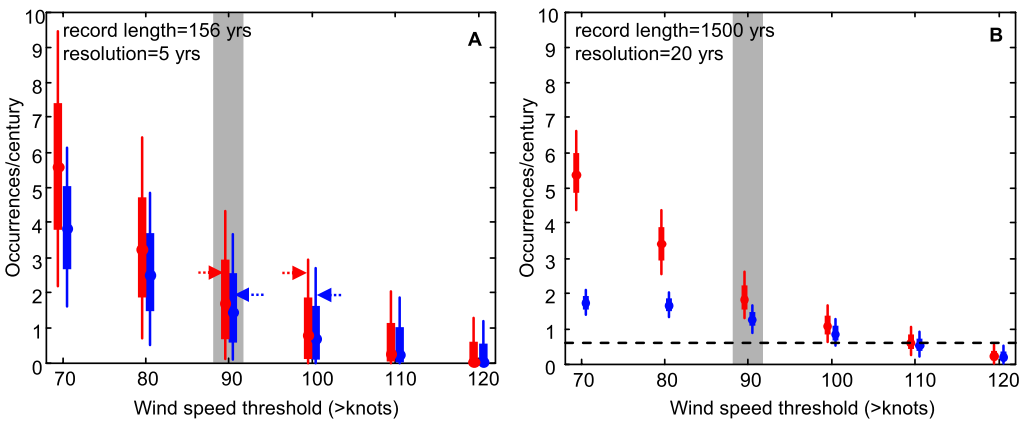

Figure 4. Model distributions predicted for events/century (red) and resolvable deposits/century (blue) using modern hurricane climatology and with varying wind speed exceedance thresholds required for overwash. Median (circle), 16th-to-84th percentiles (thick line), and 2.5-to-97.5 percentiles (thin line) are presented. Shading indicates estimated current 90 knot wind speed threshold required for overwash deposition at LPG4. (a) Results for 156 year simulations at a temporal resolution of 5 years. Actual overwash occurrence rate based on historical observation (red arrows) and number of deposits observed within historical sediments at LPG4 (blue arrows) are noted. (b) Same as Figure $4 \mathrm{a}$ but for 1500 year simulations with a temporal resolution of 20 years. Dashed line in Figure $4 \mathrm{~b}$ represents actual overwash occurrence rate observed between 2500 and 1000 years B.P. at LPG4 (Figure 1).

occurring at the site would be missed in the depositional record due to undercounting (assuming a 90 knot exceedance threshold). A comparison between historic deposits in LPG4 and hurricanes from the best track data set suggest that 1 out of 4 overwash events were likely missed over the last 156 years or a $25 \%$ reduction due to undercounting. Although this percentage is above the average obtained by model simulations, it is within the range of acceptable values based on the probability distributions obtained using such a short record (13\% of the historical overwash simulations resulted in an undercounting of $25 \%$ or more for an exceedance threshold of 90 knots). Model simulations therefore are consistent with observations for historical sediments at LPG4.

\subsection{Assessment for Earlier Active Intervals at LPG}

[21] The correspondence between modeled and observed overwash rates at LPG4 for historical sediments supports applying the model to evaluate trends observed within the paleorecord. Ten overwash layers are identified at LPG4 between 1000 and 2500 years B.P. resulting in approximately 0.6 resolvable deposits per century, a rate approximately 4 times smaller than what is observed within sediments deposited over the last 300 years (Figure 1). As discussed previously, this drop in activity may be due in part to the decreased sedimentation rates observed within these older sediments. To assess the effects of undercounting during the active interval between 1000 and 2500 years B.P., we generate additional synthetic overwash records under the present hurricane climatology, but for durations of 1500 years and with a decreased temporal resolution of 20 years.

[22] Under the same hurricane climatology, the 1500 year simulations produce the same average number of events per century as the 156 year runs (1.9 events per century, Figures $4 \mathrm{a}$ and $4 \mathrm{~b}$ ). However, extending the record length to 1500 years significantly reduces the variance about this mean. For instance, the 5th and 95th percentiles for simulations of 1500 years using a 90 knot exceedance threshold are 1.4 and 2.5 events/century, compared to a range of 0 to 3.7 events/century for the 156 year long runs. This over threefold decrease in variance for the 1500 year simulations demonstrates that millennial-scale changes in overwash activity can be assessed at a much greater confidence level at LPG than changes occurring on shorter decadal or centennial timescales.

[23] As expected, the rates of resolvable deposits per century decrease when temporal resolutions are reduced from 5 to 20 years (Figures $4 \mathrm{a}$ and $4 \mathrm{~b}$ ). On average, $32 \%$ of overwash events were missed using a temporal resolution of 20 years and an exceedance threshold of 90 knots, compared to only $11 \%$ for similar runs with a temporal resolution of 5 years. The 5 th and 95 th percentile bounds for resolvable rates of overwash for the 1500 year simulations are 0.9 and 1.6 deposits per century for an onshore wind speed threshold of 90 knots. Interestingly, although the number of resolvable deposits per century decreases significantly using a 20 year resolution, this drop is still not enough to completely explain the lower activity observed 


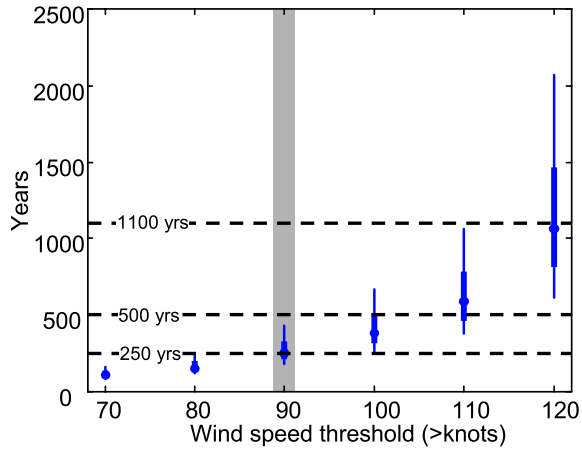

Figure 5. Model distribution for maximum time period without an overwash occurrence in simulations of 5500 years for varying exceedance onshore wind speeds required for overwash. Median (circle), 16th-to84th percentiles (thick line), and 2.5-to-97.5 percentiles (thin line) are presented. Shading indicates estimated 90 knot threshold currently required for overwash deposition at LPG4. Horizontal dashed lines indicate intervals of inactivity observed at LPG4 (Figure 1).

between 2500 and 1000 years B.P. (0.6 deposits per century) relative to the last 300 years.

[24] Our simulations indicate that a rate of 0.6 deposits per century is possible under the current hurricane climatology if the barrier's exceedance threshold was raised from 90 to 110 knots or to $57 \mathrm{~m} \mathrm{~s}^{-1}$ (Figure $4 \mathrm{~b}$ ). Such an increase could occur if the elevation of the barrier relative to sea level was higher between 1000 to 2500 years B.P. compared to its present elevation. However, an increase in the barrier's elevation between 1000 and 2500 years B.P. with no change to hurricane climatology should systematically decrease the flooding depth over the barrier during this interval. Woodruff et al. [2008] inversely modeled flooding magnitudes over the barrier at LPG based on the distribution of grain sizes for all 29 overwash deposits observed at the site. Results from the study show no systematic decrease in flooding magnitude for deposits occurring between 1000 and 2500 years B.P. when compared to historical overwash layers. Therefore, the drop in overwash rates between 1000 and 2500 years B.P. does not appear to be a result of changes to the barrier morphology.

[25] On the basis of our analyses, we estimate that at least $35 \%$ of the decrease in apparent overwash activity observed in Figure 1 between 1000 and 2500 years B.P. (compared to rates over the last 300 years) is due to a change in regional hurricane activity, with the rest likely an artifact produced solely by decreased sedimentation rates during this interval.

\subsection{Assessment for Periods of Inactivity at Laguna Playa Grande}

[26] In addition to the periods of apparent increased overwash activity, the LPG4 reconstruction also exhibits three extended intervals with no evidence for overwash deposition (3600-2500 years B.P., 1000-500 years B.P., and 500-250 years B.P., Figure 1). To assess the likelihood of a millennial scale record containing gaps of this duration under the current hurricane climatology we generate $10^{3}$ synthetic overwash records from the site, all with a duration equal to the length of the entire LPG4 record (5500 years). Probabilities are then calculated for the maximum length of inactivity produced by these simulations for varying wind speed exceedance thresholds (Figure 5). The median value for the maximum gap in activity during these 5500 year simulations was 265 years for an exceedance wind speed threshold of 90 knots, with only $5 \%$ of these simulations exhibiting a period of inactivity greater that 400 years. The 500 year and 1100 year intervals of no apparent overwash deposition between 3600 and 2500 years B.P. and $1000-500$ years B.P. are therefore significant (above 99\% confidence), and likely represent either times when overall hurricane occurrences were lower than today, or periods when the required wind speed threshold for overwash at the site was greater. The 250 year gap in overwash deposition at LPG4 between 500 and 250 years B.P. is below the median value of 265 years for these 5500 year simulations (Figure 5), indicating that this inactive interval is by itself less noteworthy. However, Donnelly and Woodruff [2007] show that a period of reduced activity observed between 1000

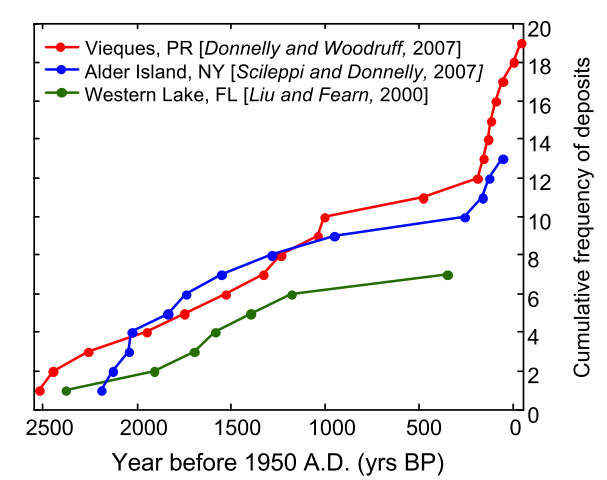

Figure 6. Cumulative frequency plots since 2500 years B.P. for millennial-scale hurricane overwash reconstructions collected from Laguna Playa Grande (red), New York (blue), and the Gulf Coast of Florida (green). Overwash records from the western North Atlantic exhibit similar trends, including a break in activity between 1000 and 500 years B.P. 
and 250 years B.P. is also observed in hurricane overwash reconstructions developed from both New York [Scileppi and Donnelly, 2007] and the Gulf Coast [Liu and Fearn, 2000] (Figure 6).

[27] A drop in relative sea level at approximately 1000 years B.P. could result in a synchronous rise in elevation for these separate barrier systems, and a resultant increase in flooding magnitudes required for hurricane overwash at all three locations. However, sea level reconstructions from all three regions indicate a period of relatively slow sea level rise over the last 6000 years [Donnelly and Webb, 2004; Lighty et al., 1982; Tornqvist et al., 2004], with no evidence for any sudden drop at approximately 1000 years B.P. Therefore, the evidence to date suggests that the period of inactivity at LPG4 between 1000 and 250 years B.P. represents a decline in western North Atlantic hurricane activity relative to current hurricane climatology, rather than synchronous local alterations to barrier morphology at the LPG, New York, and Gulf Coast sites.

\subsection{El Niño Simulations}

[28] A comparison of the LPG overwash reconstruction and a proxy record of El Niño events from Laguna Pallcacocha, Ecuador [Moy et al., 2002] suggests that the gap in overwash activity between 1000 and 500 years B.P. (and likely to 250 year B.P.) coincides with a period of more frequent, moderate-to-strong El Niño events [Donnelly and Woodruff, 2007]. This is consistent with observations from the instrumental record, which indicate that North Atlantic hurricane activity is generally suppressed during El Niño years [Bove et al., 1998; Elsner et al., 2001; Gray, 1984; Pielke and Landsea, 1999]. For instance, overall hurricane activity in the Atlantic diminishes on average to $80 \%$ of the long-term mean (since A.D. 1950) during the 19 El Niño years identified using the criteria of Pielke and Landsea [1999], where weak-to-strong El Niño years are identified when the 3-month mean SST anomaly for the Niño 3.4 region $\left(5^{\circ} \mathrm{N}-5^{\circ} \mathrm{S}, 120^{\circ}-170^{\circ} \mathrm{W}\right)$ for AugustOctober is at or exceeds $0.4^{\circ} \mathrm{C}$.

[29] On the basis of the available evidence, Donnelly and Woodruff [2007] concluded that variability in the El Niño/Southern Oscillation (ENSO) over the last several millennia has likely played an important role in controlling the frequency of intense hurricanes in the western North Atlantic. However, making quantitative estimates of the influence of El Niño on overwash activity at LPG was difficult because of the relatively short instrumental record. As an alternative in this study, we again employ the Emanuel et al. [2006] hurricane model to generate a large number of synthetic hurricanes for LPG using reanalysis data for just the 19 El Niño years since A.D. 1950. To simulate the inactive period between 1000 and 500 years B.P., 1000 five hundred-year-long overwash records are generated using a random draw from this El Niño storm archive, which likely represent the extreme condition of a constant El Niño like state at LPG. These simulations therefore provide a valuable climatic end-member that can be used to assess the degree to which El Niño alone could be responsible for the patterns observed in the LPG record.

[30] Hurricane tracks are generated for El Niño years using the techniques described by Emanuel et al. [2008]. For these simulations the hurricane model is driven using reanalysis data for the 19 El Niño years following A.D. 1950. The number of genesis points occurring over just 19 years is likely too few to obtain representative genesis probabilities for El Niño conditions. As an alternative, we apply the random storm seeding technique described by Emanuel et al. [2008]. Weak warm core vortices with peak circular wind speed of only 25 knots $(12 \mathrm{~m} / \mathrm{s})$ and a relatively low midlevel humidity anomaly are distributed randomly everywhere northward of $2^{\circ} \mathrm{N}$ and at all times. Vortices are propagated forward using the beta-and-advection (BAM) model but are steered with randomly generated wind fields conforming to reanalysis statistics for just El Niño years. The CHIPS model described by Emanuel et al. [2004] is used to determine whether these weak vortices either decay away or intensify into actual storms. To account for increased wind shear observed during El Niño years, the CHIPS model employs the same El Niño wind fields generated initially for the BAM track model. Vortices are positively identified as a storm only if winds develop to at least 40 knots $(21 \mathrm{~m}$ $\mathrm{s}^{-1}$ ) and are selected for the LPG El Niño storm archive when these disturbances pass within $75 \mathrm{~km}$ of the site. Finally, for this analysis the average radius of maximum winds for ENSO runs are adjusted to the average radius of maximum winds for the original runs to account for differences associated with the initialization methods for these two separate simulations.

[31] Apparent overwash activity is reduced at Laguna Playa Grande for the 500 year El Niño simulations to rates of between 0.3 and 1.4 deposits per century (5th and 95th percentiles), compared to 


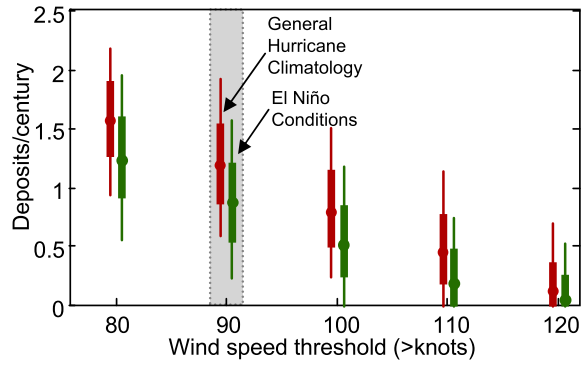

Figure 7. Model distributions for discernable deposits/ century for both overall hurricane climatology (red) and El Niño conditions (green) at Laguna Playa Grande for a period of 500 years and a temporal resolution of 20 years. The format is the same as in Figure 4 with median (circle), 16th-to-84th percentiles (thick line), and 2.5-to-97.5 percentiles (thin line). Shading denotes estimated current 90 knot wind speed threshold required for overwash deposition at LPG4. Overwash activity is reduced for the El Niño runs but not enough to explain the total lack of overwash activity observed at LGP4 between 1000 and 500 years B.P.

the higher range of 0.7 to 1.8 deposits per century for similar runs using general hurricane climatology (Figure 7). These results suggest that hurricane suppression by a change in the ENSO, even under a constant El Niño state, is not sufficient to completely explain the break in overwash activity observed at LPG between 1000 and 500 year B.P. (assuming a wind speed exceedance threshold of 90 knots).

[32] Increasing the site's exceedance threshold for overwash to 120 knots could explain the break in activity between 1000 and 500 years B.P. (Figure 7); however, as discussed earlier, this is unlikely given evidence of decreased overwash activity observed during this same interval in both the New York and Gulf Coast reconstructions (Figure 6). Results from this analysis therefore suggest that other climate forcings in addition to increased El Niño activity are likely required to explain the dramatic decline in overwash activity observed between 1000 and 500 years B.P. at the LPG, New York, and Gulf Coast sites.

\section{Discussion}

[33] Simulations for El Niño conditions suggest that large-scale climatic changes in addition to ENSO variability are required to produce the trends observed for the current paleohurricane reconstructions from the western North Atlantic. A reconstruction of diatomic assemblages from Lake Ossa, West Cameroon [Nguetsop et al., 2004] indicates a decrease in African monsoon strength occurring at approximately 1000 years B.P. This decrease may have further suppressed hurricane activity in the Atlantic [Donnelly and Woodruff, 2007]. In addition, a recent high resolution SST reconstruction from the northern Gulf of Mexico exhibits a rapid $3^{\circ} \mathrm{C}$ drop in temperature at approximately 1000 years B.P. and a later increase in SST beginning at 250 years B.P. (Figure 8a [Richey et al. [2007]). A drop in SST is also evident at approximately 1000 years B.P. in a lower resolution sedimentary record collected off the southwest coast of Puerto Rico (Figure 8b [Nyberg et al., 2002]) but with no indication of an increase in SST at 250 years B.P. In addition, the Nyberg et al. [2002] record suggests that SSTs off of southern Puerto Rico have generally been cooler than present over the last 2000 years; whereas, the recent results from the Gulf of Mexico suggest that prior to $\sim 1000$ years B.P, SSTs in this region were warmer than modern SSTs. The discrepancies between these two records stress the need for additional high-quality SST reconstructions from other regions of the western North Atlantic in order to evaluate how past changes in SST, both regional and basin-wide, have affected hurricane activity. Further, additional storm reconstructions from the western North Atlantic will provide additional assessments for the

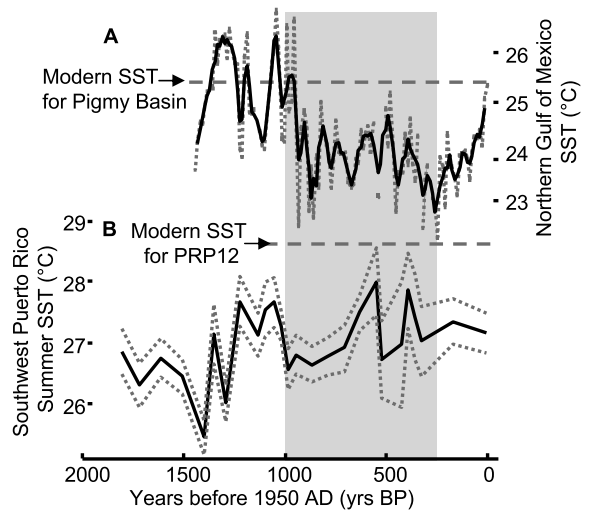

Figure 8. (a) $\mathrm{Mg} / \mathrm{Ca}$ sea surface temperature (SST) reconstruction for Pigmy Basin in northern Gulf of Mexico [Richey et al., 2007]. Markers represent individual measurements and solid line indicates threepoint running mean. (b) Reconstruction of summer SSTs $\sim 10 \mathrm{~km}$ offshore of southern Puerto Rico from core PRP12 (solid line) with $2 \sigma$ uncertainties (dotted lines) [Nyberg et al., 2002]. Dashed lines in Figures 8a and 8b indicate current SST estimates at each coring location. Discrepancies exist between the two SST reconstructions; however, both suggest a drop in temperature at $\sim 1000$ years B.P. 
trends observed within the LPG, New York, and Gulf Coast overwash reconstructions.

\section{Conclusions}

[34] Here we describe a new technique for assessing trends observed within sedimentary records of paleohurricane activity and apply it to a 5500 year reconstruction from Vieques, Puerto Rico. The fourfold decrease in apparent overwash rates at Vieques between 2500 and 1000 years B.P. when compared to apparent overwash rates during the last 300 years is determined to be largely an artifact resulting from decreased sedimentation rates during this interval, although at least $35 \%$ of the apparent drop in activity during this interval is likely due to a reduction in the overall rate of hurricane landfalls to the site. Simulations indicate that breaks in activity observed between 2500 and 3600 years B.P. and $500-1000$ years B.P. in the Vieques record are exceptionally long and unlikely to occur under the current hurricane climatology. Further, additional overwash reconstructions from the northeastern United States and Gulf Coast exhibit similar patterns of deposition over the last 2500 years, with a decline in overwash frequency occurring in all these records between 250 and 1000 years B.P. The gap in activity occurring during this interval is significant and difficult to produce even when the hurricane model is forced to a constant El Niño state. Results from this study provide further evidence that the Western Atlantic has experienced statistically significant changes in hurricane climatology since 5500 years B.P.

\section{Acknowledgments}

[35] Funding for this research was provided by the Earth Systems History Program of the National Science Foundation, Risk Prediction Initiative, National Geographic Society, Coastal Ocean Institute at WHOI, and the Andrew W. Mellon Foundation Endowed Fund for Innovative Research. We are grateful to E. Bryant, M. Gomes, E. Scileppi, and J. Tierney, who assisted with the field and lab work, and thank A. Solow for informative discussions. Special thanks to J. Elsner for providing the POT modeling code and documentation. This article benefited through constructive reviews by three anonymous referees.

\section{References}

Bove, M. C., et al. (1998), Effect of El Nino on US landfalling hurricanes, revisited, Bull. Am. Meteorol. Soc., 79(11), 2477-2482, doi:10.1175/1520-0477(1998)079<2477:EOENOO>2.0.CO;2.

Demuth, J. L., et al. (2006), Improvement of advanced microwave sounding unit tropical cyclone intensity and size estimation algorithms, J. Appl. Meteorol. Climatol., 45(11), 1573-1581, doi:10.1175/JAM2429.1.
Donnelly, J. P. (2005), Evidence of past intense tropical cyclones from backbarrier salt pond sediments: A case study from Isla de Culebrita, Puerto Rico, USA, J. Coastal Res., 142, 201-210.

Donnelly, J. P., and M. D. Bertness (2001), Rapid shoreward encroachment of salt marsh cordgrass in response to accelerated sea-level rise, Proc. Natl. Acad. Sci. U. S. A., 98(25), 14,218-14,223, doi:10.1073/pnas.251209298.

Donnelly, J. P., and T. Webb (2004), Back-barrier sedimentary records of intense hurricane landfalls in the northeastern United States, in Hurricanes and Typhoons: Past, Present and Future, edited by R. Murnane and K. B. Liu, pp. 58-95, Columbia Univ. Press, New York.

Donnelly, J. P., and J. D. Woodruff (2007), Intense hurricane activity over the past 5,000 years controlled by El Nino and the West African monsoon, Nature, 447(7143), 465-468, doi:10.1038/nature05834.

Donnelly, J. P., et al. (2001a), 700 yr sedimentary record of intense hurricane landfalls in southern New England, Geol. Soc. Am. Bull., 113(6), 714-727, doi:10.1130/00167606(2001) $113<0714$ :YSROIH $>2.0$.CO; 2 .

Donnelly, J. P., et al. (2001b), Sedimentary evidence of intense hurricane strikes from New Jersey, Geology, 29(7), 615618, doi:10.1130/0091-7613(2001)029<0615:SEOIHS $>2.0$. $\mathrm{CO} ; 2$.

Donnelly, J. P., et al. (2004a), A backbarrier overwash record of intense storms from Brigantine, New Jersey, Mar. Geol., 210(1-4), 107-121, doi:10.1016/j.margeo.2004.05.005.

Donnelly, J. P., et al. (2004b), Coupling instrumental and geological records of sea-level change: Evidence from southern New England of an increase in the rate of sea-level rise in the late 19th century, Geophys. Res. Lett., 31, L05203, doi:10.1029/2003GL018933.

Elsner, J. B., and B. H. Bossak (2001), Bayesian analysis of US hurricane climate, J. Clim., 14(23), 4341-4350, doi:10.1175/ 1520-0442(2001)014<4341:BAOUSH $>2.0$. CO; 2 .

Elsner, J. B., et al. (2001), Secular changes to the ENSO-US hurricane relationship, Geophys. Res. Lett., 28(21), $4123-$ 4126, doi:10.1029/2001GL013669.

Elsner, J. B., et al. (2008), Comparison of hurricane return levels using historical and geological records, J. Appl. Meteorol. Climatol., 47(2), 368-374, doi:10.1175/2007JAMC1692.1.

Emanuel, K., et al. (2004), Environmental control of tropical cyclone intensity, J. Atmos. Sci., 61(7), 843-858, doi: $10.1175 / 1520-0469(2004) 061<0843:$ ECOTCI $>2.0$. $\mathrm{CO} ; 2$.

Emanuel, K., et al. (2006), A statistical deterministic approach to hurricane risk assessment, Bull. Am. Meteorol. Soc., 87(3), 299-314, doi:10.1175/BAMS-87-3-299.

Emanuel, K., et al. (2008), Hurricanes and global warming: Results from downscaling IPCC AR4 simulations, Bull. Am. Meteorol. Soc., 89(3), 347-367, doi:10.1175/BAMS-89-3347.

Frappier, A., et al. (2007a), Perspective: Coordinating paleoclimate research on tropical cyclones with hurricane-climate theory and modelling, Tellus Ser. A, 59(4), 529-537.

Frappier, A. B., et al. (2007b), Stalagmite stable isotope record of recent tropical cyclone events, Geology, 35(2), 111-114, doi:10.1130/G23145A.1.

Gehrels, W. R., et al. (2005), Onset of recent rapid sea-level rise in the western Atlantic Ocean, Quat. Sci. Rev., 24(1819), 2083-2100, doi:10.1016/j.quascirev.2004.11.016.

Goldenberg, S. B., et al. (2001), The recent increase in Atlantic hurricane activity: Causes and implications, Science, 293(5529), 474-479, doi:10.1126/science.1060040. 
González, J. L., and T. E. Törnqvist (2006), Coastal Louisiana in crisis: Subsidence or sea level rise, Eos Trans. AGU, 87(45), 493, doi:10.1029/2006EO450001.

Gray, W. M. (1984), Atlantic seasonal hurricane frequency. Part I: El Nino and $30 \mathrm{mb}$ quasi-biennial oscillation influences, Mon. Weather Rev., 112, 1649-1668, doi:10.1175/ 1520-0493(1984)112<1649:ASHFPI >2.0.CO;2.

Jelesnianski, C. P., et al. (1992), SLOSH: Sea, Lake, and Overland Surges from Hurricanes, NOAA Tech. Rep. NWS 48, 71 pp., Natl. Weather Serv., Silver Spring, Md.

Kalnay, E., et al. (1996), The NCEP/NCAR 40-year reanalysis project, Bull. Am. Meteorol. Soc., 77(3), 437-471, doi:10.1175/1520-0477(1996)077<0437:TNYRP>2.0.CO;2.

Lambert, W. J., et al. (2008), Catastrophic hurricane history revealed by organic geochemical proxies in coastal lake sediments: A case study of Lake Shelby, Alabama (USA), J. Paleolimnol., 39(1), 117-131.

Lighty, R. G., et al. (1982), Acropora Palmata Reef Framework: A reliable indicator of sea level in the western Atlantic for the past 10000 years, Coral Reefs, 1(2), 125-130, doi:10.1007/BF00301694.

Liu, K. B., and M. L. Fearn (1993), Lake-sediment record of late Holocene hurricane activities from coastal Alabama, Geology, 21(9), 793-796, doi:10.1130/0091-7613(1993) 021<0793:LSROLH>2.3.CO;2.

Liu, K. B., and M. L. Fearn (2000), Reconstruction of prehistoric landfall frequencies of catastrophic hurricanes in northwestern Florida from lake sediment records, Quat. Res., 54(2), 238-245, doi:10.1006/qres.2000.2166.

Malmquist, D. L. (1997), Oxygen isotopes in cave stalagmites as a proxy record of past tropical cyclone activity, paper presented at 22nd Conference on Hurricanes and Tropical Meteorology, Am. Meteorol. Soc., Fort Collins, Colo.

Mercado, A. (1994), On the use of NOAA's storm surge model, SLOSH, in managing coastal hazards-The experience in Puerto Rico, Nat. Hazards, 10(3), 235-246, doi:10.1007/ BF00596144.

Miller, D. L., et al. (2006), Tree-ring isotope records of tropical cyclone activity, Proc. Natl. Acad. Sci. U. S. A., 103(39), 14,294-14,297, doi:10.1073/pnas.0606549103.

Moy, C. M., et al. (2002), Variability of El Nino/Southern Oscillation activity at millennial timescales during the Holocene epoch, Nature, 420(6912), 162-165, doi:10.1038/ nature 01194.

Nguetsop, V. F., et al. (2004), Late Holocene climatic changes in west Africa, a high resolution diatom record from equatorial Cameroon, Quat. Sci. Rev., 23(5-6), 591-609, doi:10.1016/j.quascirev.2003.10.007.
Nott, J. (2004), Palaeotempestology: The study of and implications review article prehistoric tropical cyclones - A review for hazard assessment, Environ. Int., 30(3), 433-447, doi:10.1016/j.envint.2003.09.010

Nott, J., and M. Hayne (2001), High frequency of 'supercyclones' along the Great Barrier Reef over the past 5000 years, Nature, 413(6855), 508-512, doi:10.1038/ 35097055 .

Nott, J., et al. (2007), Greater frequency variability of landfalling tropical cyclones at centennial compared to seasonal and decadal scales, Earth Planet. Sci. Lett., 255(3-4), 367372, doi:10.1016/j.epsl.2006.12.023.

Nyberg, J., et al. (2002), A centennial-scale variability of tropical North Atlantic surface hydrography during the late Holocene, Palaeogeogr. Palaeoclimatol. Palaeoecol., 183(1-2), 25-41, doi:10.1016/S0031-0182(01)00446-1.

Pielke, R. A., Jr., and C. N. Landsea (1999), La Nina, El Nino, and Atlantic hurricane damages in the United States, Bull. Am. Meteorol. Soc., 80(10), 2027-2033, doi:10.1175/15200477(1999)080<2027:LNAENO>2.0.CO;2.

Pielke, R. A., et al. (2008), Normalized hurricane damage in the United States: 1900-2005, Nat. Hazards Rev., 9(1), 29 42, doi:10.1061/(ASCE)1527-6988 (2008)9:1(29).

Richey, J. N., et al. (2007), 1400 yr multiproxy record of climate variability from the northern Gulf of Mexico, Geology, 35(5), 423-426, doi:10.1130/G23507A.1.

Scileppi, E., and J. P. Donnelly (2007), Sedimentary evidence of hurricane strikes in western Long Island, New York, Geochem. Geophys. Geosyst., 8, Q06011, doi:10.1029/ $2006 \mathrm{GC} 001463$.

Simpson, R. H., and H. Riehl (1981), The Hurricane and its Impact, Louisiana State Univ. Press, Baton Rouge, La.

Stockdon, H. F., et al. (2006), Empirical parameterization of setup, swash, and runup, Coastal Eng., 53, 573-588, doi:10.1016/j.coastaleng.2005.12.005.

Tornqvist, T. E., et al. (2004), Deciphering Holocene sea-level history on the US Gulf Coast: A high-resolution record from the Mississippi Delta, Geol. Soc. Am. Bull., 116(7), 10261039, doi:10.1130/B2525478.1.

Woodruff, J. D., et al. (2008), Reconstructing relative flooding intensities responsible for hurricane induced deposits from Laguna Playa Grande, Vieques, Puerto Rico, Geology, 36(5), 391-394, doi:10.1130/G24731A.1.

Wright, C. W., et al. (2001), Hurricane directional wave spectrum spatial variation in the open ocean, J. Phys. Oceanogr., 31(8), 2472-2488, doi:10.1175/1520-0485(2001) $031<2472$ :HDWSSV $>2.0 . \mathrm{CO} ; 2$. 


\title{
Chapter 5:
}

\section{Exploring typhoon variability over the mid-to-late Holocene: evidence of extreme coastal flooding from Kamikoshiki, Japan*}

\begin{abstract}
Sediment cores from two coastal lakes located on the island of Kamikoshiki in southwestern Japan (Lake Namakoike and Lake Kaiike) provide evidence for the response of a backbarrier beach system to episodic coastal inundation over the last 6400 years. Subbottom seismic surveys exhibit acoustically laminated, parallel to subparallel seismic reflectors, intermittently truncated by erosional unconformities. Sediment cores collected from targeted depocenters in both lakes contain finely laminated organic mud interbedded with coarse grained units, with depths of coarse deposits concurrent with prominent seismic reflectors. The timing of the youngest deposit at Kamikoshiki correlates to the most recently documented breach in the barrier during a typhoon in 1951 AD. Assuming this modern deposit provides an analog for identifying past events, paleotyphoons may be reconstructed from layers exhibiting an increase in grain-size, a break in fine-scale stratigraphy, and elevated Sr concentrations.

Periods of barrier breaching are concurrent with an increase in El Niño frequency, indicating that the El Niño/Southern Oscillation has potentially played a key role in governing typhoon variability during the mid-to-late Holocene. An inverse correlation is observed between tropical cyclone reconstructions from the western North Atlantic and the Kamikoshiki site, which may indicate an oscillating pattern in tropical cyclone activity between the western Northern Atlantic and the western North Pacific, or at least between the western Northern Atlantic and regions encompassing southern Japan. The two kamikaze typhoons which contributed to the failed Mongol invasions of Japan in $1274 \mathrm{AD}$ and $1281 \mathrm{AD}$ occur during a period with more frequent marine-sourced deposition at the site, suggesting the events took place during a period of greater regional typhoon activity.

* This manuscript has been submitted to Quaternary Science Reviews
\end{abstract}




\section{Introduction}

Approximately a third of all tropical cyclones in the world form within the western North Pacific (Gray, 1968; Henderson-Sellers et al., 1998), making it the most active tropical cyclone basin on earth. However, relatively little is known about how shifts in climate alter the frequency, intensity, and tracks of typhoons in this region (here "typhoon" is used to describe tropical cyclones forming in the northwest Pacific, while "hurricane" describes tropical cyclones forming in the western North Atlantic and eastern North Pacific). Large uncertainties exist in part because reliable instrumental records for typhoons only extend back to $1945 \mathrm{AD}$ (Chu et al., 2002), prohibiting the analysis of typhoon variability on timescales longer than a few decades. Significantly longer data sets for typhoon occurrences are therefore required to elucidate the dominant climatic controls of typhoon activity on the centennial-to-millennial timescales.

Natural archives of tropical cyclones can extend the documented record well beyond the observational record and help identify how tropical cyclone activity has responded to past shifts in climate (Frappier et al., 2007a; Nott, 2004). Geologic proxies

for tropical cyclones include negative $\delta^{18} \mathrm{O}$ anomalies in speleothems and tree rings (Frappier et al., 2007b; Malmquist, 1997; Miller et al., 2006; Nott et al., 2007), storminduced beach ridges and scarps (Buynevich et al., 2007; Nott and Hayne, 2001), cyclone-transported boulder deposits (Scheffers and Scheffers, 2006; Spiske et al., 2008; Suzuki et al., 2008; Yu et al., 2004), preserved offshore beds and bedforms (Duke, 1985; Ito et al., 2001; Keen et al., 2004; Keen et al., 2006), and sedimentary archives of 
freshwater flooding events (Besonen et al., 2008; Grossman, 2001). In addition, overwash deposits preserved within backbarrier beach environments can be a particularly effective proxy of long-term tropical cyclone variability (Donnelly, 2005; Donnelly et al., 2001a; Donnelly et al., 2004; Donnelly et al., 2001b; Donnelly and Webb, 2004; Donnelly and Woodruff, 2007; Emery, 1969; Liu and Fearn, 1993; Liu and Fearn, 2000; Scileppi and Donnelly, 2007; Woodruff et al., 2008b), during intervals when coastal morphology has remained relatively stable (Donnelly and Giosan, 2008; Lambert et al., 2003; Otvos, 1999; Otvos, 2002).

Recent compilations of millennial-scale hurricane reconstructions from the western North Atlantic indicate basin wide fluctuations in activity over the last 5000 years (Donnelly and Woodruff, 2007; Scileppi and Donnelly, 2007; Woodruff et al., 2008a). Although these reconstructions are still limited in number, stochastic simulations indicate that observed trends are statistically significant and unlikely to occur under the present climate (Woodruff et al., 2008a). Comparisons with previously developed climate proxies indicate that past increases in hurricane activity in the western North Atlantic occur during periods of less frequent El Niño events and stronger West African monsoons, suggesting that these climatic phenomena have played a significant role in modulating hurricane activity over the mid-to-late Holocene (Donnelly and Woodruff, 2007).

In comparison to the western North Atlantic, typhoon reconstructions from the western North Pacific are far more limited. Historical government documents of typhoon 
landfalls from the Guangdong Providence in Southern China extend back 1000 years, although complete records for typhoon strikes to the region are likely only reliable back to 1600 AD (Chan and Shi, 2000; Lee and Hsu, 1989; Liu et al., 2001; Qiao and Tang, 1993). Additional paleo-typhoon reconstructions have been constructed from boulder and atoll deposits (Yu et al., 2004; Zhu et al., 1991), but to date no millennial-scale typhoon records exist in regions other than the South China Sea.

Long-term reconstructions of typhoon variability from southern Japan may help to identify the dominant processes controlling typhoon activity in the western North Pacific on timescales greater than annual-to-decadal. Towards this end we examine the mid-tolate Holocene development of two backbarrier lagoons on the island of Kamikoshiki, Japan, and assess the depositional response of each lake to typhoon-induced breaches in the coastal barrier.

\section{Study area}

The small island of Kamikoshiki $\left(\sim 60 \mathrm{~km}^{2}\right)$ is situated approximately $30 \mathrm{~km}$ to the west of the southern Kyushu, and is the northern most island of the Koshikijima archipelago (Fig. 1). The coastline of Kamikoshiki is flanked with large lagoon systems formed by drowned coastal valleys cutoff from the sea by a long gravel bar called Nagame-no-Hama (Aramaki et al., 1969). Lake Namakoike and Lake Kaiike, are the deepest of Kamikoshiki's coastal lagoons (Fig. 1), with respective surface areas of 0.5 
$\mathrm{km}^{2}$ and $0.15 \mathrm{~km}^{2}$, and respective maximum depths of $21 \mathrm{~m}$ and $10.7 \mathrm{~m}$ (Matsuyama, 1977).

Lake Kaiike exhibits a significant chemocline at roughly $2.5 \mathrm{~m}$ and remains stratified throughout the year (Matsuyama, 1977; Nakajima et al., 2003). Anoxic bottom waters within the lake prevent bioturbation, and result in well-preserved, fine-scale $(<1$ $\mathrm{mm}$ ) sedimentary stratigraphy (Oguri et al., 2002). Modern sedimentation rates in the lake based on $\mathrm{Pb}-210$ analyses are approximately $2.3 \mathrm{~mm}$ yr-1 (Kotani et al., 2001), which suggest that sub-millimeter laminations represent depositional processes occurring on the annual-to-subannual timescales. Microscopic observations (Oguri et al., 2003a; Oguri et al., 2002) indicate that micro-laminations are constructed of higher density, diatom-rich layers (Kashima, 1989; Kubo et al., 1999), interbedded with lower density lamina of bacterial species which populate the lake's bottom and chemocline (Koizumi et al., 2004a; Koizumi et al., 2005; Koizumi et al., 2004b; Matsuyama, 2004; Matsuyama and Moon, 1998; Matsuyama and Shirouzu, 1978; Nakajima et al., 2003; Oguri et al., 2004). These previous studies have focused primarily on the upper few centimeters of Lake Kaiike sediment. Less work has been conducted on the lake's long-term depositional history, although sub-bottom seismic profiling using a Uni-boom system reveal over 20 meters of sediment accumulation (Oguri et al., 2002).

Lake Namakoike exhibits less water-column stratification than Lake Kaiike (Matsuyama, 1977); however, recent measurements suggest near meromictic conditions in its deepest reaches, with anoxic sediments similar to Kaiike (Takishita et al., 2007). 
Both Lake Kaiike and Namakoike have relatively small watersheds, with respective catchments of $0.17 \mathrm{~km}^{2}$ and $1.5 \mathrm{~km}^{2}$ (Matsuyama, 1977). The local tidal range at the site is approximately $2 \mathrm{~m}$, but modern tidal flow into both lakes is restricted to seawater seeping through the gravel barrier, resulting in a dampened tidal range of roughly $0.2 \mathrm{~m}$ (Aramaki et al., 1969). Heavy precipitation can also increase water levels in Lake Kaiike to the point that no tidal variation is observed, and flow is continuous into Lake Namakoike through a small channel which connects the two lakes (Matsuyama, 1977).

Regional glacial-isostatic modeling results and relative sea-level reconstructions suggest that sea-level at Kamikoshiki has remained fairly stable over the last 6000 yrs (Fig. 2) with the site roughly situated on the nodal point for isostatic adjustment (Nakada et al., 1991; Yokoyama et al., 1996). The 2-4 m high gravel bar (Nagame-no-hama) that separates Namakoike and Kaiike from the sea is continuous with no tidal inlets. However, during Typhoon Ruth in $1951 \mathrm{AD}$, an inlet was opened into the barrier at the north end of Lake Namakoike. The 1951 AD inlet was later repaired with a presently-standing concrete seawall (Fig. 1; Matsuyama, 1981). Thus, Typhoon Ruth was the last event to occur at the site without known human fortifications of the Nagame-no-hama barrier.

\section{Material and methods}

To assess the long-term depositional history for Lake Kaiike and Lake Namakoike we obtained high-resolution subbottom seismic data, sediment cores, and geochronologies from both lakes. Sub-bottom seismic surveys were collected in 2006 
using an EdgeTech SB-424 chirp seismic system with a 4-24 kHz pulse bandwidth. A uniform sound speed of $1500 \mathrm{~m} / \mathrm{s}$ was used to convert travel time to depth. Bottom penetration by the chirp unit was sufficient to image the entire stratigraphic sequence of both lakes $(\sim 10-20 \mathrm{~m})$ with a vertical resolution of roughly $10 \mathrm{~cm}$. Coring locations were targeted where seismic profiles revealed the longest and most complete depositional sequence from each sedimentary basin. Geographic positions for chirp survey lines and coring sites were obtained using a handheld GPS unit, which provided horizontal accuracies of 3 to $6 \mathrm{~m}$.

Sediment cores were collected using a piston push core system with $5 \mathrm{~cm}$ diameter polycarbonate and aluminum barrels (Colinvaux et al., 1999). Cores were collected in 2-3 m drives with 20-30 $\mathrm{cm}$ of sediment overlap. Consecutive drives were obtained from alternating sides of the coring platform to prevent sediment disruption at depths where drives overlapped. Additional hand-held gravity cores were collected to obtain surface samples with a well-preserved sediment/water interface.

Sediment cores were shipped to the Woods Hole Oceanographic Institution (WHOI) where they were refrigerated at $4{ }^{\circ} \mathrm{C}$ prior to being split, described and photographed. Select core halves were run through a non-destructive, X-ray fluorescence core scanner (XRF) to obtain a high resolution down-core profile $(\leq 1 \mathrm{~mm})$ of the sediment's elemental composition (Croudace et al., 2006), as well as relative density measurements using digital X-ray radiography. Discrete surface samples collected from the watershed and barrier beach were also run through the XRF to identify the elemental 
composition of allochthonous material in both lakes. Coarse fractions were determined by measuring the weight of dry sand in samples relative to the weight of bulk material, where sands were isolated using a $63 \mu \mathrm{m}$ sieve after treatment with hydrogen peroxide to remove organics.

Modern sediment chronologies were obtained for surface cores by gamma spectrometry. Measurements for ${ }^{137} \mathrm{Cs}$ (a product of atmospheric nuclear weapons testing) were gathered nondestructively using a high-resolution gamma detector. This anthropogenic radionuclide has been released to the environment predominantly since the early 1950s, the beginning of atmospheric nuclear weapons testing, with fallout reaching a maximum in 1963 AD (Frignani and Langone, 1991; Ritchie and McHenry, 1990). However, the onset of local ${ }^{137} \mathrm{Cs}$ flux to the site could potentially begin as early as 1945 AD due to the WWII atomic bombing of nearby Nagasaki, Japan, located approximately $100 \mathrm{~km}$ north of the site (Kudo et al., 1991; Saito-Kokubu et al., 2008). For radioisotope analysis, approximately $2.0 \mathrm{~g}$ of powdered sediment samples were placed in $2.54 \mathrm{~cm}$ diameter plastic jars and counted on a Canberra GCW4023S coaxial germanium well detector for $24-48 \mathrm{~h}$. Activities for ${ }^{137} \mathrm{Cs}$ were computed spectroscopically from the 661.7 keV photopeak.

Centennial-to-millennial scale chronologies were constrained by Accelerator Mass Spectrometry (AMS) ${ }^{14} \mathrm{C}$ dates of plant material. Samples were gently washed with distilled water, sonicated, dried, and dated at the National Ocean Science Accelerator Mass Spectrometry Facility in Woods Hole, Massachusetts (NOSAMS). Resulting ${ }^{14} \mathrm{C}$ 
ages were calibrated to calendar years Before Present (yr BP) using IntCal04 (Reimer et al., 2004), where $1950 \mathrm{AD}$ is defined as "Present" by convention.

\section{Results}

\subsection{Seismic data}

Chirp surveys of Lake Namakoike and Lake Kaiike reveal similar subbottom stratigraphy. Both lakes contain approximately 10-15 meters of acoustically laminated sediment lying over a reflective bedrock surface (Fig. 3). Lake Namakoike exhibits multiple subaqueous bedrock ridges that partition the lake into at least four separate submerged basins. Similar top sediments within Namaikoike depocenters consist of acoustically laminated, parallel to subparallel seismic reflectors that are generally thickest in the middle of each basin and convergent along the edges of adjacent bedrock ridges (Fig. 3).

A mainly depositional sequence within the upper-most sedimentary unit (Unit 1) drapes an erosional contact at a sediment depth of approximately 3-to-4 m (Fig. 3). Stratigraphic signatures of substantial erosion are evident below this contact surface, and include truncated stratigraphy and cut/fill features. The northern most basin surveyed in Namakoike (Basin-NA, located directly next to the Nagame-no-hama seawall), contains truncated unconformities at the base of Unit 1, which suggest downcutting of at least 1to-2 m (Fig. 3). The truncated strata below Unit 1 at the Nagame-no-hama seawall 
provide evidence for additional barrier openings prior to Typhoon Ruth in 1951 AD, and suggest this stretch of the barrier is a hotspot for breaching. In comparison, Basin-NB (located just to the south of Basin-NA, Fig. 3) contains less evidence of channel incisions and/or sediment redistribution. Preservation of strata within Basin-NB may be due to the submerged ridge separating it from Basin-NA, which provides some shelter against erosion when the barrier is compromised along the more vulnerable stretch of coast adjacent to Basin-NA.

Chirp surveys from Lake Kaiike are similar to those collected from Lake Namakoike, exhibiting a top unit of parallel laminations (Unit 1), draped over a lower unit with truncated reflectors and more complicated stratigraphy (Fig. 3). These observations are also consistent with previous Uni-boom data collected from Kaiike (Oguri et al. (2003b), that identified an acoustically conductive 2-3 m thick top unit, overlying a second unit with slightly higher levels of acoustical impedance.

\subsection{Sedimentology}

The parallel and undisturbed stratigraphy in Unit 1 suggests a complete sedimentary sequence within this upper unit (Fig. 3). In addition, Basin-NB appears to contain the most expanded record for Unit 1, with the least evidence for sediment disruption along the erosional contact at its base. Based on these stratigraphic observations we focus our initial sedimentological analyses on NKI5, a $5.5 \mathrm{~m}$ core collected from the middle of Basin-NB (core location identified in Figs. 1 and 3). 
NKI5 is primarily composed of organic-rich, finely-laminated mud, intercalated with coarser grained deposits. Depth profiles of percent coarse and x-ray gray-scale density indicate the depths for coarse beds are concurrent with prominent seismic reflectors (Fig. 4). In particular, the deposit concomitant with the erosional surface at the base of Unit 1 is distinct, containing the highest sand content observed in NKI5 ( $\sim 50 \%)$. Coarse deposits generally consist of rounded sand-to-pebble sized siliciclastic grains, interspersed with calcium carbonate shells and shell fragments. These coarse beds are low in organic material, and well mixed, with an absence of internal, fine-scale laminations. In comparison, deposits of lower acoustical impedance situated between coarser grained deposits are 10-30 times finer grained, with preserved fine-scale laminae $(<1 \mathrm{~mm})$, and contain considerably more organic detritus.

Concentrations of $\mathrm{Sr}$ are approximately 4 times larger for discrete surface samples collected along the subaerial portions of the Nageme-no-hama barrier (2075 \pm 950 int. peak area, $2 \sigma$ ) compared to sediment samples collected from the watershed and small tributaries which feed Lake Namakoike and Lake Kaiike (500 \pm 120 int., $2 \sigma)$. The rounded siliciclastic grains within NKI5 deposits and high Sr concentrations are therefore both characteristic of material derived from the site's barrier beach (Fig. 4). Higherresolution analyses of the upper $50 \mathrm{~cm}$ of NKI5 also show similar trends, with smaller peaks in percent coarse correlated to more subtle increases in Sr (Fig. 5). Sediments low in $\mathrm{Sr}$ are generally finer grained with sub-millimeter laminations (Figs 4 and 5). These characteristics suggest that this finely-laminated sediment is deposited under relatively 
quiescent conditions associated with a highly stratified water column, anoxic bottom waters, and low bioturbation.

\subsection{Geochronology}

The $1963 \mathrm{AD}{ }^{137} \mathrm{Cs}$ peak in NKI5 occurs at roughly $10 \mathrm{~cm}$ (Fig. 5), indicating sedimentation rates of roughly $2.3 \mathrm{~mm} / \mathrm{yr}$ since $1963 \mathrm{AD}$. This ${ }^{137} \mathrm{Cs}$ peak also occurs just above the most recent deposit in NKI5, between 12 and $16 \mathrm{~cm}$ (Fig. 5) suggesting this coarser layer was deposited in the 1950's, and likely by the typhoon breach to the Nagame-no-hama barrier in 1951 AD.

Radiocarbon ages in both cores increase monotonically with sediment depth indicating relatively steady long-term sedimentation rates in both cores, with the exception of a $\sim 1500$ year step-function increase in age at roughly $420 \mathrm{~cm}$ in NKI5 (Fig. 6 and Table 1). The depth of this hiatus is at the base of Unit 1 (Fig. 4), and is consistent with truncated strata indicating downcutting of sediment below this layer (Fig. 3). An additional step-function increase in age may also occur between 212 and $259 \mathrm{~cm}$ in NKI5 (Fig. 6). However, evidence for erosion is less apparent in the seismic profiles between these two depths (Fig. 4).

In general, sedimentation rates are slightly lower in KI2 than in NKI5 (Fig. 6). This is consistent with chirp surveys indicating a slightly more condensed stratigraphy in Lake Kaike relative to Basin-NB in Namakoike (Fig. 3). The sedimentation rates for both 
cores increase towards the modern, and become roughly equal at approximately $400 \mathrm{yr}$ BP (Fig. 6). These results are also consistent with the ${ }^{137} \mathrm{Cs}$ measurements for NKI5, and

${ }^{210} \mathrm{~Pb}$ analyses of sediment collected near KI2 (Kotani et al., 2001), both of which show sedimentation rates of approximately $2.3 \mathrm{~mm} / \mathrm{yr}$ for historical sediments.

Sedimentological analyses of NKI5 and discrete surface samples collected from the Nagame-no-hama barrier indicate $\mathrm{Sr}$ is a relatively good indicator of seaward-sourced, coarse grained material. The timing of Sr peaks are also similar in NKI5 and KI2, suggesting both lakes have experienced congruent periods of marine inundation (Fig. 7). For instance, deposits high in Sr are evident at both sites between approximately 3600 and $2500 \mathrm{yr}$ BP. Following this period, an interval of lower Sr levels indicates more quiescent conditions within both lakes. Evidence for another relatively active period for marine influence begins at roughly $1000 \mathrm{yr} \mathrm{BP}$, and generally lower Sr concentrations are evident in both lakes between about 300 yr BP (1650 A.D.) and present.

\section{Discussion}

\subsection{Barrier morphodynamics}

The temporal correlation between deposits in lakes Namakoike and Kaiike indicates coherence between the two systems (Fig. 7), either by exchange through the small channel which connects them or by multiple concurrent breaches through the Nagame-no-hama barrier. Seismic data collected next to the small channel connecting the 
two lakes did not show any evidence of substantial incision into the bedrock ridge partitioning the two systems, an indication that the channel has never been significantly deeper than its current depth of less than $1 \mathrm{~m}$. On the basis of these seismic observations it appears unlikely that flow through the channel was great enough to produce the erosional stratigraphy observed in both lakes (Fig. 3). The concurrent marine deposits observed in Lake Kaiike and Lake Namakoike are therefore likely due to multiple breaches through the Nageme-no-hama barrier during roughly the same time interval.

Comparing Sr depth profiles for cores NKI5 and KI2 shows concentrations of $\mathrm{Sr}$ are generally lower in KI2 than in NKI5 (Fig. 7), a pattern consistent with the slightly more sheltered location of Lake Kaiike within the northern embayment of Kamikoshiki (Fig. 1). The coarse-deposits intercalated within the finely-laminated sediments of Kaiike and Namakoiike show a gradual decrease in both $\mathrm{Sr}$ concentrations and grain-size upcore (Fig. 4 and 7). These reductions may indicate periods of inundation over the Nagame-no-hama barrier have become less severe through time, a result consistent with initial descriptions for the gradual development of the barrier over the last few millennia (Aramaki et al., 1969).

However, contrary to initial assumptions for an emergence of Nagame-no-hama following a mid-Holocene sea-level high-stand, more recent regional glacial-isostatic modeling and relative sea-level reconstructions indicate that sea-level has likely remained relatively constant at Kamikoshiki over the last 6000 years (Fig. 2; Nakada et al., 1991; Yokoyamaet al., 1996). Finely laminated sediments at the base of core NKI5 dating to 
between 6200 and 5100 yrs BP also indicate that the barrier adjacent to Namakoike was subaerial by 5000 yr BP (Fig. 7), and was sufficiently developed to support near meromictic conditions over this interval (with the exception of a minor disruption at $\sim 470$ $\mathrm{cm}$ or $\sim 5500 \mathrm{yr} \mathrm{BP})$. Therefore, while the decrease in both grain-size and Sr within successive deposits in both NKI5 and KI2 may provide evidence that under steady sealevel conditions the barrier has gradually become less susceptible to inundation, our results also indicate that the barrier was significantly developed and likely subaerial prior to $6400 \mathrm{yr} \mathrm{BP}$.

The multiple deposits in both NKI5 and KI2 strongly suggest that the barrier has been breached numerous times over the last 6400 years, with finely-laminated sediments between these deposits indicating that each of these breaches has closed naturally following the event. Several peaks in both $\mathrm{Sr}$ and grain-size are also observed within unlaminated coarser grained units (Fig. 4 and Fig. 7), which may suggest deposition by multiple events. The barrier is likely more susceptible to overwash after an initial breach and following vegetative disruption (Morris et al., 2001; Morton and Paine, 1985; Stockdon et al., 2007; White, 1979). Successive severe flooding events therefore may serve to maintain the breach opening over time. It is unclear what stimulates the refortification of the barrier and the restoration of meromictic conditions in both lakes. While some overwash by smaller flooding events is necessary to elevate subaerial portions of the barrier (Stone et al., 2004), it is likely that inlet closure occurs in general during periods of less extreme flooding, which would allow reestablishment of the Nagame-no-hama barrier without severe and repetitive disruptions. 


\subsection{Deposit origins}

Both tropical cyclones and tsunamis have the ability to inundate barrier beach systems and produce coarse deposits comparable to those observed at the site. Well documented tsunami deposits are evident along the Japanese coast; however, these deposits are primarily located along the open Pacific shoreline, and predominantly on the more northern islands of Hokkaido (Nanayama et al., 2007; Nanayama et al., 2003; Sawai, 2002), Honshu (Fujiwara and Kamataki, 2007; Komatsubara and Fujiwara, 2007; Sawai et al., 2008) and Shikoku (Okamura et al., 1997; Okamura et al., 2000; Okamura et al., 2003). Evidence for tsunami deposition is less prevalent on the southern island of Kyushu, especially at the location of the study site along the east side of Kyushu within the East China Sea. The scarcity of tsunami evidence near Kamikoshiki may in part be because this region is significantly less active seismically, compared to the subducting regions of the Kuril, Japan, trenches and Nankai trough, all located along the Pacific Coast of Japan (Taira, 2001).

Another seismically active region of Japan with tsunami potential is located to the south of the site along the Ryukyu Trench (Taira, 2001). On April 24, 1771 AD, a very large tsunami struck the Ryukyu Islands, located approximately $1000 \mathrm{~km}$ to the south of Kamikoshiki. Large coral boulders located the eastern shore of the Ryukyu Islands have been attributed to this event (Kawana and Nakata, 1994). However, recent work by

Suzuki et al. (2008) shows a relatively wide range of ${ }^{14} \mathrm{C}$ ages for the timing of transport 
of these boulders. In addition, oxygen isotope micro-profiling and skeletal growth patterns reveal that these coral blocks were likely dislodged and transported primarily during the tropical cyclone season, and not in the spring during the 1771 AD tsunami.

Tsunamis cannot be explicitly ruled out as a cause for the deposits observed in Namakoike and Kaiike. However, no significant tsunami events have been documented on the island since the beginning of the Joint Typhoon Warning Center "best track" data set in $1945 \mathrm{AD}$, compared to the 25 typhoons which have passed within $75 \mathrm{~km}$ of Kamikoshiki during this interval (Chu et al., 2002). In addition to this best track data set, the island also has a much longer written history of typhoons including multiple tropical cyclone strikes between 1883-1886 AD, which resulted in wide-spread starvation on Kamikoshiki, and the relocation of its residents to the islands of Yanagihara, and Tanegashima, Japan . Similar to instrumental observation, an extensive literature search revealed no documentation for any significant damage by a tsunami event within the recent historical records of Kamikoshiki. Therefore, the lack of any significant tsunami events at Kamikoshiki and the high likelihood of typhoon strikes to the site, both strongly suggest that a majority of breaches to the Nagame-no-hama barrier are due to tropical cyclones.

\subsection{Comparison with El Niño/Southern Oscillation proxies}

Since 1945 AD, studies using instrumental observations indicate that the El Niño/Southern Oscillation (ENSO) has had a significant influence on tropical cyclone 
activity (e.g. Trenberth et al., 2007). In the western North Atlantic there is a general suppression of hurricane genesis during El Niño years (Bove et al., 1998; Gray, 1984) . Conversely, the overall frequency of tropical cyclone occurrences remains relatively unchanged in the western North Pacific in response to ENSO variability (Elsner and Liu, 2003). However, there is a marked eastward shift in genesis location during El Niño years (Chan, 1985; Lander, 1994). Typhoons also tend to become more intense during El Niño events (Camargo and Sobel, 2005), and have frequent recurving trajectories which may result in a higher likelihood of tropical cyclone strikes along Japan and Korea (Elsner and Liu, 2003).

In order to evaluate the role of ENSO in governing typhoon activity over the midto-late Holocene, we compare patterns of typhoon-induced deposition at Kamikoshiki to an annually resolved El Niño proxy reconstruction from Laguna Pallacocha, Ecuador (Moy et al., 2002). The Laguna Pallacocha proxy is based upon clastic sediments that wash into the lake during heavy rains that occur predominantly during moderate-tostrong El Niño events. Additional proxy records of ENSO variability are also available (e.g. Cobb et al., 2003; D’Arrigo et al., 2005; Lachniet et al., 2004; Stahle et al., 1998). However, to date the Pallococha record is still the only complete, high-resolution record which exists for the mid-to-late Holocene. In addition, a strong correspondence occurs over the past two millennia between the Pallacocha record and ENSO reconstructions using stalagmite $\delta^{18} \mathrm{O}$ records from Isthmus of Panama (Lachniet et al., 2004), providing further support for the Pallacocha record as an accurate reconstruction of Holocene El Niño-like variability. 
Comparisons between the Kamikoshiki and Pallacocha records show a general correlation between periods of increased El Niño occurrence and periods of more typhoon-induced deposition at the study site (Fig. 8). For example, marine deposits in Namakoike and Kaiike between 300-to-1000 yr BP, 2500-to-3600 yr BP, and 4300-to$4800 \mathrm{yr}$ BP are roughly concurrent with periods of more El Niño activity. In contrast, laminated meromictic sediments which likely reflect more quiescence conditions in both lakes (present-to-300 yr BP, 1200-to-2200 yr BP, 3600-to-4300 yr BP, and 5200-to-6400 yr BP) occur generally during intervals of less El Niño activity. Therefore, similar to studies using instrumental observations, the millennial-scale reconstructions from both Namakoike and Kaiike support a pattern of more typhoon strikes to southern Japan during El Niño years.

\subsection{Comparison with global and regional tropical cyclone reconstructions}

On average, approximately 90 tropical storms develop each year globally (Emanuel, 2006; Henderson-Sellers et al., 1998). This number is remarkably stable with a standard deviation of only about 10, compared to local regional variations in tropical storm counts which are typically $100 \%$ of the long-term mean (Henderson-Sellers et al., 1998). It is currently unclear why the total number of tropical storms occurring globally

remains relatively stable while regional variations are so high (Emanuel, 2006), or whether this relationship existed prior to the satellite era. 
Tropical cyclone reconstructions from the western North Atlantic suggest significant hurricane variability on the centennial-to-millenial timescales (Donnelly and Woodruff, 2007; Scileppi and Donnelly, 2007; Woodruff et al., 2008a). Comparisons between the Kamikoshiki typhoon reconstruction and these hurricane proxy records suggest an inverse relationship. For instance, overwash trends within the Laguna Playa Grande reconstruction from Vieques, Puerto Rico are similar to additional reconstructions from the western North Atlantic and likely represent basin wide variations in hurricane activity (Donnelly and Woodruff, 2007; Woodruff et al., 2008a). Increased overwash activity observed in Namakoike and Kaiike between roughly 3600 to-2500 yrs BP, and 1000-to-300 yrs BP generally occurs during periods of less overwash activity at Laguna Playa Grande (Fig. 8). In contrast, the quiescence conditions in both of the Kamikoshiki lakes between roughly 300 yr BP-to-present, 2500-to-1000 yrs BP and 3600-to-4300 yrs BP are concurrent with periods of increased hurricane overwash at Laguna Playa Grande.

The inverse correlation between tropical cyclone reconstructions from the western North Atlantic and Kamikoshiki may indicate an oscillating pattern in tropical cyclone activity between the western North Atlantic and western North Pacific. However, the scarcity of millennial scale typhoon reconstructions makes it difficult to determine whether trends in the Kamikoshiki records reflect basin wide variations in activity or regional shifts in the preferred paths for typhoons. 
Observations since 1945 AD suggest ENSO may drive a seesaw pattern in typhoon activity in the western North Pacific, with a general steering of typhoons towards southern Japan during El Niño years and southern China during La Niña years (Chan, 1985). Documented typhoon landfalls to the Guangdong Providence also exhibit an inverse correlation to ENSO over the last few centuries, with a decrease in typhoon occurrences to the Guangdong Providence during strong El Niño years and an increase during strong La Niña years (Elsner and Liu, 2003). Guangdong typhoon and ENSO proxy records were not compared prior to $1600 \mathrm{AD}$ because of a rapid drop in the number of documented typhoon landfalls preceding this date. It is likely that this decrease in typhoon counts is largely an artifact of the undercounting of events within the earlier part of the Guangdong record. However, an additional drop in typhoon landfalls is also observed within the more reliable part of the reconstruction between 1600 and $1650 \mathrm{AD}$ (Fig. 9). Rates of typhoon occurrences following $1650 \mathrm{AD}$ (or $300 \mathrm{yr} \mathrm{BP}$ ) rise to some of the highest values in the Guangdong reconstruction. This transition to more documented typhoon activity in Guangdong at $\sim 300 \mathrm{yr}$ BP is concurrent with the most recent drop in Sr concentrations within NKI5 (Fig. 9). A subtler decrease in $\mathrm{Sr}$ at this time is also evident in KI2. The concurrent transition to more quiescent conditions in both Namakoike and Kaike during the rapid increases in Guangdong typhoon counts at $300 \mathrm{yr}$ BP may suggest an oscillation in tropical cyclone activity between southern China and southern Japan, an observation consistent with ENSO-driven variability in typhoon tracks. 


\subsection{Comparison with historical record of Japanese typhoons}

Currently an assemblage of historical typhoon data similar to the Guangdong reconstruction is unavailable for Japan, although efforts are underway to compile Japanese records for typhoon landfalls (e.g. Grossman and Zaiki, 2007). Historical records from Kamikoshiki Island do include a description of a series of devastating typhoon strikes between $1883 \mathrm{AD}$ and $1886 \mathrm{AD}$. Following these events most residents emigrated from Kamikoshiki due to crop destruction and the termination of ferry service to and from the island. The timing for the event layer at $35 \mathrm{~cm}$ in NKI5 is slightly older than 1883 AD (Fig. 5, assuming a steady sedimentation rate derived from the 1963 AD ${ }^{137} \mathrm{Cs}$ peak), but may still be associated with the $1883-1886$ AD typhoons given the margin of error in extrapolating recent ${ }^{137} \mathrm{Cs}$ sedimentation rates to older sediments.

In addition to the more recent 1883-1886 AD events, two famous typhoons also made landfall to the north of Kamikoshiki at the end of the $13^{\text {th }}$ century. These timely storms are cited as contributing to the failed Mongol invasions in $1274 \mathrm{AD}$ and $1281 \mathrm{AD}$, with respective armadas including 30,000 and 140,000 men (Hall, 1971). Temples and shrines at the time famously identified these tropical cyclones as "divine wind" or kamikaze, signifying their importance in maintaining Japanese sovereignty (Emanuel, 2005). Detailed observations are limited for these two early typhoons; however, it is likely that they passed just to the east of the study site before making landfall approximately $200 \mathrm{~km}$ to the north along the Kyushu mainland (Hall, 1971). A rather large Sr peak in NKI5 dates to approximately 1300 AD (Fig. 9), and is roughly 
concurrent with the timing for the Kamikaze typhoons (given ${ }^{14} \mathrm{C}$ dating uncertainties). A similar Sr spike is not evident in KI2 (Fig. 9). Therefore, more detailed chronologies from additional Kamikoshiki sediments are required in order to verify the 1300 A.D. deposit. Nonetheless, the two Kamikaze storms do appear to have occurred during a period with more frequent marine-sourced deposition at the site (Fig. 9).

\section{Conclusions}

We provide a 6400 year record of episodic coastal flooding using sediment deposits from two coastal lakes located on the remote island of Kamikoshiki in southwestern Japan. The timing of marine-flood deposits is replicated in both lakes and provides evidence for multiple coastline breaches into the two basins during periods of frequent marine inundation. Preservation of laminated sediments between marine flood deposits indicates similar quiescent intervals in both lakes, likely due to a lack of

overwash events. A deposit dating to the mid- $20^{\text {th }}$ century is consistent with a documented breach to the barrier during a typhoon in 1951 AD. This modern analog, in combination with the high frequency of typhoon strikes to the site and the absence of significant historic tsunamis, lead us to conclude that marine flood deposits are likely the result of tropical cyclones. Active breaching intervals at Kamikoshiki are concurrent with; 1) periods of more frequent El Niño events, and 2) periods of lower hurricane activity in the western North Atlantic. This pattern is consistent with instrumental observations which indicate that during El Niño years more typhoons are steered towards Japan, while hurricane activity is generally suppressed in the western North Atlantic. 
Decreases in marine-sourced deposition at Kamikoshiki starting around $300 \mathrm{yr}$ BP occur during a transition to more documented typhoon strikes in the Guangdong Providence of southern China, a pattern that is consistent with potential centennial-tomillennial scale changes in the preferred tracks for typhoons in response to ENSO variability. Failed Mongol invasions of Japan during the late $13^{\text {th }}$ century occur during a period of more frequent marine-sourced deposition at the site, which may indicate that the invasions took place during a period of greater typhoon activity for southern Japan.

\section{Acknowledgements}

The authors would like to specially thank M. Okusu, F. Woodruff, and J.W. Woodruff who helped conduct the field work for this study. We are also grateful to K. Oguri, S. Hirano, K. Kashima, and F. Nanayama for providing valuable insight and a compilation of background literature. M. Gomes, R. Sorell and J. Tierney assisted with laboratory analyses. C. Saenger and P. Lane provided thoughtful comments on the manuscript. The study was supported by the Coastal Ocean Institute(COI) and the Ocean and Climate Change Institute(OCCI) at Woods Hole Oceanographic Institute. This paper is dedicated to the memory of Makoto Ohkusu. 


\section{References}

Aramaki, M., Yamaguchi, M., and Tanaka, Y. (1969). A geomorphological and hydrological study on lagoons of kamikoshiki islands. Japan, Senshu-Shizenkagaku-Kiyo $9,1-80$.

Besonen, M. R., Bradley, R. S., Mudelsee, M., Abbott, M. B., and Francus, P. (2008). A 1,000-year, annually-resolved record of hurricane activity from Boston, Massachusetts. Geophysical Research Letters 35.

Bove, M. C., Elsner, J. B., Landsea, C. W., Niu, X. F., and O'Brien, J. J. (1998). Effect of El Nino on US landfalling hurricanes, revisited. Bulletin of the American Meteorological Society $79,2477-2482$.

Buynevich, I. V., FitzGerald, D. M., and Goble, R. J. (2007). A $1500 \mathrm{yr}$ record of North Atlantic storm activity based on optically dated relict beach scarps. Geology 35, 543-546.

Camargo, S. J., and Sobel, A. H. (2005). Western North Pacific Tropical Cyclone Intensity and ENSO. Journal of Climate 18, 2996-3006.

Chan, J. C. L. (1985). Tropical Cyclone Activity in the Northwest Pacific in Relation to the El Niño/Southern Oscillation Phenomenon. Monthly Weather Review 113, 599-606.

Chan, J. C. L., and Shi, J. (2000). Frequency of typhoon landfall over Guangdong Province of China during the period 1470-1931. Int. J. Climatol 20, 183-190.

Chu, J.-H., Sampson, C. R., Levine, A. S., and Fukada, E. (2002). The Joint Typhoon Warning Center tropical cyclone best-tracks, 1945-2000 (N. R. Lab., Ed.), Washington, D.C.

Cobb, K. M., Charles, C. D., Cheng, H., and Edwards, R. L. (2003). El Niño/Southern

Oscillation and tropical Pacific climate during the last millennium. Nature 424, 271-276.

Colinvaux, P., De Oliveira, P. E., and P., M. (1999). "Amazon pollen manual and atlas." Hardwood Acad. Publ., Amsterdam, Netherlands (NLD).

Croudace, I. W., Rindby, A., and Rothwell, R. G. (2006). "ITRAX: description and evaluation of a new multi-function X-ray core scanner." Geological Society, London. D’Arrigo, R., Cook, E. R., Wilson, R. J., Allan, R., and Mann, M. E. (2005). On the variability of ENSO over the past six centuries. Geophys. Res. Lett 32.

Donnelly, J. P. (2005). Evidence of past intense tropical cyclones from backbarrier salt pond sediments: A case study from Isla de Culebrita, Puerto Rico, USA. Journal of Coastal Research, 201-210. 
Donnelly, J. P., Bryant, S. S., Butler, J., Dowling, J., Fan, L., Hausmann, N., Newby, P., Shuman, B., Stern, J., Westover, K., and Webb, T. (2001a). 700 yr sedimentary record of intense hurricane landfalls in southern New England. Geological Society of America Bulletin 113, 714-727.

Donnelly, J. P., Butler, J., Roll, S., Wengren, M., and Webb, T. (2004). A backbarrier overwash record of intense storms from Brigantine, New Jersey. Marine Geology 210, 107-121.

Donnelly, J. P., and Giosan, L. (2008). Tempestuous highs and lows in the Gulf of Mexico. Geology 36, 751-752.

Donnelly, J. P., Roll, S., Wengren, M., Butler, J., Lederer, R., and Webb, T. (2001b). Sedimentary evidence of intense hurricane strikes from New Jersey. Geology 29, 615618.

Donnelly, J. P., and Webb, T. (2004). Back-barrier Sedimentary Records of Intense Hurricane Landfalls in the Northeastern United States. In "Hurricanes and Typhoons: Past, Present and Future." (R. Murnane, and K. B. Liu, Eds.), pp. 58-95. Columbia University Press, New York City.

Donnelly, J. P., and Woodruff, J. D. (2007). Intense hurricane activity over the past 5,000 years controlled by El Niño and the West African monsoon. Nature 447, 465-468. Duke, W. L. (1985). Hummocky cross-stratification, tropical hurricanes, and intense winter storms. Sedimentology 32, 167-194.

Elsner, J. B., and Liu, K. B. (2003). Examining the ENSO-typhoon hypothesis. Climate Research 25, 43-54.

Emanuel, K. (2006). Climate and tropical cyclone activity: A new model downscaling approach. Journal of Climate 19, 4797-4802.

Emanuel, K. A. (2005). "Divine Wind: The History and Science of Hurricanes." Oxford University Press, USA.

Emery, K. O. (1969). "A coastal pond studied by oceanographic methods." American Elsevier Publishing, New York.

Frappier, A., Knutson, T., Liu, K. B., and Emanuel, K. (2007a). Perspective: coordinating paleoclimate research on tropical cyclones with hurricane-climate theory and modelling. Tellus Series a-Dynamic Meteorology and Oceanography 59, 529-537.

Frappier, A. B., Sahagian, D., Carpenter, S. J., Gonzalez, L. A., and Frappier, B. R. (2007b). Stalagmite stable isotope record of recent tropical cyclone events. Geology 35, 111-114. 
Frignani, M., and Langone, L. (1991). Accumulation Rates and 137 Cs Distribution In Sediments Off the Po River Delta and the Emilia-Romagna Coast(Northwestern Adriatic Sea, Italy). Continental Shelf Research 11.

Fujiwara, O., and Kamataki, T. (2007). Identification of tsunami deposits considering the tsunami waveform: An example of subaqueous tsunami deposits in Holocene shallow bay on southern Boso Peninsula, Central Japan. Sedimentary Geology 200, 295-313.

Gray, W. M. (1968). Global view of the origin of tropical disturbances and storms. Monthly Weather Review 96, 669-700.

Gray, W. M. (1984). Atlantic Seasonal Hurricane Frequency. Part I: El Nino and $30 \mathrm{mb}$ Quasi-Biennial Oscillation Influences. Monthly Weather Review 112, 1649-1668.

Grossman, M. J. (2001). Large floods and climatic change during the Holocene on the Ara River, Central Japan. Geomorphology 39, 21-37.

Grossman, M. J., and Zaiki, M. (2007). Reconstructing typhoon landfalls in Japan using historical documents: 1801-1830. Papers and Proceedings of Applied Geography Conferences 30, 334-343.

Hall, J. W. (1971). "Japan: From Prehistory to Modern Times." Charles E. Tuttle Co., Tokyo, Japan.

Henderson-Sellers, A., Zhang, H., Berz, G., Emanuel, K., Gray, W., Landsea, C., Holland, G., Lighthill, J., Shieh, S. L., Webster, P., and McGuffie, K. (1998). Tropical cyclones and global climate change: A post-IPCC assessment. Bulletin of the American Meteorological Society 79, 19-38.

Ito, M., Ishigaki, A., Nishikawa, T., and Saito, T. (2001). Temporal variation in the wavelength of hummocky cross-stratification: Implications for storm intensity through Mesozoic and Cenozoic. Geology 29, 87-89.

Kashima, K. (1989). The distribution patterns of diatoms and the sedimentary process of the diatom valves in the brackish lakes at the Kamikoshiki Island, Kagoshima Prefecture, South Japan. Jpn J Benthos Res 35, 29-40.

Kawana, T., and Nakata, T. (1994). Timing of Late Holocene tsunamis originating around the Southern Ryukyu Islands, Japan, deduced from coralline tsunami deposits. Japanese Journal of Geography 103, 352-376 (In Japanese).

Keen, T. R., Bentley, S. J., Vaughan, W. C., and Blain, C. A. (2004). The generation and preservation of multiple hurricane beds in the northern Gulf of Mexico. Marine Geology 210, 79-105. 
Keen, T. R., Furukawa, Y., Bentley, S. J., Slingerland, R. L., Teague, W. J., Dykes, J. D., and Rowley, C. D. (2006). Geological and oceanographic perspectives on event bed formation during Hurricane Katrina. Geophysical Research Letters 33, -.

Koizumi, Y., Kojima, H., and Fukui, M. (2004a). Dominant microbial composition and its vertical distribution in saline meromictic lake kaiike (Japan) as revealed by quantitative oligonucleotide probe membrane hybridization. Applied and Environmental Microbiology 70, 4930-4940.

Koizumi, Y., Kojima, H., and Fukui, M. (2005). Potential sulfur metabolisms and associated bacteria within anoxic surface sediment from saline meromictic Lake Kaiike (Japan). Fems Microbiology Ecology 52, 297-305.

Koizumi, Y., Kojima, H., Oguri, K., Kitazato, H., and Fukui, M. (2004b). Vertical and temporal shifts in microbial communities in the water column and sediment of saline meromictic Lake Kaiike (Japan), as determined by a 16S rDNA-based analysis, and related to physicochemical gradients. Environmental Microbiology 6, 622-637.

Komatsubara, J., and Fujiwara, O. (2007). Overview of Holocene Tsunami Deposits along the Nankai, Suruga, and Sagami Troughs, Southwest Japan. Pure and Applied Geophysics 164, 493-507.

Kotani, T., Ozaki, M., Matsuoka, K., Snell, T. W., and Hagiwara, A. (2001).

Reproductive isolation among geographically and temporally isolated marine Brachionus strains. Hydrobiologia 446, 283-290.

Kubo, N., Sawai, Y., and Kashima, K. (1999). Water environment of the coastal brackish lakes in Kamikoshiki Island, Kagoshima Prefecture, Japan. Laguna 6, 261-271.

Kudo, A., Mahara, Y., Santry, D. C., Miyahara, S., and Garrec, J. P. (1991).

Geographical distribution of fractionated local fallout from the Nagasaki A-Bomb. J. Environ. Radioact 14, 305-316.

Lachniet, M. S., Burns, S. J., Piperno, D. R., Asmerom, Y., Polyak, V. J., Moy, C. M., and Christenson, K. (2004). A 1500-year El Nino/Southern Oscillation and rainfall history for the Isthmus of Panama from speleothem calcite. Journal of Geophysical Research-Atmospheres 109, 1-8.

Lambert, W. J., Aharon, P., and Rodriguez, A. B. (2003). An Assessment of the Late Holocene Record of Severe Storm Impacts from Lake Shelby, Alabama. TransactionsGulf Coast Association of Geological Societies 53, 443.

Lander, M. A. (1994). An Exploratory Analysis of the Relationship between Tropical Storm Formation in the Western North Pacific and Enso. Monthly Weather Review 122, 636-651. 
Lee, K., and Hsu, S. I. (1989). Typhoon records from ancient chronicles of Guangdong Province. Department of Geography Occasional Paper 98.

Liu, K.-b., Shen, C., and Louie, K.-s. (2001). A 1,000-year history of typhoon landfalls in Guangdong, southern China, reconstructed from Chinese historical documentary records. Annals of the Association of American Geographers 91, 453-464.

Liu, K. B., and Fearn, M. L. (1993). Lake-Sediment Record of Late Holocene Hurricane Activities from Coastal Alabama. Geology 21, 793-796.

Liu, K. B., and Fearn, M. L. (2000). Reconstruction of prehistoric landfall frequencies of catastrophic hurricanes in northwestern Florida from lake sediment records. Quaternary Research 54, 238-245.

Malmquist, D. L. (1997). Oxygen isotopes in cave stalagmites as a proxy record of past tropical cyclone activity. In "22nd Conference on Hurricanes and Tropical Meteorology." pp. 393-394. Amer. Met. Soc., Fort Collins.

Matsuyama, M. (1977). Limnological features of Lake Kaiike, a small lake on Kamikoshiki Island, Kagoshima Prefecture, Japan. Jap. J. Limnol 38, 9-18.

Matsuyama, M. (1981). Three Coastal Lakes on Kamikoshiki Island, Kagoshima Prefecture. Japanese Journal of Limnology 42.

Matsuyama, M. (2004). Phylogenic status of a purple sulfur bacterium and its bloom in Lake Kaiike. Limnology 5, 95-101.

Matsuyama, M., and Moon, S. M. (1998). A bloom of low-light-adapted Chromatium sp. Lake Kaiike. Jpn J Limnol 59, 79-85.

Matsuyama, M., and Shirouzu, E. (1978). Importance of photosynthetic sulfur bacteria, Chromatium sp. as an organic matter producer in Lake Kaiike. Jpn J Limnol 39, 103-111.

Miller, D. L., Mora, C. I., Grissino-Mayer, H. D., Mock, C. J., Uhle, M. E., and Sharp, Z. (2006). Tree-ring isotope records of tropical cyclone activity. Proceedings of the National Academy of Sciences of the United States of America 103, 14294-14297.

Morris, B. D., Davidson, M. A., and Huntley, D. A. (2001). Measurements of the response of a coastal inlet using video monitoring techniques. Marine Geology 175, 251272.

Morton, R. A., and Paine, J. G. (1985). Beach and vegetation-line changes at Galveston Island Texas: Erosion, deposition, and recovery from Hurricane Alicia (G. C. Bureau of Economic Geology, Ed.), pp. 39. University of Texas at Austin, Austin. 
Moy, C. M., Seltzer, G. O., Rodbell, D. T., and Anderson, D. M. (2002). Variability of El Nino/Southern Oscillation activity at millennial timescales during the Holocene epoch. Nature 420, 162-165.

Nakada, M., Yonekura, N., and Lambeck, K. (1991). Late Pleistocene and Holocene sealevel changes in Japan: implications for tectonic histories and mantle rheology. Palaeogeography, Palaeoclimatology, Palaeoecology 85, 2.

Nakajima, Y., Okada, H., Oguri, K., Suga, H., Kitazato, H., Koizumi, Y., Fukui, M., and Ohkouchi, N. (2003). Distribution of chloropigments in suspended particulate matter and benthic microbial mat of a meromictic lake, Lake Kaiike, Japan. Environmental Microbiology 5, 1103-1110.

Nanayama, F., Furukawa, R., Shigeno, K., Makino, A., Soeda, Y., and Igarashi, Y. (2007). Nine unusually large tsunami deposits from the past 4000 years at Kiritappu marsh along the southern Kuril Trench. Sedimentary Geology 200, 275-294.

Nanayama, F., Satake, K., Furukawa, R., Shimokawa, K., Atwater, B. F., Shigeno, K., and Yamaki, S. (2003). Unusually large earthquakes inferred from tsunami deposits along the Kuril trench. Nature 424, 660-663.

Nott, J. (2004). Palaeotempestology: the study of and implications Review article prehistoric tropical cyclones - a review for hazard assessment. Environment International 30, 433-447.

Nott, J., Haig, J., Neil, H., and Gillieson, D. (2007). Greater frequency variability of landfalling tropical cyclones at centennial compared to seasonal and decadal scales. Earth and Planetary Science Letters 255, 367-372.

Nott, J., and Hayne, M. (2001). High frequency of 'super-cyclones' along the Great Barrier Reef over the past 5,000 years. Nature 413, 508-512.

Oguri, K., Hirano, S., Sakai, S., Nakajima, Y., Suga, H., Sakamoto, T., Koizumi, Y., Fukui, M., and Kitazato, H. (2003a). Formational processes of sedimentary microstructure in meromictic Lake Kaiike sediments, Japan. Geochimica Et Cosmochimica Acta 67, A348-A348.

Oguri, K., Itou, M., Sakai, S., Hisamitsu, T., Hirano, S., Kitazato, H., Koizumi, Y., Fukui, M., and Taira, A. (2002). A study on anoxic environment in brackish lake, Kaiike, Kagoshima prefecture: A gateway to ocean anoxic events in the Earth history. In "Frontier Research on Earth Evolution." pp. 243-247. JAMSTEC, Yokosuka.

Oguri, K., Itou, M., Sakai, S., Hisamitsu, T., Hirano, S., Kitazato, H., Koizumi, Y., Fukui, M., and Taira, A. (2003b). A study on anoxic environment in brackish lake, Kaiike, Kagoshima prefecture: A gateway to ocean anoxic events in the Earth history. In "Frontier Research on Earth Evolution." pp. 243-247. JAMSTEC, Yokosuka. 
Oguri, K., Sakai, S., Suga, H., Nakajima, Y., Koizumi, Y., Kojima, H., Fukui, M., and Kitazato, H. (2004). Turbidity variations seen at a sediment surface in meromictic Lake Kaiike, Japan. In "Frontier Research on Earth Evolution." pp. 1-6. JAMSTEC, Yokosuka.

Okamura, M., Kurimoto, T., and Matsuoka, H. (1997). Coastal and lake deposits as a monitor. Chikyu Monthly 19, 469-473 (In Japanese).

Okamura, M., Matsuoka, H., Tsukuda, E., and Tsuji, Y. (2000). Tectonic movements of recent 10000 years and observations of historical tsunamis based on coastal lake deposits, pp. 162-168 (In Japanese). Chikyu Month. Symp.

Okamura, M., Tsuji, Y., and Miyamoto, T. (2003). Seismic activities along Nankai Trough recorded in coastal lake deposits. Kaiyo Monthly 35, 312-314 (In Japanese).

Otvos, E. G. (1999). Quaternary Coastal History, Basin Geometry and Assumed Evidence for Hurricane Activity, Northeastern Gulf of Mexico Coastal Plain. Journal of Coastal Research 15, 438-443.

Otvos, E. G. (2002). Discussion of "Prehistoric Landfall Frequencies of Catastrophic Hurricanes...'(Liu and Fearn, 2000). Quaternary Research 57, 425-428.

Qiao, S. X., and Tang, W. Y. (1993). Compilation and research of climatic data from historical records of the Guangzhou area. Guangzhou: Guangdong People's Press.

Reimer, P. J., Baillie, M. G. L., Bard, E., Bayliss, A., Beck, J. W., Bertrand, C. J. H., Blackwell, P. G., Buck, C. E., Burr, G. S., Cutler, K. B., Damon, P. E., Edwards, R. L., Fairbanks, R. G., Friedrich, M., Guilderson, T. P., Hogg, A. G., Hughen, K. A., Kromer, B., McCormac, G., Manning, S., Ramsey, C. B., Reimer, R. W., Remmele, S., Southon, J. R., Stuiver, M., Talamo, S., Taylor, F. W., van der Plicht, J., and Weyhenmeyer, C. E. (2004). IntCal04 terrestrial radiocarbon age calibration, 0-26 cal kyr BP. Radiocarbon 46, 1029-1058.

Ritchie, J. C., and McHenry, J. R. (1990). Application of Radioactive Fallout Cesium-137 for Measuring Soil Erosion and Sediment Accumulation Rates and Patterns: A Review. Journal of Environmental Quality 19, 215.

Saito-Kokubu, Y., Yasuda, K., Magara, M., Miyamoto, Y., Sakurai, S., Usuda, S., Yamazaki, H., Yoshikawa, S., Nagaoka, S., and Mitamura, M. (2008). Depositional records of plutonium and $137 \mathrm{Cs}$ released from Nagasaki atomic bomb in sediment of Nishiyama reservoir at Nagasaki. Journal of Environmental Radioactivity 99, 211-217.

Sawai, Y. (2002). Evidence for 17th-century tsunamis generated on the Kuril-Kamchatka subduction zone, Lake Tokotan, Hokkaido, Japan. Journal of Asian Earth Sciences 20, 903-911. 
Sawai, Y., Fujii, Y., Fujiwara, O., Kamataki, T., Komatsubara, J., Okamura, Y., Satake, K., and Shishikura, M. (2008). Marine incursions of the past 1500 years and evidence of tsunamis at Suijin-numa, a coastal lake facing the Japan Trench. The Holocene 18, 517.

Scheffers, A., and Scheffers, S. (2006). Documentation of the impact of Hurricane Ivan on the coastline of Bonaire (Netherlands Antilles). Journal of Coastal Research 22, 1437 1450 .

Scileppi, E., and Donnelly, J. P. (2007). Sedimentary evidence of hurricane strikes in western Long Island, New York. Geochemistry Geophysics Geosystems 8.

Spiske, M., Borocz, Z., and Bahlburg, H. (2008). The role of porosity in discriminating between tsunami and hurricane emplacement of boulders - A case study from the Lesser Antilles, southern Caribbean. Earth and Planetary Science Letters 268, 384-396.

Stahle, D. W., Cleaveland, M. K., Therrell, M. D., Gay, D. A., D'Arrigo, R. D., Krusic, P. J., Cook, E. R., Allan, R. J., Cole, J. E., and Dunbar, R. B. (1998). Experimental Dendroclimatic Reconstruction of the Southern Oscillation. Bulletin of the American Meteorological Society 79, 2137-2152.

Stockdon, H. F., Sallenger, A. H., Holman, R. A., and Howd, P. A. (2007). A simple model for the spatially-variable coastal response to hurricanes. Marine Geology 238, 1-20.

Stone, G. W., Liu, B., Pepper, D. A., and Wang, P. (2004). The importance of extratropical and tropical cyclones on the short-term evolution of barrier islands along the northern Gulf of Mexico, USA. Marine Geology 210, 63-78.

Suzuki, A., Yokoyama, Y., Kan, H., Minoshima, K., Matsuzaki, H., Hamanaka, N., and Kawahata, H. (2008). Identification of 1771 Meiwa Tsunami deposits using a combination of radiocarbon dating and oxygen isotope microprofiling of emerged massive Porites boulders. Quaternary Geochronology 3, 226-234.

Taira, A. (2001). Tectonic evolution of the Japanese Island Arc system. Annual Reviews of Earth and Planetary Sciences 29, 109-134.

Takishita, K., Tsuchiya, M., Kawato, M., Oguri, K., Kitazato, H., and Maruyama, T. (2007). Genetic Diversity of Microbial Eukaryotes in Anoxic Sediment of the Saline Meromictic Lake Namako-ike (Japan): On the Detection of Anaerobic or Anoxic-tolerant Lineages of Eukaryotes. Protist 158, 51-64.

Trenberth, K. E., Josey, S. A., P., A., Bojariu, R., Easterling, D. U., Tank, A. K., Parker, D. E., Rahimzadeh, F. I., Renwick, J. A., Rusticucci, M., Soden, B., and Zhai, P. (2007). Observations: surface and atmospheric climate change. In "Climate Change 2007: The Physical Science Basis: Contribution of Working Group I to the Fourth Assessment Report of the Intergovernmental Panel on Climate Change." (S. Solomon, Q. D., M. 
Manning, Z. Chen, M. Marquis, K. B. Averyt, M. Tignor, and H. L. Miller, Eds.), Cambridge, U.K.

White, P. S. (1979). Pattern, process, and natural disturbance in vegetation. The Botanical Review 45, 229-299.

Woodruff, J. D., Donnelly, J. P., Emanuel, K., and Lane, P. (2008a). Assessing sedimentary records of paleohurricane activity using modeled hurricane climatology. Geochemistry Geophysics Geosystems 9.

Woodruff, J. D., Donnelly, J. P., Mohrig, D., and Geyer, W. R. (2008b). Reconstructing relative flooding intensities responsible for hurricane-induced deposits from Laguna Playa Grande, Vieques, Puerto Rico. Geology 36, 391-394.

Yokoyama, Y., Nakada, M., Maeda, Y., Nagaoka, S., Okuno, J., Matsumoto, E., Sato, H., and Matsushima, Y. (1996). Holocene sea-level change and hydro-isostasy along the west coast of Kyushu, Japan. Palaeogeography, Palaeoclimatology, Palaeoecology 123, 4.

Yu, K. F., Zhao, J. X., Collerson, K. D., Shi, Q., Chen, T. G., Wang, P. X., and Liu, T. S. (2004). Storm cycles in the last millennium recorded in Yongshu Reef, southern South China Sea. Palaeogeography Palaeoclimatology Palaeoecology 210, 89-100.

Zhu, Y. Z., Nie, B. F., and Wang, Y. Q. (1991). Coral reef sediments respectively in the southern and northern parts of Nansha Islands. In "Symposium on Geology, Geophysics and Reef Islands of Nansha Islands and Adjacent Areas." pp. 224-232. Ocean Press, Beijing. 
KAMIKOSHIKI RADIOCARBON RESULTS

\begin{tabular}{|c|c|c|c|c|c|c|c|}
\hline $\begin{array}{c}\text { Index } \\
\text { Number }\end{array}$ & $\begin{array}{c}\text { Lab } \\
\text { Number }\end{array}$ & Core & $\begin{array}{l}\text { Depth } \\
(\mathrm{cm})\end{array}$ & $14 \mathrm{C}$ age & $\begin{array}{c}\text { Cal yr BP } \\
(1 \sigma)\end{array}$ & $\delta 13 C(\%)$ & Material Dated \\
\hline 1 & OS-62015 & NKI5 & $118-119$ & $410 \pm 25$ & $(473-507)$ & -26.64 & leaf \\
\hline 2 & OS-57839 & NKI5 & $146-147$ & $820 \pm 30$ & $(690-756)$ & -28.7 & leaf \\
\hline 3 & OS-62101 & NKI5 & $211-213$ & $1290 \pm 30$ & $(1182-1277)$ & -28.52 & leaf \\
\hline 4 & OS- 57952 & NKI5 & $258-259$ & $2330 \pm 100$ & $(2158-2675)$ & -26.27 & woody debris \\
\hline 5 & OS- 57888 & NKI5 & $344-345$ & $2850 \pm 40$ & $(2881-3058)$ & -25.88 & woody debris \\
\hline 6 & OS-67805 & NKI5 & $388-389$ & $3100 \pm 35$ & $(3266-3371)$ & -28.74 & leaf \\
\hline 7 & OS- 62016 & NKI5 & $423-425$ & $4450 \pm 30$ & $(4974-5267)$ & -27.79 & woody debris \\
\hline 8 & OS- 57912 & NKI5 & $547-548$ & $5390 \pm 30$ & $(6185-6274)$ & -26.86 & woody debris \\
\hline 9 & OS- 61946 & $\mathrm{~K} 12$ & $56-57$ & $270 \pm 35$ & $(157-426)$ & -30.67 & leaf \\
\hline 10 & OS- 57911 & $\mathrm{~K} 12$ & $115-116$ & $980 \pm 30$ & $(802-932)$ & -26.78 & woody debris \\
\hline 11 & OS- 62217 & $\mathrm{~K} 12$ & $134-135$ & $1090 \pm 30$ & $(961-1052)$ & -28.92 & leaf \\
\hline 12 & OS-62111 & $\mathrm{K} 12$ & $223-224$ & $2210 \pm 25$ & $(2156-2307)$ & -29.96 & bark \\
\hline 13 & OS- 57782 & $\mathrm{~K} 12$ & $291-292$ & $2890 \pm 30$ & (2969-3067) & -29.06 & twig \\
\hline 14 & OS- 57889 & $\mathrm{~K} / 2$ & $392-392$ & $3860 \pm 30$ & $(4193-4405)$ & -28.31 & woody debris \\
\hline
\end{tabular}

Table 1. Kamikoshiki radiocarbon age model data 

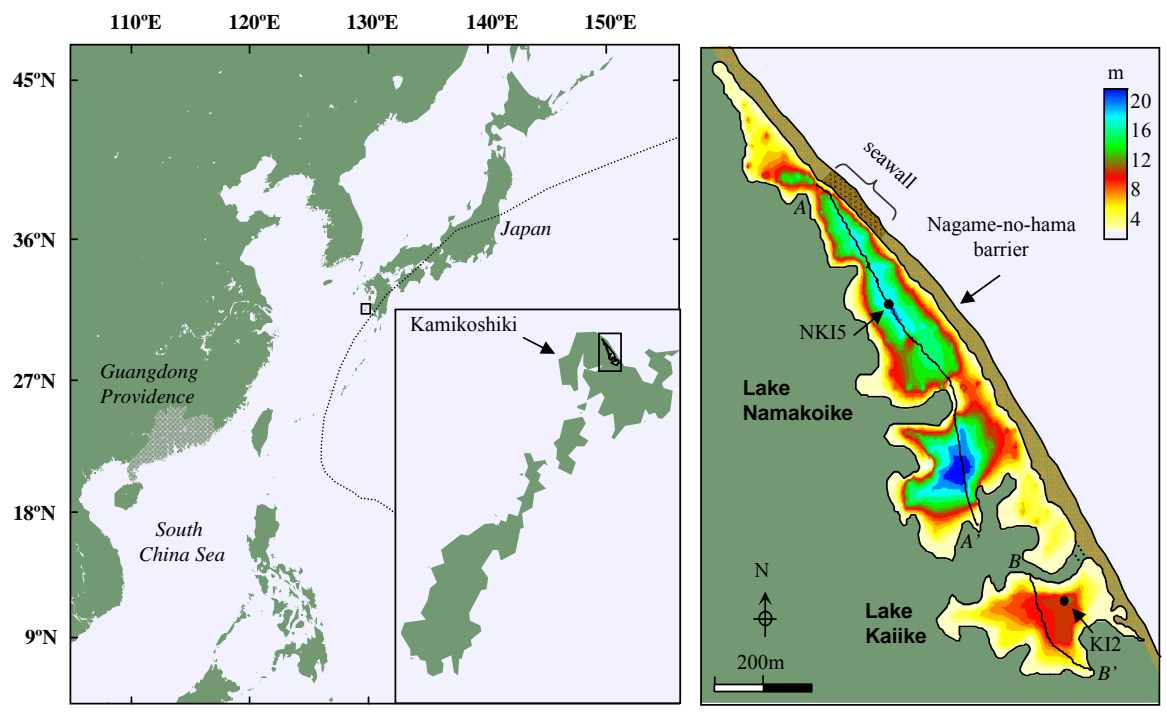

Fig. 1. (Left) Map of the western North Pacific showing study area (open square). (Left inset) Regional map of the Koshikijima Island archipelago. Lake Namakoike and Lake Kaiike (highlighted with open square) are located on the northern most island of Kamikoshiki.(Right) Bathymetric map of lakes Namakoike and Kaiike with chirp sonar tracklines and coring locations referenced in the text. Bathymetry obtained by Aramaki et al. (1969) and Oguri et al. (2002), and updated with seismic surveys from this study. 


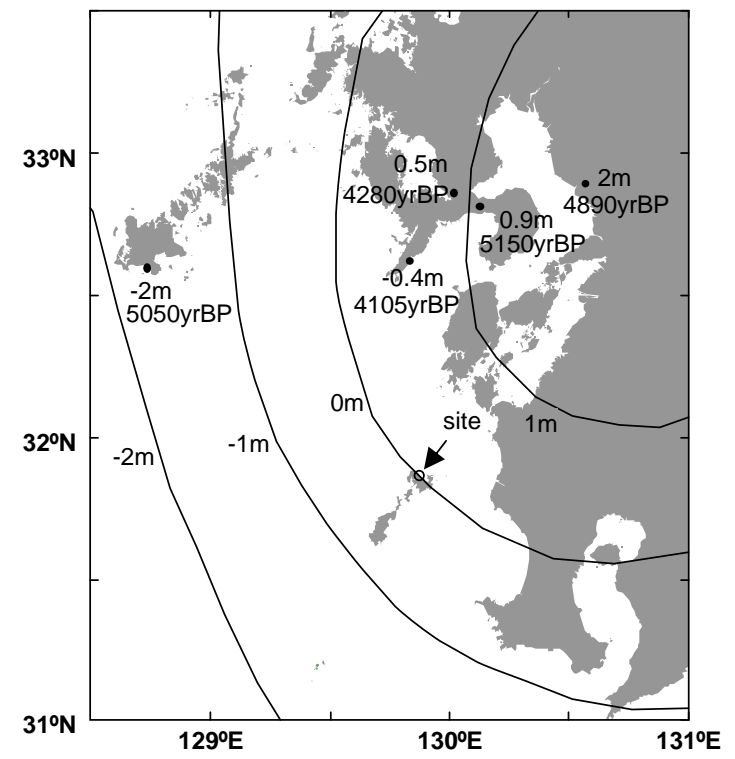

Fig. 2. (Black circles) Reconstructions of relative sea-level during the mid-Holocene for western Kyushu (Yokoyama, 1996), compared to (contours) glacial-isostatic model predictions for relative sea-level at $6000 \mathrm{yr}$ BP (after Nakada, 1991, Ice models ARC3+ANT3B, Viscosity model A). 
(su) $\perp M \perp$

(sw) $\perp M \perp$
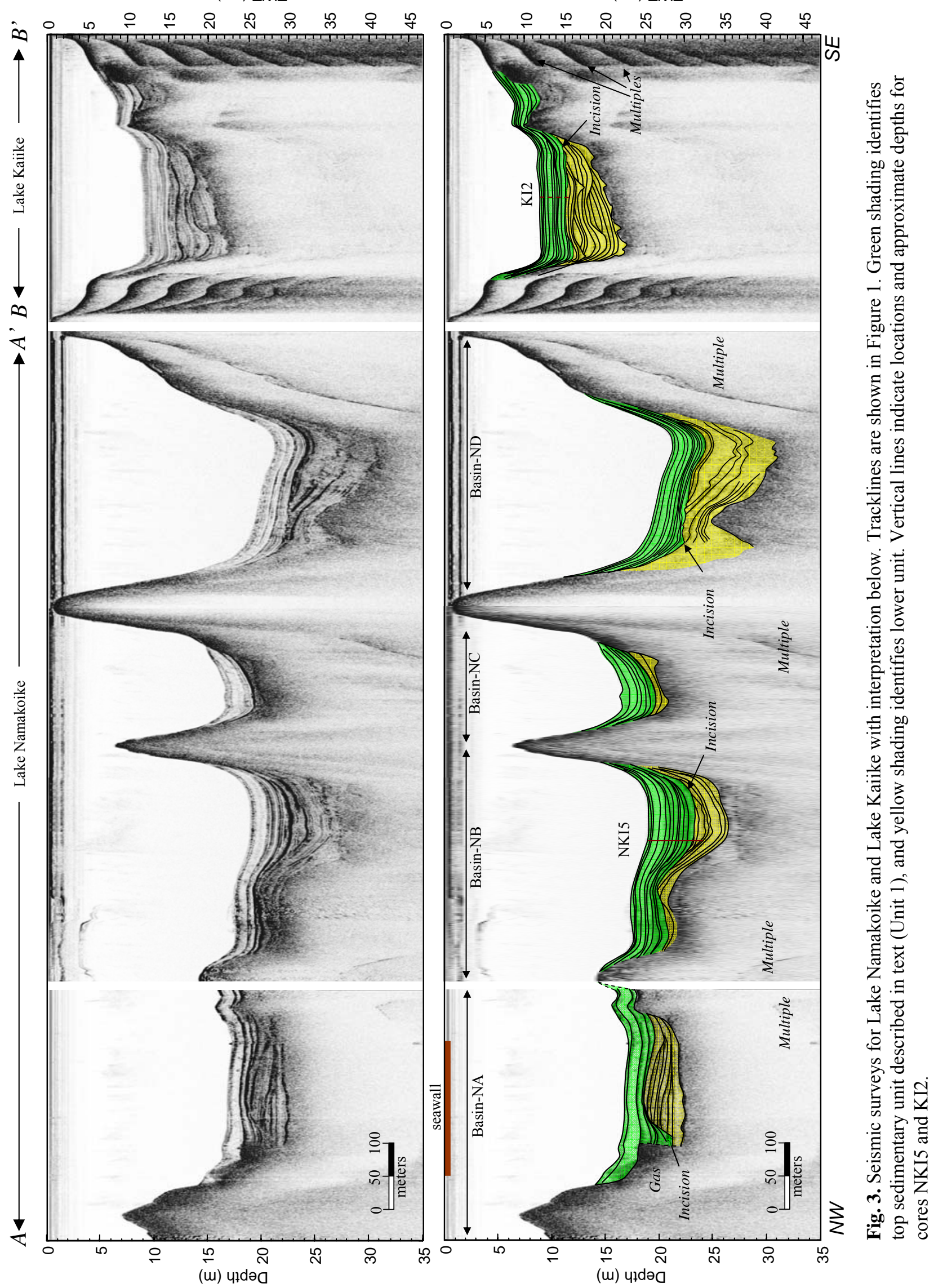


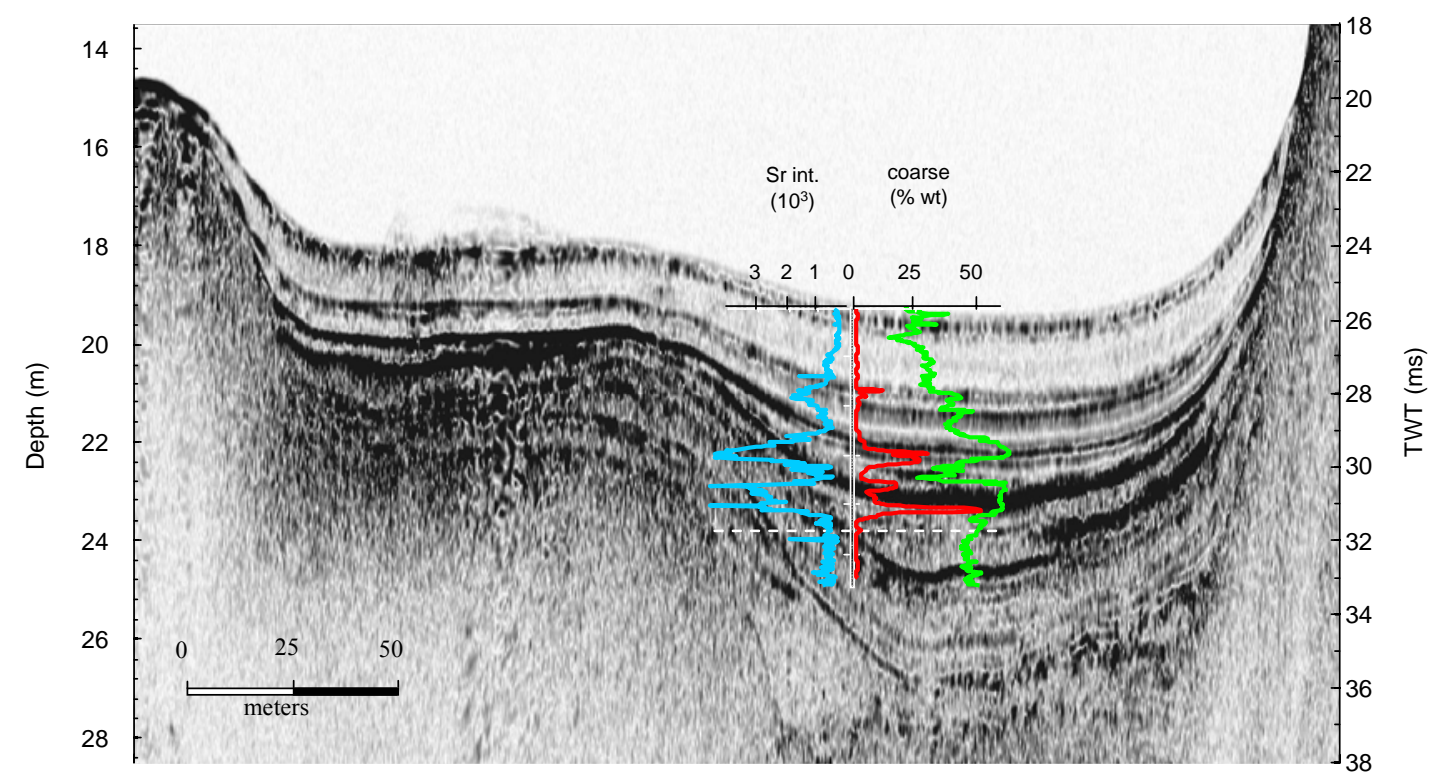

Fig. 4. NKI5 down-core profiles for percent coarse (red), Sr peak area integral (blue), and $\mathrm{X}$-ray grayscale density (green). Note Sr concentrations increase to the left and Sr and Xray density to the right. X-ray grayscale density is relative. Profiles for NKI5 are superimposed on seismic survey from Basin-NB (Fig. 2 and 3), with core position in the middle of the $\mathrm{y}$-axes between $\mathrm{Sr}$ and percent coarse profiles. Dashed white line denotes depth of erosional contact in NKI5 at the base of Unit 1 (Fig. 3). 


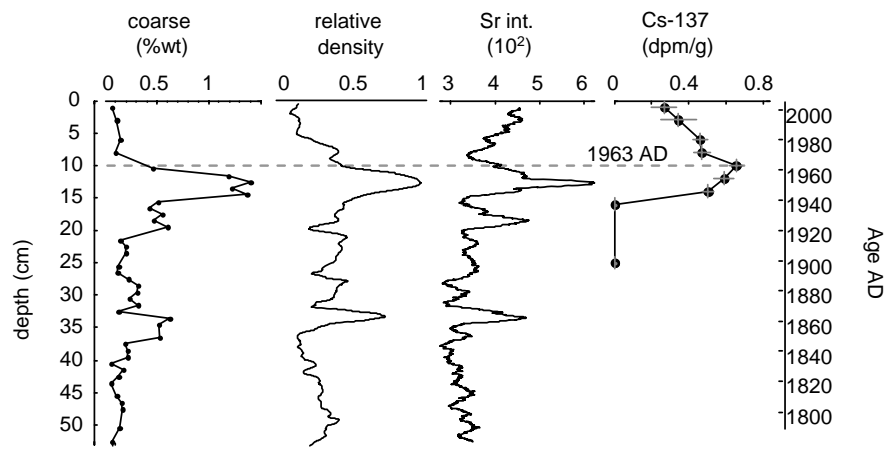

Fig. 5. Higher-resolution analyses of the upper $50 \mathrm{~cm}$ of NKI5. (From left to right) Depth profiles of percent coarse, Sr, x-ray gray-scale relative density, and detectable ${ }^{137} \mathrm{Cs}$ activity (error bars in gray). Age model on right is based on accumulation rate of $2.3 \mathrm{~mm}$ yr-1 from $1963 \mathrm{AD}{ }^{137} \mathrm{Cs}$ peak (dashed line). 


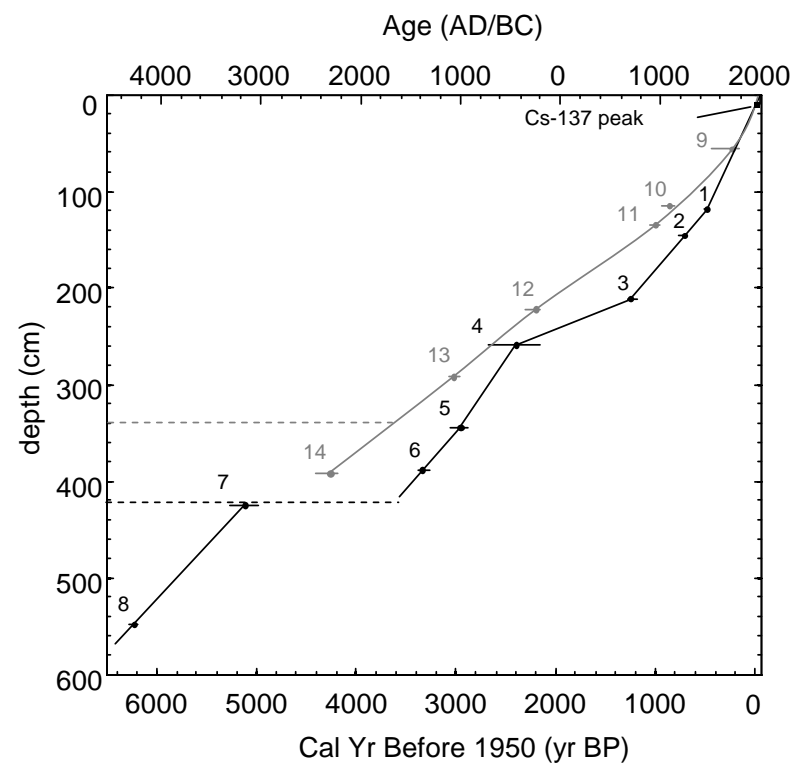

Fig. 6. Age versus depth plot of chronological data for cores NKI5 (black) and KI2 (gray). Horizonal solid lines denote 1 standard deviation for radiocarbon ages.

Numbers in plot coincide with sample identification in Table 1. The 1963 AD peak in ${ }^{137} \mathrm{Cs}$ is noted with a square. Depth for erosional contact at the base of Unit 1 (Fig. 3) for NKI5 and KI2 are noted with dashed black and gray lines, respectively. 


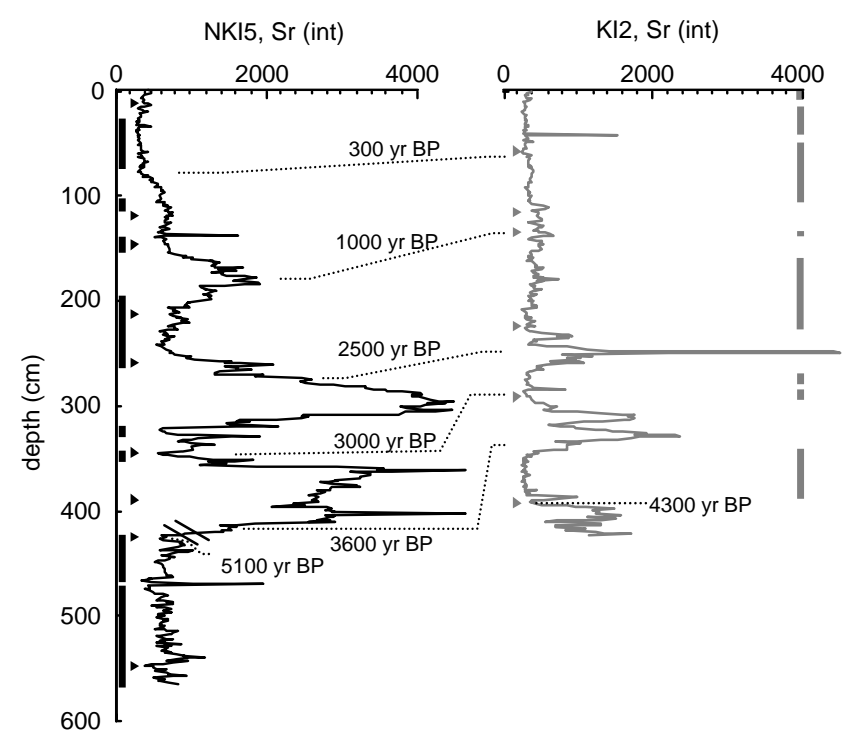

Fig. 7. Sr peak integrated area for cores NKI5 (black) and KI2 (gray) (See Fig.1 for locations). Thicker vertical lines indicate intervals with fine-scale $(<1 \mathrm{~mm})$ laminations. Solid arrows represent the depth of radiocarbon-dated samples from each core. Thin dashed lines indicates depths of equal age between cores based on the age model presented in Fig. 6. 


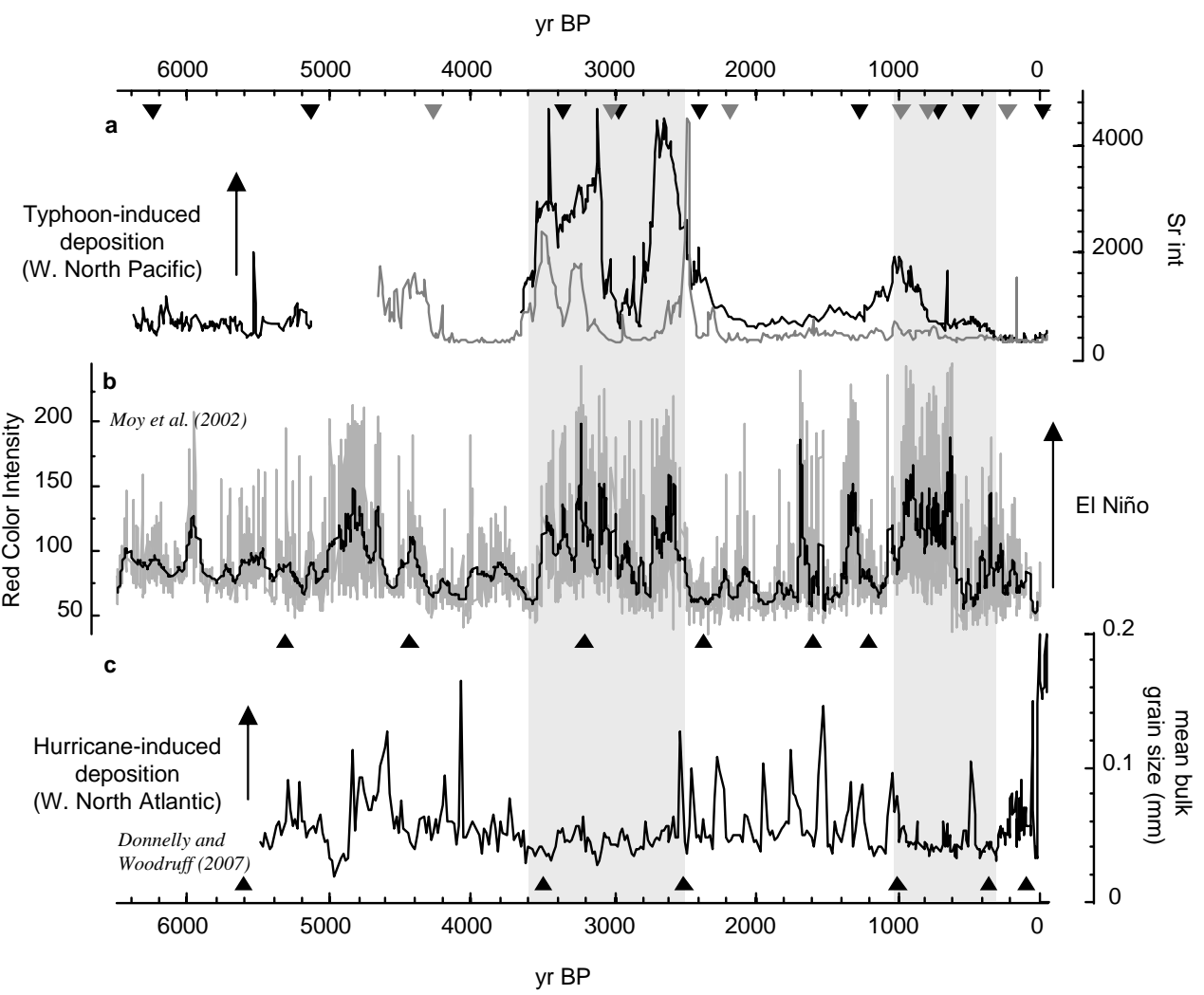

Fig. 8: a) Sr time-series for cores NKI5 (black) and KI2 (gray), compared to b) El Niño reconstructions from Laguna Pallcocha, Ecuador (Moy et al., 2002), and c) proxy records of hurricane-induced sedimentation from Laguna Playa Grande, Vieques, Puerto Rico (Donnelly and Woodruff, 2007). Solid arrows in each plot identify age controls. The El Niño proxy is based upon red clastic sediments which wash into during El Niño events. Shaded line in plot is red color intensity and solid line is the 50 point running average. Peaks in Laguna Playa Grande bulk grain-size above roughly the sand/silt transition $(>63 \mu \mathrm{m})$ represent hurricane-induced deposits (Woodruff et al., 2008). Vertical shaded bars in plots represent periods of increased El Niño frequency following $4000 \mathrm{yr} \mathrm{BP}$, which are generally concurrent with both an increase in typhoon-induced deposition at the Kamikoshiki site, and a decrease in hurricane-induced deposition in the western North Atlantic. 


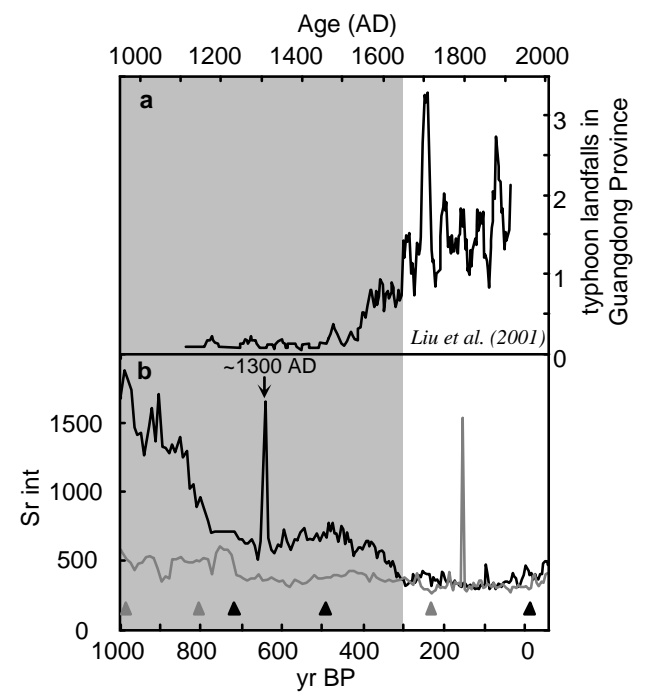

Fig. 9: a) Guangdong typhoon landfalls (twenty-one year running average) after Liu et al. (2001), and b) Sr peak integrated area for cores NKI5 (black) and KI2 (gray). Solid arrows at bottom of plot identify age controls. 


\section{Appendix A1: Supplemental information for Chapter $2^{*}$}

*Published originally as supplemental information for: Donnelly, J.P., and Woodruff, J.D., 2007, Intense hurricane activity over the past 5,000 years controlled by El Niño and the West African monsoon: Nature, v. 447, p. 465-468. 
Figure S1
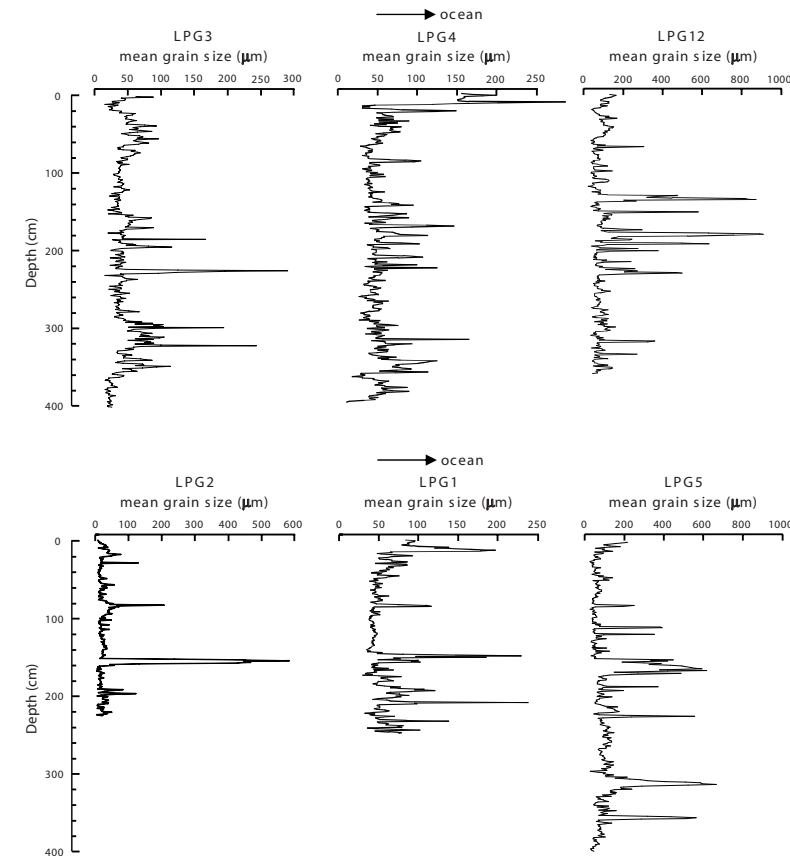

Figure S2

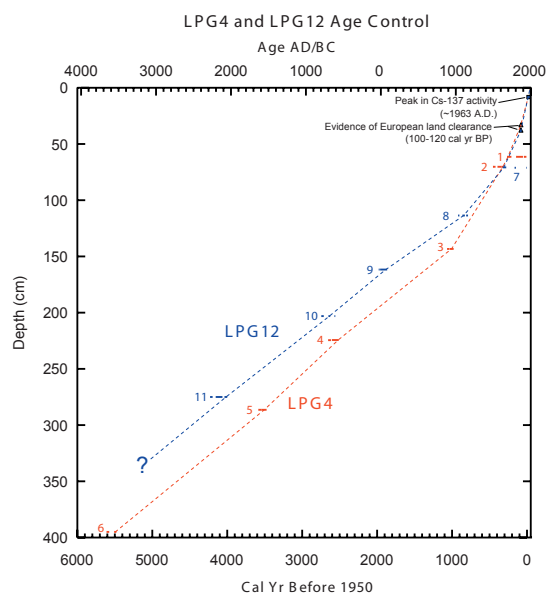

Figure S2 - Age versus depth plot of chronological data for LPG4 and LPG12. Radiocarbon ages are calibrated to calendar years at 1 standard deviation (see Table S1). Geochemical evidence ( $\mathrm{Ti}$ and $\mathrm{Fe}$ ) of increased input of terrestrial sediment associated with European land clearance for sugarcane production between 1830 and $1850 \mathrm{AD}$. is noted with triangles. The peak in Cesium-137 in LPG12 associated with a peak in atmospheric nuclear weapons testing in $1963 \mathrm{AD}$ is noted with a square. The sedimentation rates of LPG4 and LPG12 are similar throughout with rates of about $0.5 \mathrm{~mm} \mathrm{yr}-1$ in the earlier part of the record and rates of approximately $2 \mathrm{~mm}$ yr-1 over the last several hundred years. However, there is an offset of about $30 \mathrm{~cm}$ between the calibrated radiocarbon ages in LPG4 and LPG12 for the earlier part of the record. This offset may reflect a difference in sedimentation rates between the two cores in the early part of the last millenium and/or the LPG12 record may have experienced roughly $30 \mathrm{~cm}$ of erosion due to one or more of the events in the last 1500 years. As LPG12 is located next to the barrier it most likely experiences higher energy during overwash events and is more susceptible to sediment erosion resulting in the truncations of the record. The more distal LPG4 likely provides a more complete record, and given that barrier sediments must be transported over 100 meters,

Nyberg, J., Malmgren, B. A., Kuijpers, A. \& Winter, A. A centennial-scale variability of tropical North Atlantic surface hydrography during the late Holocene. Palaeogeography Palaeoclimatology Palaeoecology 183, 25-41 (2002)

.Rayner, N. A. et al. Global analyses of sea surface temperature, sea ice, and night marine air
Figure S1 - Bulk grain-size data from both transects. Mean grain-size data from bulk sediment for transect presented in the paper (LPG12, LPG4, and LPG3 (same as Fig. 2)) and transect of cores to the east (i.e. LPG5, LPG1, and LPG2; see Fig. 1). Note the mean grain size scales (x-axis) are set differently for each plot. Cores LPG12 and LPG5 are located closest to the barrier and cores LPG3 and LPG2 are located the furthest from the barrier.

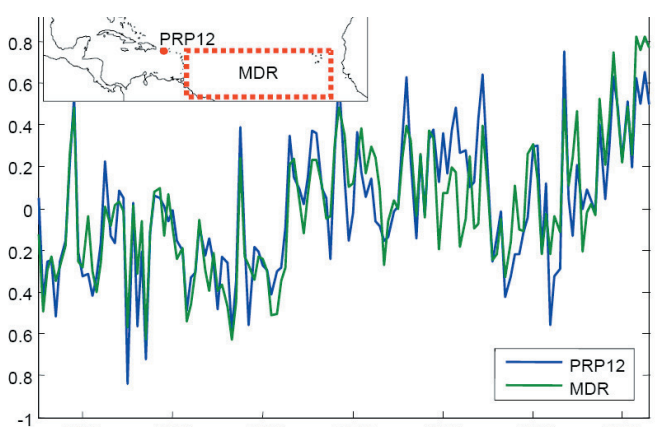

coarse-grained sediments at this site are most likely transported by the most extreme events. Lines connecting depths in LPG4 and LPG12 of approximately the same age in Fig. 2 are derived from the age models shown with dashed lines. The 5000 yr BP correlation line in Fig. 2 is based on the LPG4 age model and an extrapolation of the roughly linear sedimentation rate in core LPG12.

Figure S3 - Sea surface temperature (SST) comparison. SST anomalies for the main development region (MDR) compared to the SSTs just to the south of Puerto Rico where paleo-proxy reconstructions for SST are available (core PRP12, Nyberg et al., 2002). Inset map identifies the location of PRP12 (red circle) and the MDR (red dashed box, as defined by Emanuel (2005)). Monthly SST data was obtained from the Hadley Centre Sea Ice and SST data set (HADISST, Rayner et al., 2003) and averaged over the months of AugustOctober. SSTs for PRP12 $\left(17.9^{\circ} \mathrm{N}, 66.6^{\circ} \mathrm{W}\right)$ are based on the values for the $1^{\circ}$ grid cell centered at $17.5^{\circ} \mathrm{N}$ and $66.5^{\circ} \mathrm{W}$. Data for the MDR was obtained by averaging the HADISST data from within the box identified in the inset map $\left(6^{\circ} \mathrm{N}-18^{\circ} \mathrm{N}\right.$ and $\left.20^{\circ} \mathrm{W}-60^{\circ} \mathrm{W}\right)$. SSTs for the MDR and PRP12 are highly correlated $\left(\mathrm{r}^{2}=0.75\right.$, $\mathrm{n}=137$ ) suggesting that the SST reconstruction available at PRP12 is likely a good proxy for MDR SSTs.

temperature since the late nineteenth century. J. Geophys. Res.108, 4407, doi:10.1029/ 2002JD002670 (2003).

Emanuel, K. Increasing destructiveness of tropical cyclones over the past 30 years. Nature 436, 686-688 (2005) 
Table S1: Laguna Playa Grande radiocarbon results

\begin{tabular}{|c|c|c|c|c|c|c|c|}
\hline $\begin{array}{l}\text { Index } \\
\text { No. }\end{array}$ & $\begin{array}{l}\text { Lab } \\
\text { number }\end{array}$ & Core & ${ }^{14} \mathrm{C}$ age & $\begin{array}{c}1 \sigma \text { calendar age } \\
(\text { cal yr BP })\end{array}$ & $\delta^{13} \mathrm{C}(\%)$ & $\begin{array}{c}\text { Sample } \\
\text { depth } \\
(\mathrm{cm})\end{array}$ & Material Dated \\
\hline 1 & OS-41547 & LPG4 & $125 \pm 45$ & $\begin{array}{c}15-41 \\
59-146 \\
214-234 \\
238-268\end{array}$ & -25.59 & $61-62$ & woody debris \\
\hline 2 & OS-41362 & LPG4 & $340 \pm 20$ & $\begin{array}{l}319-337 \\
348-392 \\
426-457\end{array}$ & -26.71 & $70-71$ & woody debris \\
\hline 3 & OS-41360 & LPG4 & $1140 \pm 25$ & $\begin{array}{c}983-1034 \\
1048-1067\end{array}$ & -18.91 & $143-144$ & $\begin{array}{l}\text { seeds/woody } \\
\text { debris }\end{array}$ \\
\hline 4 & OS-56742 & LPG4 & $2810 \pm 30$ & $\begin{array}{c}2502-2618 \\
2621-2651 \\
(\Delta R=0)\end{array}$ & -2.03 & $224-225$ & $\begin{array}{l}\text { Gastropods shells } \\
\text { (Heleobops sp.) }\end{array}$ \\
\hline 5 & OS-41361 & LPG4 & $3320 \pm 30$ & $3481-3541$ & -17.22 & $286-287$ & $\begin{array}{l}\text { seeds/woody } \\
\text { debris }\end{array}$ \\
\hline 6 & OS-44220 & LPG4 & $4840 \pm 35$ & $\begin{array}{l}5486-5509 \\
5581-5609\end{array}$ & -23.65 & 394.5-395.5 & Wood \\
\hline 7 & OS-50218 & LPG12 & $240 \pm 30$ & $\begin{array}{c}0-1 \\
153-168 \\
282-307\end{array}$ & -28.23 & $70-71$ & wood \\
\hline 8 & OS-50219 & LPG12 & $940 \pm 30$ & $\begin{array}{l}797-818 \\
822-870 \\
898-916\end{array}$ & -28.46 & $112-113$ & wood \\
\hline 9 & OS-50177 & LPG12 & $1970 \pm 45$ & $\begin{array}{l}1876-1951 \\
1960-1971 \\
1978-1986\end{array}$ & -25.92 & $161-162$ & wood \\
\hline 10 & OS-50360 & LPG12 & $2570 \pm 40$ & $\begin{array}{l}2546-2560 \\
2617-2634 \\
2702-2754\end{array}$ & -26.07 & 201-202 & wood \\
\hline 11 & OS-50176 & LPG12 & $3750 \pm 45$ & $\begin{array}{l}3994-4038 \\
4076-4156 \\
4206-4222\end{array}$ & -25.03 & $273-274$ & wood \\
\hline * & OS-50217 & LPG12 & $605+40$ & $\begin{array}{l}552-567 \\
585-614 \\
617-647\end{array}$ & -26.07 & $17-18$ & wood \\
\hline
\end{tabular}




\title{
Appendix A2 : Supplemental information for Chapter $3^{*}$
}

\author{
Appendix A2. 1. Methods \\ Appendix A2.2. Archival Data \\ Ti and bulk grain size data (Figure A2.1) \\ Radiocarbon results (Table A2.1) \\ Grain size versus settling velocity (Figure A2.2) \\ Vertical grain-size distribution for the 1350 yr BP deposit (Figure A2.3) \\ Variations in thickness of the 1350 yr BP deposit (Figure A2.4) \\ Appendix A2.3. Wave runup estimates for the 1928 AD hurricane \\ Appendix A2.4. Estimated flow, shear velocities and head losses \\ Appendix A2.5: Significance of sediment resuspension \\ Appendix A2.6. Discussion of deposit genesis: hurricanes versus tsunamis \\ References
}

*Published originally as supplemental information for: Woodruff, J.D., Donnelly, J.P., Mohrig, D., and Geyer, W.R., 2008b, Reconstructing relative flooding intensities responsible for hurricane-induced deposits from Laguna Playa Grande, Vieques, Puerto Rico: Geology, v. 36, p. 391-394. 


\section{Appendix A2}

\section{Appendix A2. 1. Methods}

Cores were collected using a Vohnout/Colinvaux piston corer in 5-cm diameter polycarbonate barrels. Short $10-\mathrm{cm}$ diameter push cores were taken at select core locations in order to better capture the sediment/water interface and provide adequate material for radio-isotopic analyses. These push cores were extruded in the field and sampled every $0.5 \mathrm{~cm}$. Measurements of the activity of Cs-137 (a product of atmospheric nuclear weapons testing) were conducted using a high-resolution gamma detector. The locations for all coring sites were determined using a handheld GPS unit, which provided a horizontal accuracy of 3 to 6 meters. Sediment cores were split in the laboratory and select core halves were run through a non-destructive automated core scanner to obtain millimeter to sub-millimeter resolution X-ray fluorescence measurements of the sediment's elemental composition based on methods described by Croudace et al. (2006). Initial grain size analysis was conducted on contiguous $1 \mathrm{~cm}$ bulk samples using a Beckman-Coulter LS13320 laser diffraction particle size analyzer. After the coarse grained events were identified with the LS13320, isolated coarse grain layers were sub-sampled at $1 \mathrm{~cm}$ resolution. Clay and silt were removed from these isolated deposits using a $63 \mu \mathrm{m}$ sieve and the sand was dried and run through a digital image processing particle size and shape analyzer (Retsch Camsizer system) to obtain accurate grain-size distributions for the coarse fraction of each sample. After initial grain-size analyses for the bulk sediment, each overwash sample was treated with $\mathrm{H}_{2} \mathrm{O}_{2}$ and $\mathrm{HCl}$ solutions to remove organics and carbonate material and the remaining sediment was dried and re-run through the Camsizer system again to obtain grain-size 
distributions for the now isolated siliciclastic material. Each sample was run through the Camsizer system a minimum of three times to ensure reproducibility and the average of these runs was used for analysis. In order to quantify the settling rate for siliciclastic and shell material from the site, both of these materials were independently sieved using 10 consecutive bin sizes between $63 \mu \mathrm{m}$ and $2000 \mu \mathrm{m}$. This binned sediment was then settled through a $1.5 \mathrm{~m}$ long, hanging pan settling tube using methods described by Syvitski et al (1991).Samples of wood, seeds, and shells were radiocarbon dated at the NOSAMS Facility at Woods Hole Oceanographic Institution (WHOI). Resulting radiocarbon ages were calibrated to calendar years using the IntCal04 (Reimer et al., 2004) and Marine04 (Hughen et al., 2004) calibration data sets. Ages are reported in calendar years before present (BP) with present being 1950 A.D. by convention. References to historic events are reported in years A.D. 


\section{Appendix A2. 2. Archival data}

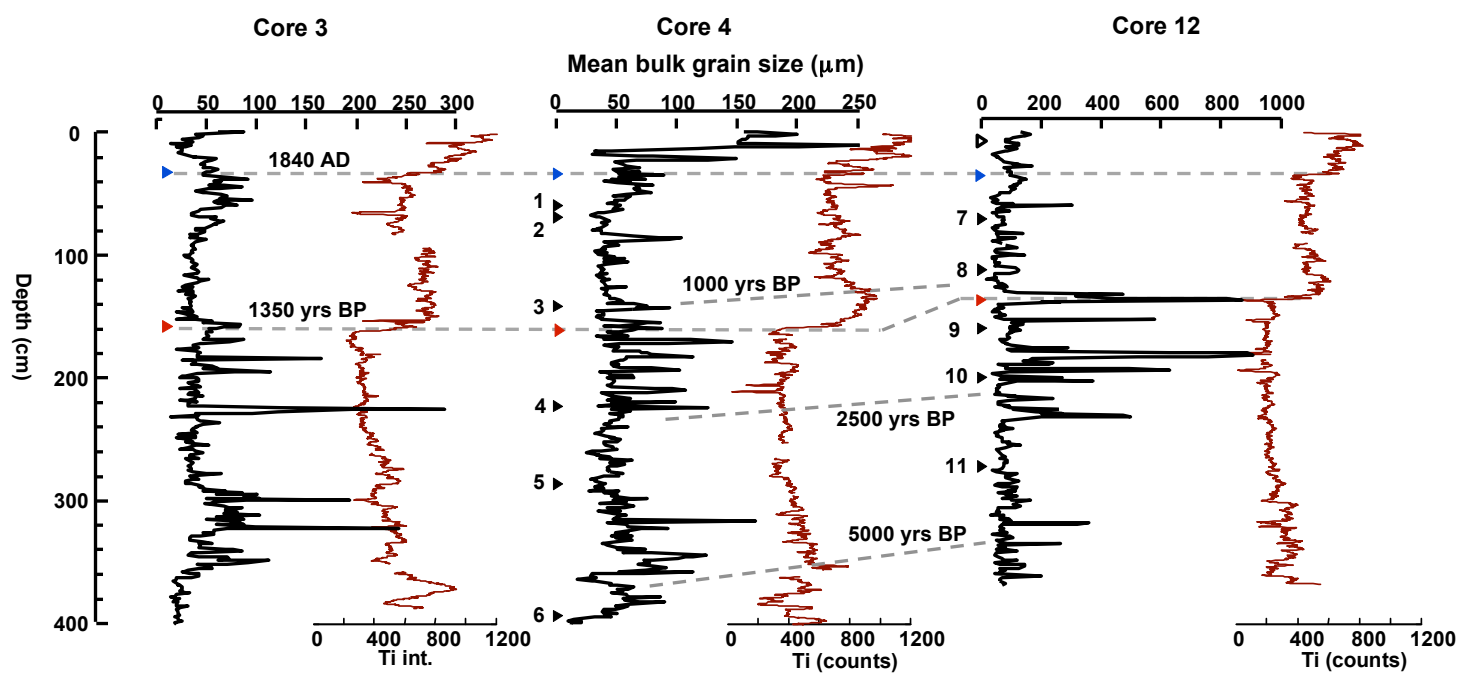

Figure A2.1: Ti and bulk grain size data. Mean bulk grain size (black) and Ti measurements (red) for cores collected along the middle shore-normal transect at LPG (see Figure 1 in main text for core positions). Solid black arrows represent the depth of radiocarbon dated samples from Core 4 and Core 12 with sample index numbers referenced in Table DR1. The depth of abrupt increases in Ti which dates to $1840 \mathrm{AD}$ and $\sim 1350 \mathrm{yr}$ BP are noted with solid blue and red arrows, respectively (ages based on a linear interpolation between Cs-137 and C-14 dates obtained from Core 12, but are also consistent with C-14 dates obtained from Core 4). Dashed grey lines indicate depths of equal age base on the presented chronological constraints. Figure adapted from Donnelly and Woodruff (2007).

TABLE A2.1. LAGUNA PLAYA GRANDE RADIOCARBON RESULTS*

\begin{tabular}{lclrrrrl}
\hline \hline $\begin{array}{l}\text { Index } \\
\text { Number }\end{array}$ & Core & Depth $(\mathrm{cm})$ & $14 \mathrm{C}$ date & Cal yrs BP & $(2 \sigma)$ & \multicolumn{1}{c}{ d13C } & \multicolumn{1}{c}{ Material Dated } \\
\hline 1 & 4 & $61-62$ & $125+45$ & 104 yrs BP & $(-2-277)$ & -25.59 & woody debris \\
2 & 4 & $70-71$ & $340+20$ & 369 yrs BP & $(314-467)$ & -26.71 & woody debris \\
3 & 4 & $143-144$ & $1140+25$ & 1010 yrs BP & $(969-1168)$ & -18.91 & seeds/woody debris \\
4 & 4 & $224-225$ & $2810+30$ & 2503 yrs BP & $(2438-2690)$ & -2.03 & Gastropods shells (Heleobops sp.) \\
5 & 4 & $286-287$ & $3320+30$ & 3500 yrs BP & $(3472-3633)$ & -17.22 & Seeds/woody debris \\
6 & 4 & $394.5-395.5$ & $4840+35$ & 5597 yrs BP & $(5479-5651)$ & -23.65 & wood \\
7 & 12 & $70-71$ & $240+30$ & 295 yrs BP & $(0-428)$ & -28.23 & wood \\
8 & 12 & $112-113$ & $940+30$ & 846 yrs BP & $(791-925)$ & -28.46 & wood \\
9 & 12 & $161-162$ & $1970+45$ & 1914 yrs BP & $(1821-2037)$ & -25.92 & wood \\
10 & 12 & $201-202$ & $2570+40$ & 2728 yrs BP & $(2495-2762)$ & -26.07 & wood \\
11 & 12 & $273-274$ & $3750+45$ & 4116 yrs BP & $(3978-4242)$ & -25.03 & wood \\
\hline
\end{tabular}




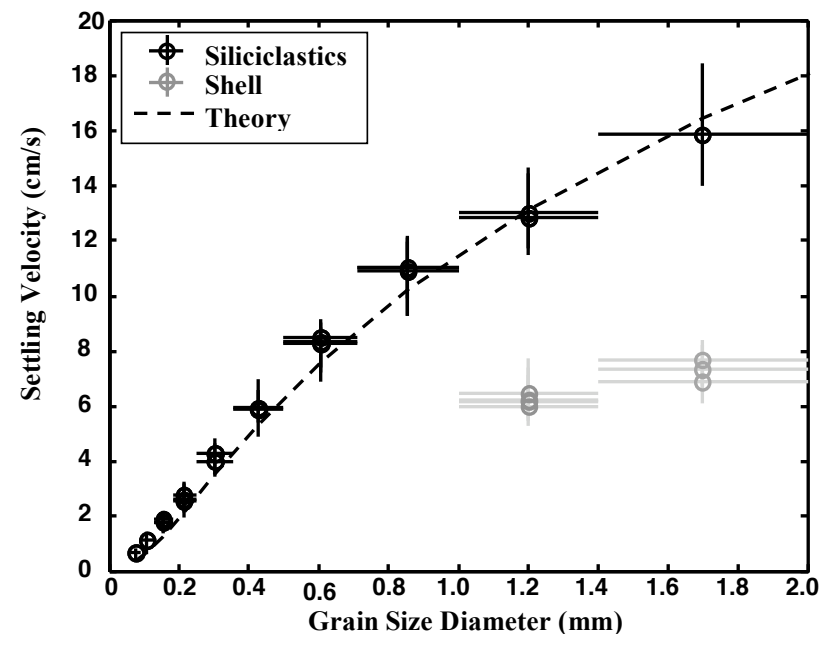

Figure A2.2: Grain size versus settling velocity for LPG sediment. Mean settling velocities $\left(w_{s}\right)$ measured for siliciclastics (black circles) and shell material (gray circles). Vertical error bars indicate $1 \sigma$ range for $w_{s}$ and horizontal error bars indicate ranges of grain diameters in each bin size. Comparisons between the actual mean settling velocities measured for LPG siliciclastics sediments and values predicted by Ferguson and Church (2004) for naturally shaped quartz sands (black dotted line) reveal an excellent fit and support using the relationship for analyses in this study. 


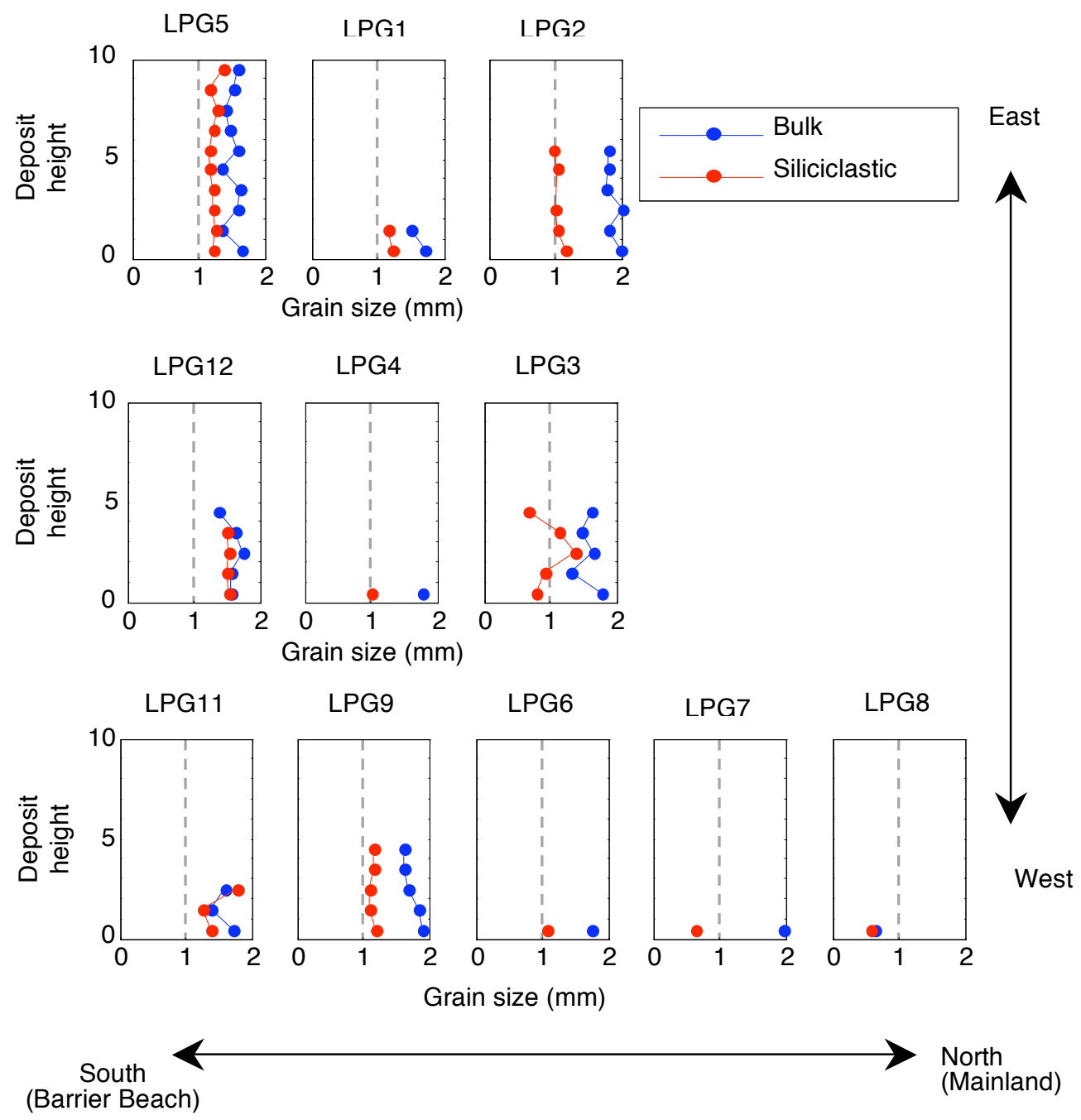

Figure A2.3: Vertical grain-size distribution for $1350 \mathrm{yr}$ BP deposit. Vertical variations in grain size (for material $>63 \mu \mathrm{m}$ ) measured at $1 \mathrm{~cm}$ increments from the $1350 \mathrm{yr}$ BP deposit. Bulk measurements are plotted in blue and measurements for siliciclastics are in red. Cores are arranged along the three shore normal transects with arrows indicating orientation (See site map in Fig. 1 of main text for core locations). 


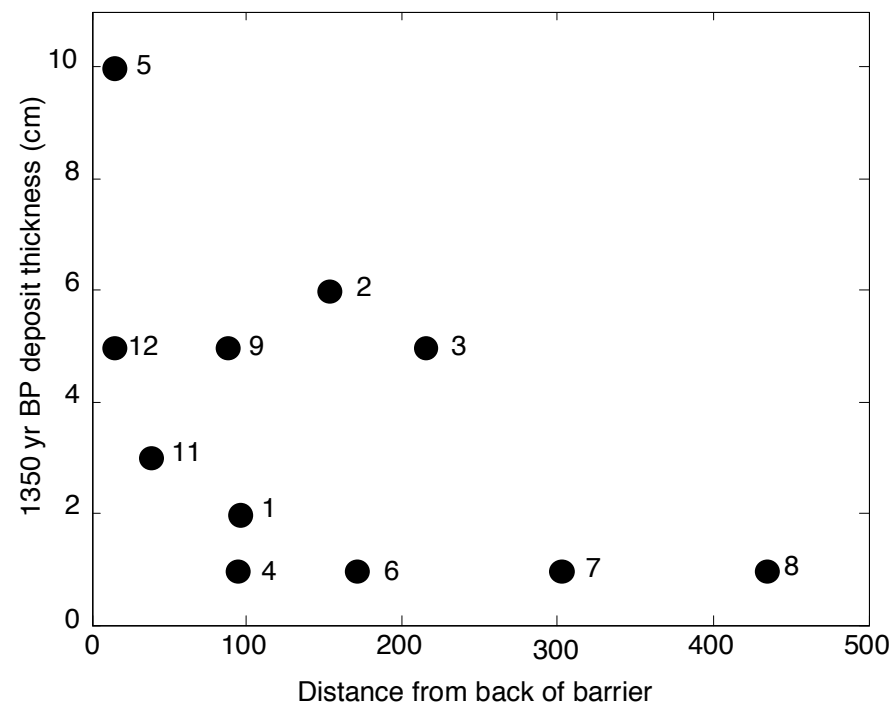

Figure A2.4: Shore-normal variations in deposit thickness for 1350 yr BP deposit. Numbers represent coring locations identified in Fig. 1 of main text. The thickness of the deposit was variable but generally thinned away from the barrier and towards the mainland. 


\section{Appendix A2. 3: Wave runup estimates for the 1928 AD event at LPG}

Wave heights at the LPG barrier during a hurricane are significantly smaller than offshore due to breaking in the surf zone. This cross-shore gradient in wave height is balanced by an increase in water level onshore whose time-averaged mean is defined as wave setup (Fredsoe and Deigaard, 1992). The vertical oscillation in water elevation about this time-averaged mean is defined as swash. Wave runup is the cumulative constructive effect of wave setup and swash (Stockdon et al., 2006). The wave setup $\left(\eta_{\text {setup }}\right)$ and $2 \%$ exceedance value for runup $\left(R_{\max }\right)$ have been empirically related to the offshore significant wave height $\left(H_{o}\right)$, wavelength $\left(L_{o}\right)$ and the slope of the beach $(\beta)$, (Stockdon et al., 2006). In addition, for an extremely dissipative beach where $\beta$ is small relative to the offshore wave steepness $\left(\beta /\left(H_{o} / L_{o}\right)^{1 / 2}<0.3\right)$, Stockdon et al. (2006) suggests that a more accurate approximation can be obtained using, $R_{\max }=\alpha\left(H_{o} L_{o}\right)^{1 / 2}$, where $\alpha$ is 0.016 and 0.043 for $\eta_{\text {setup }}$ and $R_{\max }$, respectively.

The 1928 AD hurricane passed just $75 \mathrm{~km}$ to the south of LPG with an average maximum sustained wind speed $\left(U_{\text {wind }}\right)$ of $72 \mathrm{~m} / \mathrm{s}$ and a central pressure $\left(P_{\mathrm{o}}\right)$ of $931 \mathrm{mbar}$ (Landsea et al., 2004). Estimates of $H_{o}$ for the 1928 AD event range between $17 \mathrm{~m}$ and 16 $\mathrm{m}$, using the separate empirical relationships $H_{o}=0.235 U_{\text {wind }}$ and $H_{o}=0.2\left(P_{r}-P_{o}\right)$, described respectively by Ochi (1998) and Hsu et al. (2000). Here $P_{r}$ is the pressure at the edge of the storm ( 1013 mbar). These wave heights are similar to those recently measured during Hurricane Ivan in 2004 (Wang et al., 2005), where a dominant wave period of 17 seconds and a corresponding wave length of $450 \mathrm{~m}$ was observed. For the $1928 \mathrm{AD}$ event we therefore assume a value of $16.5 \mathrm{~m}$ and $450 \mathrm{~m}$ for $H_{o}$ and $L_{o}$, 
respectively. Wind speeds are slightly slower during Ivan $\left(U_{\max }=60 \mathrm{~m} / \mathrm{s}\right)$ than estimated for the $1928 \mathrm{AD}$ event suggesting that the estimates for $1928 \mathrm{AD}$ wave dimensions might be considered a lower bound for the actual conditions occurring during the event.

The beach slope at LPG is approximately 0.05 which suggests highly dissipative conditions during the $1928 \mathrm{AD}$ event $\left(\beta /\left(H_{o} / L_{o}\right)^{1 / 2}=0.26\right)$. Based on the approximations presented by Stockdon et al. (2006) we estimate values for $\eta_{\text {setup }}$ and $R_{\max }$ of $1.4 \mathrm{~m}$ and $3.7 \mathrm{~m}$, respectively during the $1928 \mathrm{AD}$ hurricane.

\section{Appendix A2. 4: Estimating flow, shear velocities and head losses}

A rough approximation for how wave heights might diminish while propagating across the lagoon at LPG is obtained by using Bernoulli's principle to estimate the total energy head in the fluid and then accounting for the head lost by the fluid due to frictional interactions with the bed. The total head, $H$ for waves entering the lagoon can be approximated by:

$$
H=\frac{U_{b}^{2}}{2 g}+h_{b}
$$

Where $\mathrm{g}$ is gravity, $U_{b}$ is the mean flow velocity and $h_{b}$ is the average flow depth in the bore while propagating over the barrier (see Fig. 1B in the main text for schematic). Estimated values for $h_{b}$ range between 2 and $4 \mathrm{~m}$ based on the reconstruction for Core 3 presented in Figure 4 of the main text. Assuming flow is critical over the barrier crest, these wave heights correspond to flow velocities of $4.4 \mathrm{~m} / \mathrm{s}$ and $6.3 \mathrm{~m} / \mathrm{s}$, and values for $H$ ranging from $3 \mathrm{~m}$ to $6 \mathrm{~m}$. 
The total head lost by waves traveling a distance $L$ in the lagoon due to friction is estimated as:

$$
\Delta H=\frac{u_{*_{L}}^{2} L}{g h_{L}}
$$

Where $u *$ is the shear velocity in the lagoon which can be related to the mean flow, $U_{L}$, with a non-dimensional drag coefficient, $C_{D}$ :

$$
u_{* L}=\sqrt{C_{D}} U_{L}
$$

Here we assume a logarithmic velocity profile to obtain $C_{D}$ :

$$
C_{D}=\left(\frac{\kappa}{\ln \left(h_{L} / z_{o}\right)-1}\right)^{2}
$$

Where, $\kappa$ is von Karman's constant $(0.40), z_{o}$ is approximately equivalent to $d_{50} / 12$ and $d_{50}$ is the median grain size of the bed material, $\sim 100 \mu \mathrm{m}$ (Fig. DR1, Soulsby, 1997). We assume that the lagoon has already been partially flooded when the largest storm waves enter $\left(h_{o} \approx 2 \mathrm{~m}\right)$, such that mean flow velocities within the bore when propagating across the lagoon can be expressed as: $U_{L}=\frac{h_{L}-h_{o}}{h_{L}} \sqrt{g h_{L}}$ (Whitham, 1974). Rough approximations for $U_{L}$ and $h_{L}$ can be obtained numerically for given values of $U_{b}$ and $h_{b}$ assuming flow is conserved $\left(U_{b} h_{b}=U_{L} h_{L}\right)$. Based on these approximations we estimate values of $u *$ range between $8 \mathrm{~cm} / \mathrm{s}$ and $15 \mathrm{~cm} / \mathrm{s}$ (Table DR2). Using the distance of Core 3 from the back of the barrier as $L(214 \mathrm{~m})$ and estimated values for $u_{L}$ yield a head loss of approximately $0.04 \mathrm{~m}$ to $0.09 \mathrm{~m}$ for $2 \mathrm{~m}$ to $4 \mathrm{~m}$ high bores propagating across the lagoon to core site 3 . The head loss due to friction therefore represents only a small fraction 
( $\sim 1 \%)$ of the total energy head of waves entering the lagoon, and suggests that frictional effects should not significantly diminish the considered wave heights at the LPG site.

\begin{tabular}{lcccccccc}
\multicolumn{10}{c}{ TABLE DR2. FLOW VELOCITY, SHEAR VELOCITY AND HEAD LOSS ESTIMATES } \\
\hline \hline \begin{tabular}{l}
\hline \\
$h_{b}$
\end{tabular} & $\begin{array}{c}U_{b} \\
(\mathrm{~m})\end{array}$ & $\begin{array}{c}H \\
(\mathrm{~m} / \mathrm{s})\end{array}$ & $\begin{array}{c}h_{o} \\
(\mathrm{~m})\end{array}$ & $\begin{array}{c}h_{L} \\
(\mathrm{~m})\end{array}$ & $\begin{array}{c}U_{L} \\
(\mathrm{~m} / \mathrm{s})\end{array}$ & $C_{D}$ & $\begin{array}{c}u_{*} L \\
(\mathrm{~m} / \mathrm{s})\end{array}$ & $\begin{array}{c}\Delta H \\
(\mathrm{~m})\end{array}$ \\
\hline 2 & 4.4 & 3 & 2 & 3.5 & 2.5 & 0.001 & 0.08 & 0.04 \\
4 & 6.3 & 6 & 2 & 5.4 & 4.6 & 0.001 & 0.15 & 0.09 \\
\hline
\end{tabular}

\section{Appendix A2. 5: Significance of sediment resuspension}

The advective/settling model assumes that flows initially traveling over the barrier suspend coarse grained sediment high into the water column due to intense vertical mixing by breaking waves and enhanced turbulence in the boundary-layer. Once this flow enters the lagoon, turbulence is reduced significantly. The high concentrations of coarse grained sediment suspended by flows over the barrier can therefore no longer be sustained in the lagoon and sediment settles out at a rate far greater than what is resuspended from the bed. To test this assumption we compare estimates for the flux of suspended sediment from the barrier to those that could be produced just by resuspension in the lagoon. The equilibrium volumetric suspended sediment transport rate, $q_{s}$ is obtained both along the barrier and within the lagoon by taking the integral through the water depth for the product of the estimated flow velocities, $U(z)$ and suspended sediment concentrations, $C(z)$ during inundation,

$$
q_{s}=\int_{z_{a}}^{h} U(z) C(z) d z
$$


Where $z_{a}$ is a reference height above the bed at which a reference concentration $C_{a}$ is calculated, and $h$ is the water depth (Graf, 1971). For a sediment concentration profile we assume a linear increase in eddy diffusivity with height so that,

$$
C(z)=C_{a}\left(\frac{z}{z_{a}}\right)^{-R o}
$$

In this expression, $R_{o}$ is the Rouse number or suspension parameter, $R_{o}=w_{s} / \kappa u_{*}, w_{s}$ is the particle settling velocity, $\kappa$ is von Karman's constant $=0.4$, and $u *$ is the total shear velocity. Note that Equation 5.2 does not assume that sediment concentrations go to zero at the water surface and is therefore more suited for our application when compared to a typical Rouse profile with a parabolic eddy diffusivity profile (Soulsby, 1997).

To obtain $C_{a}$ we use the expression described by Smith and McLean (1977), McLean (1992), and Wiberg et al. (1994):

$$
C_{a}=f_{i} C_{b e d} \frac{\gamma_{o} S}{1+\gamma_{o} S}
$$

In this expression $f_{i}$ is the fraction of sediment in class $i, C_{b e d}$ is the maximum permissible volume concentration in the bed (1-porosity), $\gamma_{o}$ is the resuspension parameter which we assume to be roughly $10^{-3}$ based on the results of Smith and McLean (1977), and $S$ is the normalized excess shear stress, $S=\left(\tau_{s f}-\tau_{c r}\right) / \tau_{c r}$, where $\tau_{s f}$ is the shear stress at the surface of the bed and $\tau_{c r}$ is the critical shear stress required for the initiation of sediment motion. We obtain $z_{a}$ based on a rough estimate for the particle saltation height, 2D, where $D$ is the grain size (Wiberg et al., 1994). In addition, for simplicity we have assumed $f_{\mathrm{i}}$ as 1 . This assumption is less true for bed material within the lagoon where the 
coarser grains in suspension compose a much smaller fraction of the original muddy/silt substrate. Our calculations for $q_{s}$ in the lagoon during inundation should therefore be considered an upper bound. This estimate is still useful since we are assessing whether the maximum equilibrium suspended sediment flux in the lagoon is significantly smaller than the flux advected in from the barrier. Finally, we assume a smooth bed such that, $\tau_{s f}=\tau_{o}=\rho C_{D} U^{2}$, where $\tau_{o}$ is the effective bed shear stress experienced by the flow. Methods for obtaining $U$ and the drag coefficient, $C_{D}$ in the lagoon are described in Appendix DR4. A drag coefficient of 0.003 is assumed over the barrier during flooding which is consistent with mean $C_{D}$ values observed in the surf zone by Feddersen et al. (2003). To estimate $\tau_{c r}$ a constant dimensionless critical shear stress, $\tau *_{c r}$ of 0.06 is assumed which is reasonable for the flow conditions and grain sizes considered (Wiberg and Smith, 1987), where

$$
\tau_{*_{c r}}=\frac{\tau_{c r}}{D g\left(\rho_{s}-\rho\right)}
$$

In this expression $\tau_{c r}$ is the critical shear stress at the bed for the initiation of motion of a particle with a diameter of $D$ and a density $\rho_{s}$, in a fluid with a density of $\rho$, and $g$ is the acceleration of gravity.

Finally, for this analysis velocity is expressed with a logarithmic velocity distribution,

$$
U(z)=\frac{u_{*}}{\kappa} \ln \left(\frac{z}{z_{o}}\right)
$$

Where $z_{o}$ is the bed roughness length (Appendix DR4).

Introducing the suspension distribution, Eq. 5.2 and the expression for velocity, Eq. 5.5 into Eq. 5.1 we obtain, 


$$
q_{s}=\int_{z_{a}}^{h} \frac{u_{*}}{\kappa} \ln \left(\frac{z}{z_{o}}\right) C_{a}\left(\frac{z}{z_{a}}\right)^{-R o} d z
$$

which integrates to,

$$
q_{s}=\frac{u_{*} C_{a}}{\kappa(R o-1)^{2}}\left(z_{a}\left((R o-1) \ln \left(\frac{z_{a}}{z_{o}}\right)+1\right)-h\left(\frac{h}{z_{a}}\right)^{-R o}\left((R o-1) \ln \left(\frac{h}{z_{o}}\right)+1\right)\right)
$$

Table DR3 presents the results of using Eq. 5.7 with the inundation conditions estimated at the site, and for the $\mathrm{D}_{95}$ grains observed in Core 3 (Table DR2 and Figure 4 in main text). Estimated bottom shear stresses, $\tau_{o}$, drop significantly from 59-118 Pa along the barrier to 6-21 Pa within the lagoon. Consequently, the Rouse suspension parameter, $R_{o}$ increase from $0.5-0.8$ over the barrier to $1.5-2.0$ within the lagoon. In both cases $R_{o}$ transitions from $>1$ over the barrier to $<1$ within the lagoon. This suggests that near bed vertical velocity fluctuations dominate over particle settling rates for flows over the barrier, but transition in the lagoon to a regime where particle settling can overcome turbulent mixing. Excess shear stresses (S) also decrease by a factor of 10 in the lagoon (Table DR3). The net result is suspended sediment fluxes from the barrier being approximately 100-1000 times greater than resuspension fluxes within the lagoon, strongly suggesting that the settling of sediment advected in from the barrier dominates over lagoon resuspension. 
TABLE A2.3. ESTIMATES FOR EQUILIBRIUM SUSPENDED SEDIMENT FLUX

\begin{tabular}{lcccccccc} 
Location & $\begin{array}{c}h \\
(\mathrm{~m})\end{array}$ & $\begin{array}{c}U \\
(\mathrm{~m} / \mathrm{s})\end{array}$ & $C_{D}$ & $\begin{array}{c}D \\
(\mathrm{~mm})\end{array}$ & $\begin{array}{c}\tau_{o} \\
(\mathrm{~Pa})\end{array}$ & $S$ & $R o$ & $\begin{array}{c}q_{s} \\
\left(\mathrm{~m}^{2} / \mathrm{s}\right)\end{array}$ \\
\hline \multicolumn{7}{l}{ Flooding depth over barrier $=2 \mathrm{~m}$} \\
Barrier & 2.0 & 4.4 & 0.003 & 0.4 & 59 & 151 & 0.5 & $2 \times 10^{-2}$ \\
Lagoon & 3.5 & 2.5 & 0.001 & 0.4 & 6 & 15 & 1.5 & $9 \times 10^{-6}$ \\
& & & & & & & & \\
\multicolumn{2}{l}{ Flooding depth over barrier $=4 \mathrm{~m}$} \\
Barrier
\end{tabular}

\section{Appendix A2. 6: Discussion of deposit genesis: hurricanes versus tsunamis}

We have interpreted that a majority of the deposits in the LPG record are the result of intense hurricane events. This is primarily due to the high frequency of hurricane strikes to the site, and the correlation of historical hurricanes to overwash deposits. Tsunami occurrences at the site are much less frequent with 1 documented event greater than $2 \mathrm{~m}$ over the last 500 years (O'Loughlin and Lander, 2003). During hurricane activity the beach at LPG is highly dissipative (Appendix DR3). Studies suggest that under these conditions infragravity waves ( $\mathrm{T}=0.3$ to 4 minutes) account for between roughly $63 \%$ to $98 \%$ of the swash height (Ruessink et al., 1998). These low frequency infragravity oscillations are still shorter than a typical tsunami event whose period can range between 10 minutes and 2 hours (Mei, 1989). We see no evidence in the LPG record for an anomalous deposit that might represent a significant tsunami event. However, hurricane flooding at LPG may still mimic smaller scale tsunami events whose periods and wave heights are closer in magnitude to those occurring during a storm (Morton et al., 2007). We are therefore currently unable to unequivocally assess the 
origin for any individual deposit prior to the documented record, however, the high frequency of both hurricane occurrences and overwash layers observed at LPG, along with the correlation of recent overwash layers to documented intense hurricanes strikes, strongly suggests that a majority of the overwash layers observed at LPG are the result of intense hurricane activity rather than tsunami events.

\section{References:}

Croudace, I.W., Rindby, A., and Rothwell, R.G., 2006, ITRAX: description and evaluation of a new multi-function X-ray core scanner: London, Geological Society.

Donnelly, J.P., and Woodruff, J.D., 2007, Intense hurricane activity over the past 5,000 years controlled by El Nino and the West African monsoon: Nature, v. 447, p. 465-468.

Feddersen, F., Gallagher, E.L., Guza, R.T., and Elgar, S., 2003, The drag coefficient, bottom roughness, and wave-breaking in the nearshore: Coastal Engineering, v. 48, p. 189-195.

Ferguson, R.I., and Church, M., 2004, A simple universal equation for grain settling velocity: Journal of Sedimentary Research, v. 74, p. 933-937.

Fredsoe, J., and Deigaard, R., 1992, Mechanics of coastal sediment transport: Singapore, World Scientific, $369 \mathrm{p}$.

Graf, W.H., 1971, Hydraulics of Sediment Transport: Littleton, CO, USA, Water Resour. Publ.

Hsu, S.A., Martin, M.F., Jr., and Blanchard, B.W., 2000, An Evaluation of the USACE's Deepwater Wave Prediction Techniques under Hurricane Conditions During Georges in 1998: Journal of Coastal Research, v. 16, p. 823-829.

Hughen, K.A., Baillie, M.G.L., Bard, E., Beck, J.W., Bertrand, C.J.H., Blackwell, P.G., Buck, C.E., Burr, G.S., Cutler, K.B., Damon, P.E., Edwards, R.L., Fairbanks, R.G., Friedrich, M., Guilderson, T.P., Kromer, B., McCormac, G., Manning, S., Ramsey, C.B., Reimer, P.J., Reimer, R.W., Remmele, S., Southon, J.R., Stuiver, M., Talamo, S., Taylor, F.W., van der Plicht, J., and Weyhenmeyer, C.E., 2004, Marine 04 marine radiocarbon age calibration, 0-26 cal kyr BP: Radiocarbon, v. 46, p. 1059-1086.

Landsea, C.W., Anderson, C., Charles, N., Clark, G., Dunion, J., Fernandes-Partagas, J., Hungford, P., Neumann, C.J., and Zimmer, M., 2004, The Atlantic Hurricane Database Re-analysis Project Documentation for 1851-1910 Alterations and Addition to the HURDAT Database, in Murnane, R., and Liu, K.B., eds., Hurricanes and Typhoons: Past, Present and Future: New York City, Columbia University Press, p. 178-221.

McLean, S.R., 1992, On the calculation of suspended load for noncohesive sediments: Journal of Geophysical Research, v. 97, p. 5759-5770. 
Mei, C.C., 1989, The Applied Dynamics of Ocean Surface Waves, in Liu, P.L.-F., ed., Advances Series on Ocean Engineering, Volume 1: Singapore, World Scientific, p. 740 .

Morton, R.A., Gelfenbaum, G., and Jaffe, B., 2007, Physical criteria for distinguishing sandy tsunami and storm deposits using modern examples: Sedimentary Geology, v. 200, p. $184-207$.

O'Loughlin, K.F., and Lander, J.F., 2003, Caribbean Tsunamis: A 500-year history from 1498-1998: The Netherlands, Kluwer Academic Publishers.

Ochi, M.K., 1998, Ocean Waves: Cambridge, U.K., Cambridge University Press.

Reimer, P.J., Baillie, M.G.L., Bard, E., Bayliss, A., Beck, J.W., Bertrand, C.J.H., Blackwell, P.G., Buck, C.E., Burr, G.S., Cutler, K.B., Damon, P.E., Edwards, R.L., Fairbanks, R.G., Friedrich, M., Guilderson, T.P., Hogg, A.G., Hughen, K.A., Kromer, B., McCormac, G., Manning, S., Ramsey, C.B., Reimer, R.W., Remmele, S., Southon, J.R., Stuiver, M., Talamo, S., Taylor, F.W., van der Plicht, J., and Weyhenmeyer, C.E., 2004, IntCal04 terrestrial radiocarbon age calibration, 0-26 cal kyr BP: Radiocarbon, v. 46, p. 1029-1058.

Ruessink, B.G., Kleinhans, M.G., and van den Beukel, P.G.L., 1998, Observations of swash under highly dissipative conditions: Journal of Geophysical Research, v. 103, p. 3111-3118.

Smith, J.D., and McLean, S.R., 1977, Spatially averaged flow over a wavy surface: Journal of Geophysical Research, v. 82, p. 1735-1746.

Soulsby, R., 1997, Dynamics of marine sands: London, Thomas Telford Publications, $249 \mathrm{p}$.

Stockdon, H.F., Holman, R.A., Howd, P.A., and Sallenger, A.H., Jr., 2006, Empirical parameterization of setup, swash, and runup: Coastal Engineering, v. 53, p. 573588.

Syvitski, J.P.M., Asprey, K.W., and Clattenburg, D.A., 1991, Principles, design, and calibration of settling tubes, in Syvitski, J.P.M., ed., Principles, methods, and application of particle size analysis: Cambridge, Cambridge University Press, $p$. 45-63.

Wang, D.W., Mitchell, D.A., Teague, W.J., Jarosz, E., and Hulbert, M.S., 2005, Extreme Waves Under Hurricane Ivan: Science, v. 309, p. 896.

Whitham, G.B., 1974, Linear and nonlinear waves: New York, Wiley.

Wiberg, P.L., Drake, D.E., and Cachione, D.A., 1994, Sediment resuspension and bed armoring during high bottom stress events on the northern California inner continental shelf: measurements and predictions: Continental Shelf Research, v. 14, p. 1191-1219.

Wiberg, P.L., and Smith, D.E., 1987, Calculations of the Critical Shear Stress for Motion of Uniform and Heterogeneous Sediments: Water Resource Research, v. 23, p. 1471-1480. 


\section{Appendix A3: Supplemental XRF Results from Vieques, Puerto Rico}

\section{A3.1. XRF versus ICP measurements}

Eight discrete sediment samples collected from core LG6 were dried and run through an Inductively Coupled Plasma Emission Spectrometer (ICP) at Brown University to obtain the percent mass for selected elements in each sample (Table A3.1). A comparison between XRF and ICP results show that there is a reasonable relationship between measured XRF counts and percent mass for the range of $\mathrm{Fe}, \mathrm{Ti}, \mathrm{Ca}$, and $\mathrm{Sr}$ concentrations observed within Laguna Playa Grande sediments (Figure A3.1).

\begin{tabular}{|c|c|c|c|c|c|c|c|c|}
\hline \multirow[b]{2}{*}{$\begin{array}{l}\text { Depth } \\
\text { (cm) }\end{array}$} & \multicolumn{4}{|c|}{ Titanium } & \multicolumn{4}{|c|}{ Iron } \\
\hline & $\begin{array}{l}\text { XRF } \\
\text { (int) }\end{array}$ & $\begin{array}{l} \pm 2 \sigma \\
\text { (int) }\end{array}$ & $\begin{array}{c}\text { ICP } \\
(\% \text { mass })\end{array}$ & $\begin{array}{c} \pm 2 \sigma \\
(\% \text { mass })\end{array}$ & $\begin{array}{l}\text { XRF } \\
\text { (int) }\end{array}$ & $\begin{array}{l}2 \text { sig } \\
\text { (int) }\end{array}$ & $\begin{array}{c}\text { ICP } \\
(\% \text { mass })\end{array}$ & $\begin{array}{c} \pm 2 \sigma \\
(\% \text { mass })\end{array}$ \\
\hline 18 & 658 & 153 & 0.336 & 0.007 & 36899 & 5748 & 4.125 & 0.364 \\
\hline 28 & 629 & 102 & 0.317 & 0.020 & 35394 & 2458 & 3.797 & 0.700 \\
\hline 90 & 451 & 84 & 0.241 & 0.010 & 25581 & 1897 & 3.042 & 0.148 \\
\hline 140 & 546 & 100 & 0.304 & 0.015 & 30433 & 1974 & 3.731 & 0.288 \\
\hline 190 & 224 & 99 & 0.112 & 0.007 & 12738 & 1331 & 1.577 & 0.103 \\
\hline 240 & 206 & 73 & 0.111 & 0.006 & 12716 & 1178 & 1.400 & 0.105 \\
\hline 250 & 177 & 72 & 0.104 & 0.004 & 12564 & 1479 & 1.475 & 0.133 \\
\hline \multirow[t]{2}{*}{385} & 372 & 84 & 0.192 & 0.004 & 25881 & 2749 & 2.773 & 0.148 \\
\hline & \multicolumn{4}{|c|}{ Calcium } & \multicolumn{4}{|c|}{ Strontium } \\
\hline $\begin{array}{l}\text { Depth } \\
(\mathrm{cm})\end{array}$ & $\begin{array}{l}\text { XRF } \\
\text { (int) } \\
\end{array}$ & $\begin{array}{l} \pm 2 \sigma \\
\text { (int) } \\
\end{array}$ & $\begin{array}{c}\text { ICP } \\
\text { (\% mass) } \\
\end{array}$ & $\begin{array}{c} \pm 2 \sigma \\
(\% \text { mass }) \\
\end{array}$ & $\begin{array}{l}\text { XRF } \\
\text { (int) } \\
\end{array}$ & $\begin{array}{l} \pm 2 \sigma \\
\text { (int) } \\
\end{array}$ & $\begin{array}{c}\text { ICP } \\
\text { (\% mass) } \\
\end{array}$ & $\begin{array}{c} \pm 2 \sigma \\
(\% \text { mass }) \\
\end{array}$ \\
\hline 18 & 4016 & 874 & 6.304 & 1.872 & 3407 & 287 & 0.083 & 0.004 \\
\hline 28 & 4176 & 639 & 6.935 & 0.287 & 3258 & 355 & 0.079 & 0.003 \\
\hline 90 & 7643 & 1011 & 10.129 & 0.715 & 3408 & 466 & 0.075 & 0.005 \\
\hline 140 & 4937 & 1462 & 7.156 & 0.209 & 2554 & 524 & 0.057 & 0.003 \\
\hline 190 & 9884 & 2015 & 15.513 & 1.517 & 5217 & 705 & 0.122 & 0.005 \\
\hline 240 & 11158 & 2224 & 14.715 & 2.737 & 5399 & 548 & 0.123 & 0.009 \\
\hline 250 & 11338 & 3479 & 14.915 & 2.190 & 5741 & 752 & 0.123 & 0.006 \\
\hline 385 & 11208 & 1380 & 15.253 & 1.910 & 5850 & 808 & 0.115 & 0.008 \\
\hline
\end{tabular}

Table A3.1: XRF peak integrated area measurements for Core 6 versus percent mass obtained by Inductively Coupled Plasma Emission Spectrometer (ICP) . 

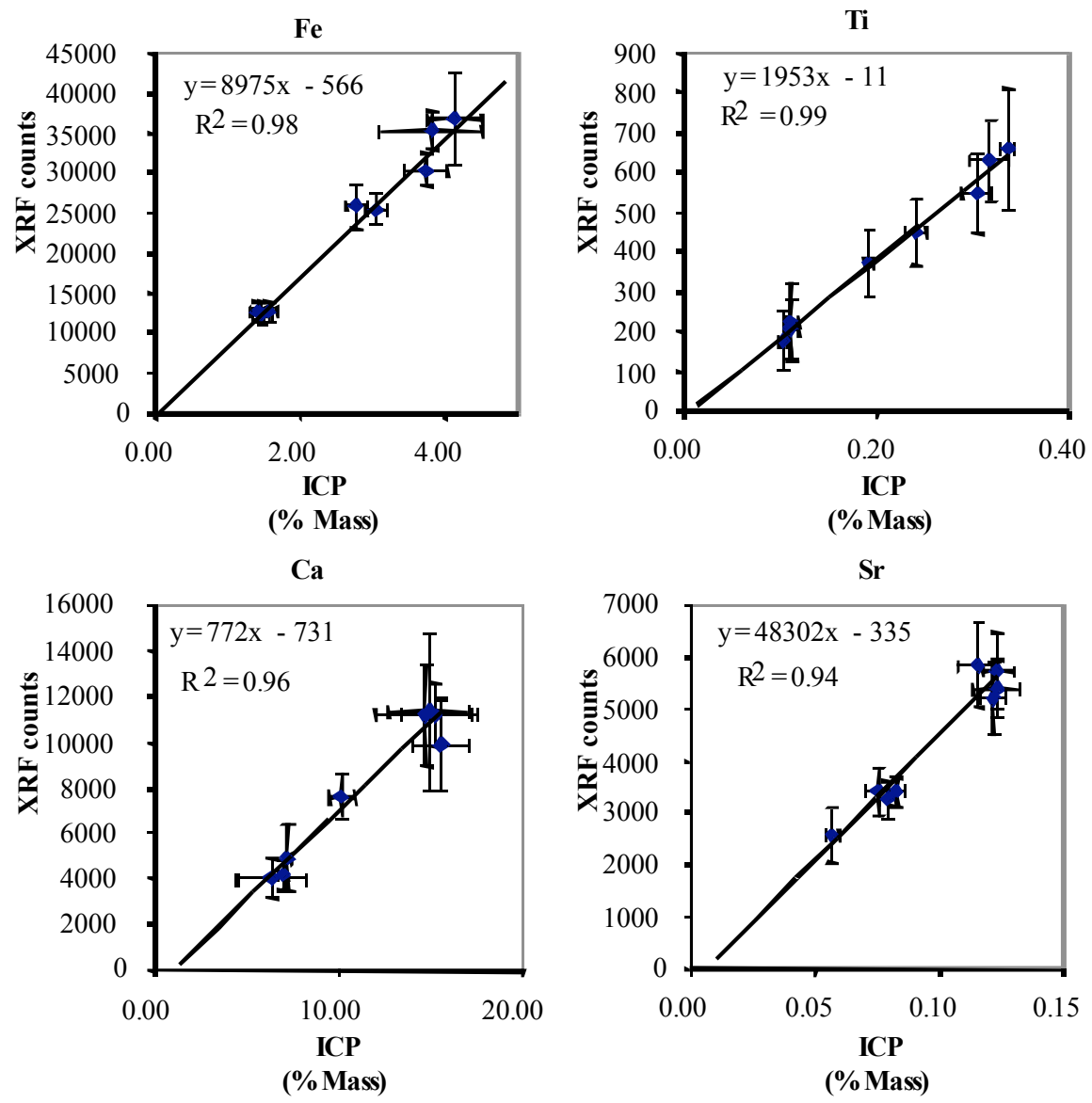

Figure A3.1: XRF calibrations based on ICP percent mass measurements obtained for the 8 discrete samples analyzed from core LG6.

\section{A3.2. Elemental Composition for Watershed and Barrier Beach Sediments}

Discrete surface samples from both the watershed and along the barrier beach system of Laguna Playa Grande were collected and run through the XRF to identify the elemental composition of source material to the basin. The mean concentrations of the primary elements identified using the XRF for these sediments are displayed in Table A3.2. These results are based on a limited number of samples from these two regions, however, the table 
does show that material derived from the watershed and barrier beach are distinct in their elemental makeup.

Relative to the terrestrial samples, the elemental composition of beach sediments in Laguna Playa Grande are depleted in iron and titanium and enriched in calcium and strontium. Given that the watershed and barrier beach material are observed to be elementally distinct, and that the sediments in Laguna Playa Grande are likely composed primarily of these two end member sources, it seems likely that variations in the geochemistry of the lagoon sediment from the area would indicate changes in the relative supply of beach and watershed sediments to the lagoon.

\begin{tabular}{|l|r|r|}
\hline \multicolumn{3}{|c|}{ Watershed Samples $(\mathrm{n}=10)$} \\
\hline Element & $\begin{array}{c}\text { mean } \\
\text { concentration } \\
(\% \text { mass })\end{array}$ & $\begin{array}{c}2 \sigma \\
(\% \text { mass })\end{array}$ \\
\hline $\mathrm{Fe}$ & 3.26 & 2.48 \\
\hline $\mathrm{Ti}$ & 0.27 & 0.16 \\
\hline $\mathrm{Ca}$ & 2.47 & 0.78 \\
\hline $\mathrm{Sr}$ & 0.06 & 0.02 \\
\hline
\end{tabular}

\begin{tabular}{|l|r|r|}
\hline \multicolumn{3}{|c|}{ Beach Samples (n=7) } \\
\hline & $\begin{array}{c}\text { mean } \\
\text { Element } \\
(\% \text { mass })\end{array}$ & $\begin{array}{c}2 \sigma \\
(\% \text { mass })\end{array}$ \\
\hline $\mathrm{Fe}$ & 0.73 & 0.32 \\
\hline $\mathrm{Ti}$ & 0.14 & 0.04 \\
\hline $\mathrm{Ca}$ & 47.02 & 10.42 \\
\hline $\mathrm{Sr}$ & 0.21 & 0.06 \\
\hline
\end{tabular}

Table A3.2: XRF Results for Laguna Playa Grande surface samples.

Figure A3.2 displays an example for the variations in geochemistry observed in coarse grain deposits with in Laguna Playa Grande. Relative to the fine grained sediments above and below them, these coarse grain layers were observed to be depleted in Fe and Ti while highly enriched in $\mathrm{Ca}$ and $\mathrm{Sr}$. This is consistent with these strata being composed primarily of barrier beach sediments and supports the theory that this material was carried into the lagoon during extreme overwash events. 

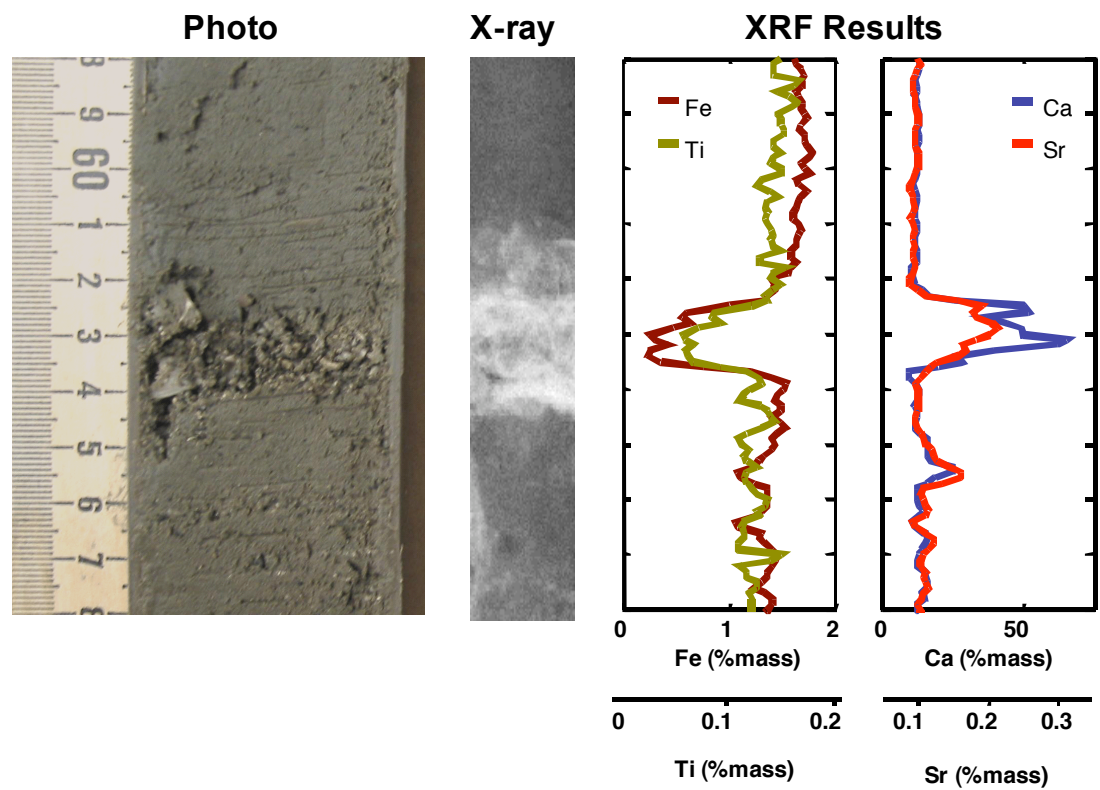

Figure A3.2: Geochemistry of fine and coarse grained sedimentary units for core LG12 from 148 to $158 \mathrm{~cm}$. Fine grain sediments are relatively high in terrestrial sourced $\mathrm{Fe}$ and $\mathrm{Ti}$ while low in marine sourced $\mathrm{Ca}$ and $\mathrm{Sr}$. The reverse is true for coarse grain laminae, with low $\mathrm{Fe}$ and $\mathrm{Ti}$ concentrations and relatively high levels of $\mathrm{Ca}$ and $\mathrm{Sr}$, and is indicative of a seaward origin for these coarse deposits. 
Appendix A4: Permission letters from co-authors 


\section{WoOds Hole OCEANOGRAPHiC InSTITUTION}

October 24,2008

Joint Committee for Marine Geology and Geophysics (c/o Academic Programs Office)

Woods Hole Oceanographic Institution, MS 31

360 Woods Hole Road

Woods Hole, MA 02543-1541

Dear JCMGG members,

Jonathan D. Woodruff has my authorization to use the following manuscripts, on which I am a coauthor as part of his Ph.D. thesis:

1. Woodruff, J.D., Donnelly, J.P. and Emanuel, K., 2008, Assessing sedimentary records of paleo-hurricane activity using modeled hurricane climatology. Geochemistry, Geophysics, Geosystems, v. 9 (9), p. 1-12

2. Woodruff, J.D., Donnelly, J.P., Mohrig, D. and Geyer, W.R., 2008, Reconstructing relative flooding intensities responsible for hurricane-induced deposits from Laguna Playa Grande, Vieques, Puerto Rico. Geology, v. 36, p. 391-394

3. Woodruff, J.D., Donnelly, J.P., and Okusu, A., in review, Exploring typhoon variability over the mid-to-late Holocene: evidence of extreme coastal flooding from Kamikoshiki, Japan.

Quaternary Science Reviews

4. Donnelly, J.P. and Woodruff, J.D., 2007, Intense hurricane activity over the past 5,000 years controlled by El Nino and the West African monsoon. Nature, v. 447, p. 465-468.

Mr. Woodruff has authored more than $50 \%$ of manuscripts 1,2 , and 3, including performing most of the analysis and preparing the majority of the text. Manuscript 4 is a two author publication which we both worked closely on, and the contributions by Mr. Woodruff and myself are equivalent (50$50)$.

Sincerely,

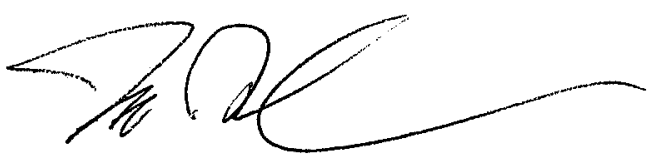

Jeffrey P. Donnelly

MS\#22 • Woods Hole, MA 02543 • 508.289.2994 • Fax 508.457.2187 • jdonnelly@whoi.edu http://www.whoi.edu/science/GG/dept/personnel/personnel_scientist_donnelly.htm 
DEPARTMENT OF GEOLOGICAL SCIENCES

THE UNIVERSITY OF TEXAS AT AUSTIN

John A. and Katherine G. Jackson School of Geosciences · http://www.geo.utexas.edu/

1 University Station, C1100 Austin, TX 78712-0254 • (512) 471-5172 FAX (512) 471-9425

Joint Committee for Marine Geology and Geophysics

(c/o Academic Programs Office)

Woods Hole Oceanographic Institution

360 Woods Hole Road

Woods Hole, MA 02543-1541

October 27, 2008

To Whom It Concerns,

Jonathan D. Woodruff has my authorization to use the following manuscript, on which I am a co-author, as part of his Ph.D. thesis:

Woodruff, J.D., Donnelly, J.P., Mohrig, D. and Geyer, W.R., 2008, Reconstructing relative flooding intensities responsible for hurricane-induced deposits from Laguna Playa Grande, Vieques, Puerto Rico. Geology, v. 36, p. 391-394

Mr. Woodruff authored greater than $50 \%$ of this manuscript, including performing most of the necessary analyses and preparing a majority of the text.

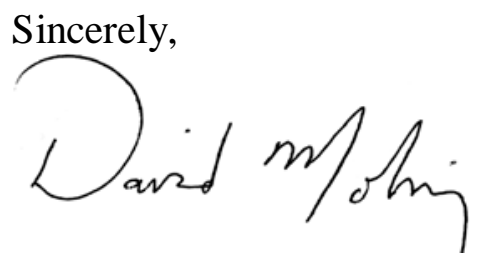

David Mohrig

Associate Professor of Geology

Department of Geological Sciences

Jackson School of Geosciences

The University of Texas at Austin

1 University Station, C1100

Austin, TX 78712-0254

phone: 512-471-2282ｅ-mail: mohrig@mail.utexas.edu 


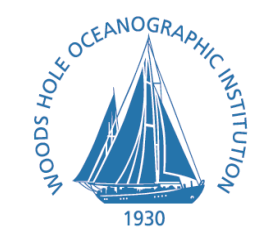

\section{Woods Hole Oceanographic Institution}

Dr. W. Rockwell Geyer, Senior Scientist, Applied Ocean Physics and Engineering Department

Oct. 24,2008

Joint Committee for Marine Geology and Geophysics

c/o Academic Programs Office

Woods Hole Oceanographic Institution

360 Woods Hole Road

Woods Hole, MA 02543-1541

To Whom It May Concern:

Jonathan D. Woodruff has my authorization to use the following manuscript, on which I am a coauthor as part of his Ph.D. thesis:

Woodruff, J.D., Donnelly, J.P., Mohrig, D. and Geyer, W.R., 2008, Reconstructing relative flooding intensities responsible for hurricane-induced deposits from Laguna Playa Grande, Vieques, Puerto Rico. Geology, 36, 391-394.

Mr. Woodruff has authored more than $50 \%$ of this manuscript, including performing most of the analysis and preparing the majority of the text.

Yours truly,

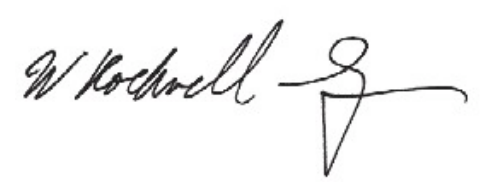

W. Rockwell Geyer

Senior Scientist 


\section{PROGRAM IN ATMOSPHERES, OCEANS, AND CLIMATE}

MASSACHUSETTS INSTITUTE OF TECHNOLOGY

DEPARTMENT OF EARTH, ATMOSPHERIC, AND

PLANETARY SCIENCES

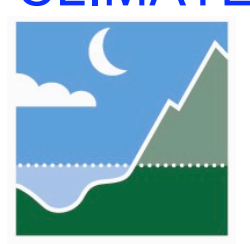

Joint Committee for Marine Geology and Geophysics

2008

c/o Academic Programs Office

Woods Hole Oceanographic Institution

360 Woods Hole Road

Woods Hole, MA 02543-1541

To Whom It May Concern,

Jonathan D. Woodruff has my authorization to use the following manuscript, on which I am a co-author as part of his Ph.D. thesis:

Woodruff, J.D., Donnelly, J.P. and Emanuel, K., 2008, Assessing sedimentary records of paleo-hurricane activity using modeled hurricane climatology. Geochemistry,

Geophysics, Geosystems, v. 9 (9), p. 1-12

Mr. Woodruff has authored much more than $50 \%$ of this manuscript, including performing most of the analysis and preparing the majority of the text.

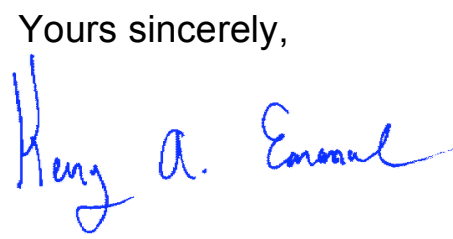

Kerry A. Emanuel

Professor of Atmospheric Science

Room 54-1620, MIT, Cambridge, MA 02139

Telephone: (617) 253-2462 Fax: (617) 253-6208 Email: emanuel@texmex.mit.edu World Wide Web: http://wind.mit.edu/ emanuel/home.html 